\title{
THE TREATMENT OF INFANT \\ SLEEP DISTURBANCE BY \\ GRADUATED EXTINCTION
}

\author{
A thesis \\ submitted in partial fulfilment \\ of the requirements for the Degree \\ of \\ Master of Science in Psychology \\ in the \\ University of Canterbury \\ by \\ Carolyn F. Lawton \\ University of Canterbury \\ 1985
}


Infant sleep disturbance has been effectively treated with extinction by removal of parental attention but this procedure can produce adverse side-effects and can meet with parental resistance. This study evaluated an alternative procedure using graduated extinction to treat infant sleep disturbance. Graduated extinction required parents to gradually reduce the amount of time they spent attending to their child, eventually withdrawing attention completely. Baseline measures of sleep-related behaviour, including frequency and duration of night-waking, sleep onset latency and bedtime delay, were made by parents for twelve children between 6 and 19 months. Seven children received graduated extinction, and five received direct extinction in a multiple-baseline across subjects design. Social validation measures were taken during baseline and at the end of treatment, and sleep-related behaviours were again assessed for one week at two-months follow-up.

Clinically significant improvements in infant sleep behaviour were evident for four out of six subjects exposed to graduated extinction and for three out of four given extinction. Data for two subjects were unavailable for analysis. Improvements were maintained at follow-up. Parents reported high satisfaction with the procedures and improved family lifestyles. The quality of parental compliance with treatment was lower for graduated extinction than for extinction. The conclusions revealed that while graduated extinction was effective in treating infant sleep disturbance, it is no more effective than extinction, which has practical and clinical advantages in almost all cases. 


\section{ACKNOWLEDGEMENTS}

Sincere thanks to my supervisor, Mr. Neville Blampied, for his time, support and encouragement during the preparation of this thesis. Special thanks also to Ms. Karyn France for the training she provided, and for the helpful guidance and suggestions she gave regarding the procedures used in this project. I am much obliged to Dr. W.A.M. Black who read chapters of this work, making useful suggestions.

The author is indebted to nurses of the Plunket Society for their regular referral of suitable families to the Sleep Programme. My appreciation is also extended to the families who participated and put so much time and effort into recording data over an extended period. Finally, I would like to thank my parents who have supported and encouraged me throughout my education. 
CONTENTS

CHAPTER

PAGE

ABSTRACT ................. . II

ACKNOWLEDGEMENTS . . . . . . . . . . . . . III

CONTENTS . . . . . . . . . . . . . . . IV

LIST OF TABLES AND FIGURES . . . . . . . . VI

1. INTRODUCTION . . . . . . . . . . . . . 1

1.1 Behaviour Management of Infant

Sleep Disturbance . . . . . . . . . 1

1.2 Rationale............ . . 22

2. METHOD . . . . . . . . . . . . 32

2.1 Subjects . . . . . . . . . . 32

2.2 Measures . . . . . . . . . 33

2.3 Reliability . . . . . . . . . . 38

2. 4 Therapist . . . . . . . . . . . 39

2.5 Experimental Design and Procedure. . 40

2.6 Social Validation and Acceptability . 48

2.7 Data Analyses....... . . . 49

3. $\operatorname{RESULTS}$. . . . . . . . . . . . 52

3.1 Reliability . . . . . . . . . 52

3.2 Graduated Extinction and Extinction: Behavioural Effects. . . . . . 54

3.3 Graduated Extinction and Extinction: Composite Behavioural Effects. . . 76

3.4 Parental Responses........ 81

3.5 Social Validation and Acceptability . 86

4. DISCUSSION . . . . . . . . . . . . . 96

4.1 Summary of Results . . . . . . . . 96

4.2 Constraints on the Interpretation of Results . . . . . . . . . . . 99

4.3 Clinical Evaluation of Graduated Extinction . . . . . . . . . 110

4.4 Conclusions . . . . . . . . . . 112 
APPENDICES . . . . . . . . . . . . . . . . 119

A. Getting children to sleep....... 119

B. Playing the mind game......... 124

C. Many babies have sleep problems . . . 125

D. Research consent form . . . . . . 126

E. Letter of notification to GP . . . . . 127

F. Daily Sleep Diary . . . . . . . . . 128

G. Weekly Sleep Behaviour Scale . . . . 130

H. Weekly Sleep Behaviour Scale ..... . 131

I. Structured interview . . . . . . . 132

J. Photograph of reliability apparatus . . . 135

K. Criteria for transcribing the event record to numerical values . . . . . . . 136

L. Protocol . . . . . . . . . . 137

M. Maintenance instructions . . . . . . 141

N. Sleep Programme Evaluation Ouestionnaire. . 142

○. Missing data ......... 145

P. Raw data ........... . 147 
1. Studies of night-waking . . . . . . . . . 4

2. Studies of bedtime delay and sleep onset latency . . . . . . . . . . . . . 7

3. Factors associated with infant sleep disturbance . . . . . . . . . . . . . 9

4. Demographic characteristics of subjects . . . 34

5. Sleep problems, their onset and precipitating factors reported by parents for each subject 35

6. Past and current management attempts reported by parents . . . . . . . . . . . . 36

7. Order of presentation to the study for each subject, and the number of days each spent in baseline, intervention and follow-up phases. . . . . . . . . . . . . . . 43

8. Reduction of parental attention time for night-waking, scheduled for each subject in the graduated extinction group . . . . . 4 45

9. Means and standard deviations for number of wakings per night for each subject in each experimental condition . . . . . . . . 56

10. Statistical evaluation of the presence of change due to intervention using the C-statistic (Tryon, 1982). . . . . . . 58

11. Means and standard deviations for duration of wakings per night (minutes) for each subject during each experimental condition . . . . 63

12. Means and standard deviations for sleep onset latency per night (minutes) for each subject during each experimental condition

13. Means and standard deviations for bedtime delay per night (minutes) for each subject during each experimental condition . . . . 74

14. Distribution of the types of parental response to infant night-waking during baseline and intervention . . . . . . . . . . . . 84

15. The effects of intervention on each behavioural measure for each subject . . . . . 98 
1. Number of wakings per night for subjects in the graduated extinction condition during baseline, intervention and followup . . . . . . . . . . . . . . . 55

2. Number of wakings per night for subjects in the extinction condition during baseline, intervention and follow-up . . . . 60

3. Duration of wakings per night (minutes) for subjects in the graduated extinction condition during baseline, intervention and follow-up . . . . . . . . . . 62

4. Duration of wakings per night (minutes) for subjects in the extinction condition during baseline, intervention and follow-up... . 65

5. Sleep onset latency per night (minutes) for subjects in the graduated extinction condition during baseline, intervention and follow up . . . . . . . . . . . . 68

6. Sleep onset latency per night (minutes) for subjects in the extinction condition during baseline, intervention and follow-up . . . 71

7. Bedtime delay per night (minutes) for subjects in the graduated extinction condition during baseline, intervention and follow up . . . . . . . . . . . . 73

8. Bedtime delay per night (minutes) for subjects in the extinction condition during baseline, intervention and follow-up. . . 75

9. Composite weekly scores on sleep Behaviour scale for subjects in the graduated extinction condition during baseline, intervention and follow-up . . . . . . . . . . 77

10. Composite weekly scores on sleep Behaviour scale for subjects in the extinction condition during baseline, intervention and follow-up .............. . 79 
11. Mean composite weekly scores on sleep Behaviour scale for graduated extinction and extinction subjects during baseline, intervention and follow-up. . . . . . 80

12. Composite daily scores on the Deviation from Ideal scale for each subject during the last fifteen days of baseline and the last fifteen days of intervention... . . 82

13. Cumulative number of parental responses to each subject's waking during baseline, intervention and follow-up . . . . . . 83

14. Security scores obtained on the Flint Infant Security scale for each subject during baseline, intervention and maintenance phases. 88

15. A-State and A-Trait scores obtained on the State-Trait Anxiety Inventory by fathers of each subject during baseline, intervention and maintenance phases... . . . 90

16. A-State and A-Trait scores obtained on the State-Trait Anxiety Inventory by mothers of each subject during baseline, intervention and maintenance phases. . . . . . . 91 


\section{INTRODUCTION}

\subsection{BEHAVIOUR MANAGEMENT OF INFANT SLEEP DISTURBANCE:} A review of the literature.

Behaviour management of infant sleep disturbance has received surprisingly little attention, considering the scope of the problem. A large proportion of infants experience difficulty sleeping. One of the most common complaints that parents make about young children is that they wake regularly at night. The causes of infant sleep disturbance are unclear. There has been a lack of systematic studies of both the etiology and management of the problem. The treatment literature consists predominantly of unsubstantiated advice to medical practitioners.

The potential benefits of a behavioural approach have been suggested by a small number of case studies, which have mainly dealt with children and adolescents. Recent studies by Seymour, Bayfield, Brock and During (1983) and France and Hudson (1984) demonstrated the success of a behavioural approach to management and have called attention to the need for further investigation.

\section{Scope of the Problem}

Infant sleep disturbance has been defined as sleep behaviour that is sufficiently irregular and demanding to cause parents concern, and which occurs beyond the age when it is appropriate and acceptable. There are no firmly established age limits beyond which disturbed sleep is defined as inappropriate and a problem. However, most researchers agree that the majority of infants sleep through the night before the age of six months (Moore and Ucko, 1957

Disturbed sleep behaviour can be characterised by several different patterns of wakefulness:

(a) failure to sleep through the night (night-waking);

(b) initial difficulty in falling to sleep (sleep onset latency) ; 
(c) bed refusal and resistance to going to bed (bedtime delay);

(d) going to sleep in an inappropriate location, usually the parents' bed.

The sleep behaviours described above have been differentiated from other infant sleep disorders on the basis of sleep polygrams (Anders and Weinstein, 1972). None of these disturbances have been associated with abnormal electroencephalograms (EEG's). Sleep disorders such as somnambulism, pavor nocturnis and sleep apnea have been associated with abnormal brain wave activity, as measured by EEG's.

sleep disturbance is a problem affecting a large proportion of infants, aged between 6 and 24 months, for at least some periods (Basler, Largo and Molinari, 1980; Fergusson, 1982; Fergusson, Shannon and Horwood, 1981; Werry and Carlielle, 1982). Infants with sleep disturbances have been divided into three groups (Fergusson et al., 1981) First, the "chronic" group who since birth have never slept through the night. Second, the "acute" group who began to resist going to bed, or wake at night, after a period of sleeping through. Third, the "intermittent" group who have had periods of disturbed sleep throughout infancy.

Night-waking

\section{Incidence}

Night-waking is the most common and problematic sleep disturbance. The reported incidence rates of nightwaking range from 20 to 53 percent for infants. Much of the variability results from differences in the criteria used to define sleep disturbance. Researchers have defined night-waking either as:

(a) waking that occurred with a particular frequency per week, or

(b) waking that caused parents concern.

Even amongst those researchers who have defined the severity of night-waking according to its frequency 
different criteria exist. For example, Moore and Ucko (1957) considered that waking once or more per week between midnight and 5 a.m. was significant, whereas Jenkins, Bax and Hart (1980) did not consider the frequency of nightwaking significant unless it had occurred on four or more nights of the week. Table 1 summarises studies of nightwaking. Two studies conducted in New Zealand, (Fergusson et al., 1981; Werry and Carlielle, 1982) showed that the prevalence of night-waking in this country was comparable to other countries.

Studies that have based their estimates of prevalence on whether night-waking is experienced as a problem by parents have reported lower incidence rates than studies employing frequency criteria. A number of studies (see Table 1) have reported both statistics. Results consistently showed that approximately 50 percent of parents, with infants who woke, did not perceive this as problem behaviour. The definition of night-waking adopted for the purposes of this review considered night-waking to be a problem only if it was of concern to parents. This suggests that studies that have based their incidence rates on frequency criteria alone cannot be interpreted as a realistic estimate of 'problem' night-waking. However, even if frequency-based rates are inflated, sufficient evidence exists suggesting that a substantial proportion of parents (15 to 25 percent) report that their child wakes regularly at night and causes them concern (see Table 1).

It is interesting to note the frequency with which night-waking occurs without parents being aware of its occurrence. Anders (1979) used continuous time-lapse video recordings to observe 36 nine-month old infants for an entire night's sleep. Eighty-six percent of the infants woke during the night. Only 45 percent of the parents reported that night-waking had occurred. He concluded that many infants woke and fell back to sleep on their own. parents recorded waking during the night only if the child attracted their attention in some way. Children in another sample most often cried, called out and got out of bed to attract their parents' attention (Werry and Carlielle, 1981). 
Table 1

Studies of Night-Waking

\begin{tabular}{|c|c|c|c|c|c|c|}
\hline Author (s) & $\mathrm{N}$ & $\begin{array}{c}\text { Age } \\
\text { (months) }\end{array}$ & Severity/Week & \multicolumn{2}{|c|}{ Frequency } & \\
\hline Anders (1979) & 36 & 9 & & $\begin{array}{l}\text { Video } \\
\text { Mother's } \\
\text { report }\end{array}$ & $\begin{array}{l}86 \% \\
45 \%\end{array}$ & \\
\hline Basler et al. (1980) & 320 & $18-36$ & $\begin{array}{c}\text { "occasionally' } \\
>1\end{array}$ & & $\begin{array}{l}40 \% \\
29 \%\end{array}$ & $(268)^{a}$ \\
\hline Bernal (1973) & 77 & 14 & 'regularly' & & 278 & \\
\hline Blurton-Jones et al. (1978) & 59 & $15-39$ & $>2$ & & 238 & \\
\hline Carey $(1974)$ & 60 & $6-12$ & $>4$ & & $25 \%$ & \\
\hline Fergusson et al. (1981) & 1144 & 24 & $>1$ & $\begin{array}{l}\text { Early } \\
\text { Late } \\
\text { Intermit- } \\
\quad \text { tent }\end{array}$ & $\begin{array}{l}11 \% \\
19 \% \\
17 \%\end{array}$ & $478(248)$ \\
\hline Jenkins et al. (1980) & 64 & $12-18$ & $>4$ & & $23 \%$ & \\
\hline Moore \& Ucko (1957) & 104 & $6-12$ & $>1$ & & 538 & \\
\hline Ragins \& Schachter (1971) & 48 & $21-27$ & $\begin{array}{l}>7 \text { consecutive } \\
\text { nights in last } 3 \\
\text { months }\end{array}$ & & 228 & $\begin{array}{l}\text { (currently } \\
148 \\
\text { in past } 1 !\end{array}$ \\
\hline Richman (1981a) & 771 & $12-24$ & $>1$ & & $44 ㅇ$ & \\
\hline Roberts \& Schoellkopf (1951) & 777 & 30 & & & $38 \div$ & $(8.5 \%)$ \\
\hline Werry \& Carlielle (1981) & 196 & $3-60$ & $\begin{array}{l}>2 \\
>1\end{array}$ & & $\begin{array}{l}33 \text { 음 } \\
46 \text { 영 }\end{array}$ & $(3 ㅇ)$ \\
\hline
\end{tabular}

Note: Adapted from Werry \& Carlielle (1981, Table 1).

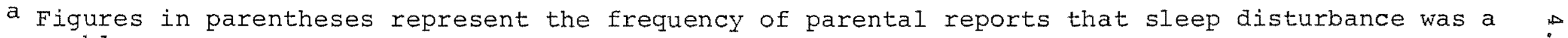
problem. 


\section{Significance for parents}

The significance of the problem for parents is indicated by evidence that night-waking is often a long-term disturbance of sleep; that it does not necessarily decrease with age; that it is often associated with other problem behaviours; and that it has an effect on the whole family.

The long-term chronic nature of sleep disturbance has been frequently noted (Bax, 1980; Fergusson et al., 1981; Werry and Carlielle, 1981). Some infants woke regularly at night for over a year. Longitudinal studies have observed a continuity in night-waking (Bax, 1980; BlurtonJones, Rosetti-Ferreira, Farquar-Brown and McDonald, 1978 ; Richman, 1981b). Infants who woke at one age were likely to continue to wake at an older age. In one sample (Bax, 1980), 20 percent of the infants woke at 12 months. Of these 40 percent were still waking at 18 months and 40 percent at 24 months, although not necessarily the same individuals.

The incidence of night-waking has been generally assumed to decrease with age (Seymour et al., 1983), although the evidence is contradictory. An age-related decline in frequency was endorsed by Richman, stevenson and Graham (1975) and Richman (1981a). These authors reported that 20 percent of $1-2$ year-olds woke at night, which declined to 14 percent by the age of 3 . Jenkins et al. (1980) reported similar figures, 24 and 14 percent, respectively. Other studies failed to find evidence that the rate of waking diminished with increasing age. Basler et al. (1980) reported an increase in frequency between the ages of 4 and 5. Seiler (1972) and Werry and Carlielle (1981) failed to observe the expected drop-off at age 2 . The old homily that waking is something that children will outgrow is only partially supported. From a clinical perspective it may be preferable to conclude, as France and Hudson (1984) did, that waking does not delimit with age. At least parents may seek assistance rather than vainly wait till their child "grows out of it". The significance of the problem for both the child and the parents is clear from two studies that investigated the incidence of a wide 
range of problem behaviours in pre-school children (Jenkins et al., 1980; Richman et al., 1975). An association between sleep disturbance and other behaviour problems was evident in both studies. Chavin and Tinson (1980) surveyed a group of infants referred with "serious" sleeping problems. Parents reported that the infants concerned were more irritable, fussy and overactive as a result of their sleeping difficulties.

An infant who wakes at night can have a distressing influence on the whole family. Chavin and Tinson reported that 30 percent of parents in the sample felt that they had suffered chronic fatigue as a result of disturbed sleep. Thirty-seven percent said it had caused serious arguments in the family, and 8 percent admitted to severely abusing their child. Not only are the family affected but the child becomes a potential target for abuse.

In summary, then, night-waking is a common event in the lives of infants. It endures over long periods, extending into early childhood, and many parents experience it as a serious problem.

Sleep onset latency, bedtime delay and sleeping in the parents' bed

The majority of research has not distinguished these sleep disturbances from night-waking. Where this has been done, a close association between these difficulties and night-waking is observed. Chavin and Tinson (1980) reported that 35 percent of their sample of infants referred for night-waking also resisted going to bed. Children who slept in their parents' bed also tended to be night-wakers. Most infants were taken to their parents' bed after waking during the night (Richman et al., 1975; Roberts and Schoellkopf, 1951; Werry and Carlielle, 1981). These researchers reported that between 5 and 15 percent of their samples fitted into this category.

Table 2 summarises the studies that have reported rates of sleep onset latency and bedtime delay separately from night-waking. A distinction between sleep onset latency and bedtime delay was not often drawn. The term 
Table 2

Studies of bedtime delay, BD, and sleep onset latency, SOL (settling difficulties).

\begin{tabular}{|c|c|c|c|c|c|}
\hline Author (s) & $\mathrm{N}$ & $\begin{array}{c}\text { Age } \\
\text { (months) }\end{array}$ & Severity/Week & \multicolumn{2}{|c|}{ Frequency } \\
\hline Basler et al. (1980) & 320 & $18-36$ & 'regularly' & & $13 \%(8 \%)^{a}$ \\
\hline Jenkins et al. (1980) & 96 & $6-18$ & $>2$ & & 218 \\
\hline Ragins \& Schachter (1971) & 48 & $21-27$ & $\begin{array}{l}>7 \text { consecutive } \\
\text { nights in last } \\
3 \text { months }\end{array}$ & $\begin{array}{l}\text { SOL } \\
\text { BD }\end{array}$ & $\begin{array}{l}15 \% \\
15 \%\end{array}$ \\
\hline Richman et al. (1975) & 828 & 36 & & & 13 \\
\hline Roberts \& Schoellkopf (1951) & 783 & 30 & & $\mathrm{BD}$ & $12 \%$ \\
\hline Werry \& Carlielle (1981) & 196 & $3-60$ & & $\begin{array}{l}\text { SOL } \\
\text { BD }\end{array}$ & $\begin{array}{l}3 \% \\
6 \%\end{array}$ \\
\hline
\end{tabular}

a Frequency of parental reports that settling at bedtime was a problem. 
"settling difficulty" was often used to describe bedtime problems and presumably included both behaviours.

To conclude, bedtime problems occur frequently during infancy. The incidence is between 12 to 15 percent of infants (see Table 2). There is a tendency for the frequency to increase with age in early childhood. Sleep onset latency, bedtime delay and sleeping in the parents' bed are strongly associated with night-waking. Many parents may have to cope with what could be termed a "sleep disturbance syndrome" rather than one of the contributing behaviours in isolation.

\section{Causal Factors}

The causes of infant sleep disturbance are unclear. Empirical evidence has shown that a number of factors are associated with sleep problems, but the results have often been contradictory. Table 3 is a summary of the relationships reported in the literature. Most of the research has been correlational. Even those studies that applied longitudinal designs have not always been able to clarify causal relationships (Bernal, 1973; Blurton-Jones et al., 1978; Moore and Ucko, 1957).

Studies can be grouped according to whether they have concentrated on associations between child characteristics and infant sleep disturbance, environmental factors and sleep disturbance or an interaction.

Child characteristics

There are several child characteristics that have generally been agreed to covary with the frequency of infant sleep disturbance. Perinatal complications and temperamental or constitutional factors are the most commonly associated factors (see Table 3 ). The relevant studies have all collected data retrospectively. Mothers were asked to recall information about pregnancy, delivery, labour and the subsequent development of their child. Wenar (1967) found that mothers' retrospective report of perinatal status and the infant's temperament was often unreliable. Ragins and Schachter (1971) also found that mothers were unable to recall details of their child's past sleeping pattern 
Table 3

Factors associated with infant sleep disturbance

\begin{tabular}{|c|c|c|}
\hline Factor & Relationship & No Relationship \\
\hline Birth order & Fergusson et al. (1979) & $\begin{array}{l}\text { Bernal (1973) } \\
\text { Moore \& Ucko (1957) } \\
\text { Seiler (1972) }\end{array}$ \\
\hline Breast feeding & ${ }^{\mathrm{a}}$ Carey (1975) & $\begin{array}{l}\text { Bernal (1973) } \\
\text { Moore \& Ucko (1957) }\end{array}$ \\
\hline $\begin{array}{l}\text { Daytime sleep }<2 \text { years } \\
\text { Daytime sleep }>2 \text { years }\end{array}$ & $\begin{array}{l}\text { bFergusson et al. (1979). } \\
\text { a Moore \& Ucko (1957) }\end{array}$ & \\
\hline Life events since 12 months & Fergusson et a1. (1979) & \\
\hline Maternal anxiety & $\begin{array}{l}\text { Ragins \& Schachter (1971) } \\
\text { Richman (1981a) }\end{array}$ & \\
\hline
\end{tabular}


Table 3 cta...

\begin{tabular}{|c|c|c|}
\hline Factor & Relationship & No Relationship \\
\hline $\begin{array}{l}\text { Parental Handling: } \\
\text { (a) Play at feedtime } \\
\text { (b) Speed of response to daytime } \\
\text { crving }\end{array}$ & $\begin{array}{l}\mathrm{ab}_{\text {Moore \& Ucko }}(1957) \\
\text { Blurton-Jones et al. (1978) }\end{array}$ & Bernal (1973) \\
\hline (c) Management techniques & $\begin{array}{l}\text { Blurton-Jones et al. (1978) } \\
\text { Moore \& Ucko (1957) }\end{array}$ & Bernal (1973) \\
\hline Perinatal Abnormality & $\begin{array}{l}a_{\text {Bernal (1973) }} \\
a_{\text {Blurton-Jones et al. (1978) }} \\
a_{\text {Moore \& Ucko (1957) }}\end{array}$ & Fergusson et al. (1979) \\
\hline $\begin{array}{l}\text { Race (Mother's) } \\
\text { Season of the year }\end{array}$ & & $\begin{array}{l}\text { Fergusson et al. (1979) } \\
\text { Moore \& Ucko (1957) }\end{array}$ \\
\hline sleeping Arrangement & $\begin{array}{l}\text { Campbel1 (1981) } \\
\text { Moore \& Ucko (1957). }\end{array}$ & Seiler (1972) \\
\hline Social Class & & Bernal (1973) \\
\hline
\end{tabular}

Note: Enlarged and adapted from France (1982, Figure 1).

a Positive relationship reported

b Negative relationship reported 
accurately. These problems indicate that while there may be a relationship between these child characteristics and night-waking, any conclusions or interpretations drawn from the studies can only be tentative.

Researchers who have investigated whether childrelated demographic factors, such as birth order, gender, race and socioeconomic class, are associated with sleep problems have most often failed to find an effect.

A relationship between infant sleep cycles and infant sleep disturbance has also been sought. Anders and Weinstein (1972) compared the sleep polygraph recordings of infants with sleep problems and those without. They observed no essential differences. Anders, Carskadon and Dement (1980) studied the development of sleep organisation in infants. They speculated that those infants who were continuing to wake beyond the age when most infants slept through the night may be neurologically immature. They proposed that delays in CNS maturation, which would be unlikely to produce abnormal EEG recordings, could be related to sleep disturbance. Maturational delays could affect both sleep onset mechanisms and mechanisms controlIing the transitions between REM (rapid eye movement) and nREM (quiet) sleep, which could result in sleep onset latency and frequent night-waking.

The studies reviewed thus far need to be interpreted with caution before reaching a conclusion. A causal explanation of infant sleep disturbance remains impossible. It is tentatively proposed that child characteristics such as temperament, perinatal adversity and CNS maturation probably act to increase the vulnerability of some infants to the development of sleeping difficulties. They can be usefully conceptualised as predisposing factors to the development of night-waking.

Closer analysis of data presented by Bernal (1973) exemplifies the need for caution when inferring that causeeffect relationships have been established. A claim that future night-waking could be predicted from obstetric factors was made. Yet five infants in the control group had experienced sub-optimal birth conditions equivalent to 
those in the problem group. The conclusion relating suboptimal birth conditions to later night-waking is not supported.

There is a clear need for longitudinal prospective studies if causal relationships are to be ascertained. Ideally, a sample of mothers who have conceived, would be observed during pregnancy and labour and the infants followed-up over an extended period. Those infants who developed inappropriate sleep behaviours could be compared with those who learned to sleep through the night. If consistent differences between the two groups were then found a causal statement might be possible.

Environmental factors

The influence of environmental factors, particularly parental handling, on infant sleep disturbance has been the other major area of research. Case studies have cited environmental changes, such as illness, holidays, death in the family and moving house, as precipitants of nightwaking (Illingworth, 1968; Williams, 1959). Parents in Chavin and Tinson's (1980) sample also dated their problems back to similar events.

The role of parental handing, and other aspects of parental care, in the etiology of infant sleep disturbance has received considerable attention in the research (see Table 3). The results have been contradictory. Some studies have discovered correlations between various aspects of parental handling and infant sleep disturbance. But as is the case in all correlational research, the direction of causation, if any, has remained uncertain.

Researchers have looked at the following aspects of parental handling and their covariance with the phenomenon:
(a) maternal anxiety,
(b) speed of response to crying,
(c) play at feedtime,
(d) management strategies, and
(e) child-rearing philosophy. 
Ragins and Schachter (1971) reported an association between maternal anxiety and sleep problems. It is unclear that maternal anxiety is a cause rather than a consequence of the problem. Richman (1981b) found that sleep disturbance was associated with strained family relationships.

Parental mishandling has been frequently proposed as an important cause of sleep problems. Investigators have studied parents' speed of response to the infant's crying, whether parents interacted positively with the child at feedtime and what strategies parents used to settle their child at night. Attempts to find consistent patterns in parent behaviour related to sleep disturbance have generally failed. Two parent behaviours that have been more consistently correlated with night-waking are:

(a) the use of a greater number of techniques to settle the child, such as reassurance, feeding, rocking and so on; and

(b) the inconsistent application of techniques aimed at settling the child.

However, these findings have not made it possible to ascertain whether sleep problems are the consequence of parents' use of diverse management techniques, applied inconsistently or whether parents have responded to a child who is more wakeful and difficult to settle by trying every method they know.

Illingworth (1966) and Spock (1949) have speculated that changes in society's child-rearing philosophies have resulted in a greater incidence of infant sleep disturbance. They have argued that the swing from rigid to permissive child-rearing practices, that began in the 1930's and 1940's has been responsible:

Twenty years ago, strictness and regulation were the psychologic and pediatric laws of the land [U.S.A.] . . - [Today we have] a more friendly attitude toward babies, a more natural, relaxed regimen for their care, a respect for their individual . . and developmental needs . . . But this swift transition is not without its difficulties. . . [Previously] some people [were] so enthusiastic for regulation... 
[now] a corresponding minority [are] totally and uncritically devoted to self-regulation and self expression . . . Chronic resistance to sleep in infancy is a behaviour problem which was formerly rare but is now becoming more frequent. Its frequency seems related to the trend toward self-regulation and greater kindliness to babies and to confusion in how to apply this philosophy. (Spock, 1949, p.89).

\section{Interaction}

More recently, many researchers have avoided making causal statements on the basis of child or environmental factors alone, and have attributed infant sleep disturbance to the interaction between child characteristics and environmental factors (Anders and Weinstein, 1972; Carey, 1974; Douglas, 1983; France, 1982; Hirschberg, 1957; Richman, 198Ib, Seymour et al., 1983; Snow, Jacklin and Maccoby, 1980). The most common explanation for this interaction process has derived from well-established behaviour principles.

Analysis of any behaviour based on learning principles looks at three aspects of behaviour:

(a) antecedents,

(b) behaviour, and

(c) consequences; $(A-B-C)$.

Behaviour is primarily controlled by its consequences, which cause it to become more or less frequent. Consequences that cause a behaviour to become more frequent are called reinforcers, and are essential for the acquisition of a behaviour. Consequences also cause the antecedent stimuli that precede the behaviour to become cues which set the occasion for future occurrences of the behaviour.

Dorsel (1978) analysed the infant crying response in terms of its consequences, and the effect these had on the response itself and on the parents. His analysis is presented below, but the discussion has been adapted to apply to inappropriate sleeping behaviour rather than the crying response. Acquisition of inappropriate sleeping behaviour results from four factors: 
(1) Reinforcement provided by the parent. Parents often respond to waking and crying at night, or at bedtime, by attending to their child. They may reassure their child with physical contact, give him/her a drink, tell stories or take the child to their bed. These consequences of crying-out, refusing to go to bed or other inappropriate child behaviour, reinforce that behaviour. The child then learns to cry more or demand more because s/he has been reinforced.

(2) Reinforcement provided by the child. once mother or father have attended to the child s/he stops crying or demanding and settles down to sleep. Since crying operates as an aversive stimulus for parents, its termination as a consequence of their response to it, negatively reinforces that parental response. Parents become more likely to attend to their child at night because they have been reinforced.

(3) The schedule of reinforcement. The persistence of crying during the night, demanding to sleep in the parents' bed and refusing to go to bed is increased if parents use a schedule of partial reinforcement. Such a schedule frequently arises, as many parents do not wake each time the child cries out at night or temporarily decide to ignore the crying.

The precise schedule on which reinforcement is delivered will also affect the persistence of these inappropriate behaviours. operant research into other behaviour has demonstrated that variable ratio schedules are the most effective in maintaining a response (Reynolds, 1975). This schedule frequently operates, since most parents do not consistently respond to their child's demands after the same period of time. They respond after a varying amount of crying and calling out, depending on the situation. 
(4) The quantitative dimensions of the inappropriate sleeping behaviours.

Not all types of crying, whining or demanding are equally reinforced. Long, loud crying is more frequently reinforced due to its high level of aversiveness. Quiet crying is not reinforced as often because it is easy to ignore. An escalation in crying and demanding behaviour results, because it is most effective in obtaining reinforcement.

Patterson (1976) and Patterson and Reid (1973) have emphasised the coercive nature of much child behaviour (an example is crying). These authors have developed a "coercion hypothesis" to account for the development and maintenance of conduct disorders in children. They have emphasised the role of negative reinforcement. Coercive behaviour on the part of one family member is positively reinforced when it results in the compliance with the coercive individual's demands. The removal of the aversive event applied by the coercive individual strengthens compliance by negative reinforcement in the compliant family member. Inappropriate infant sleep behaviour has been shown to escalate in this manner. Night crying or bed refusal by the child is a coercive behaviour which is positively reinforced by parental attention. This parental attention is itself negatively reinforced because it terminates, avoids or postpones further crying and other noxious child behaviour.

The basic assumption of the behavioural approach, underlying the discussion thus far, is that parental attention is a powerful reinforcer for inappropriate sleep behaviour. Seymour et al. (1983) suggested how child characteristics might interact with parental attention to produce infant sleep disturbance.

A child with a difficult temperament may produce tentative and overly responsive parenting, which in turn maintains irritability and wakefulness in the child (p.217).

Seymour et al. (1983) have allowed that some infants may be more vulnerable to waking than others, but emphasise that 
parents who respond to this behaviour are in effect reinforcing it.

Antecedent stimuli that precede a behaviour and set the occasion for its occurrence were mentioned earlier. Inappropriate stimuli can become the cues that set the occasion for problem sleep behaviour because the behaviour has been regularly reinforced in the presence of these antecedents. For example, many children will only go to sleep in their parents' presence. These children have never acquired the appropriate discriminative stimuli for sleep. That sleep can become under the control of inappropriate stimuli is evident in Ragins and Schachter's (1971) findings that children who had settling difficulties required elaborate rituals involving their parents' presence before falling asleep.

In summary, the causes of infant sleep disturbance are unclear. However, functional analysis of parent and infant behaviour has revealed that inappropriate infant sleep behaviour is likely to be an interaction between

(a) constitutional and perinatal, predisposing factors;

(b) environmental events such as illnesses or holidays, precipitating factors; and

(c) parental attention and handing, perpetuating factors. As France (1982) suggested, the relative role of constitutional, perinatal and handling factors may be different for infants who have woken continually since birth, the chronic wakers, than for infants who have started to wake following a period of sleeping through, the late wakers. The waking of the chronic group could be related to constitutional and perinatal factors whereas that of late wakers may be maintained by inappropriate contingencies. The importance of parental handling in maintaining, rather than causing, infant sleep problems has principal implications for management. Causal factors cannot be altered, but maintaining factors have potential to be changed. 


\section{Management}

Considering the prevalence and impact of infant sleep disturbance on family wellbeing there is remarkably little research into management strategies and their efficacy. A high proportion of parents seek assistance for the problem from friends, relatives, general practitioners and community health nurses (Chavin and Tinson, 1980; Fergusson et al., 1979; Werry and Carlielle, 1981). GF's are the most commonly consulted professional group (Werry and Carlielle, 1981) although many consult the increasing number of baby books and magazine articles written for parents (Douglas and Levere, 1982). More recently psychologists and other health professionals have begun to offer management advice based on behavioural principles (Douglas, 1983; Douglas and Levere, 1982; Douglas and Richman, 1982; France, 1982; France and Hudson, 1984; Inglis, 1976; Richman, 1981b, Seymour et al., 1983).

Medication

Werry and Carlielle's (1981) survey found that GP's in New Zealand usually managed sleep problems with sedative medication, and advised parents that their child would soon outgrow the problem. Although frequently prescribed, there is little agreement about the administration of sedative medication or its efficacy. Valman (1981) recommended large initial doses of trimeprazine tartrate, later decreased. Illingworth (1966) suggested starting with a low dose of chloral hydrate, and increasing the dose if it is ineffective.

The effectiveness of medication for the management of infant sleep disturbance has not been adequately demonstrated. Russo, Gururaj and Allen (1976) performed one of the few controlled studies evaluating medication. They found that diphenhydramine reduced the number of wakings per night and the sleep onset latency (time taken to fall asleep after placement in bed) in the experimental group. Due to the lack of follow-up data the durability of these improvements is not known. 
Chavin and Tinson (1980) asked parents about their use of medication. Seventy-one percent of their sample with sleeping problems had resorted to medication. Only 11 percent of these thought it was effective, and most of these said the improvement had been temporary. Many continued to use the medication despite thinking that it was ineffective, as they were concerned that the problem would deteriorate further if they stopped. Hood (1975) claimed that phenergan, a sedative that can be purchased without a prescription, is often misused in this way in N.Z.

As with most drugs, continued exposure to sedative medication has been found to result in dependency in infants (Anders and Guilleminault, 1976). Long-term use of medication also resulted in increased irritability and overactivity in infants. Richman (1981a) and Valman (1980) both observed high relapse rates when medication was terminated. All of these findings cast doubt on the efficacy of medication for the management of infant sleep disturbance.

Medical advice

Most of the remaining literature on management consists of discussion articles offering advice, predominantly in medical journals (Anderson, 1951; Battle, 1970; Bax, 1980; Illingworth, 1951, 1966, 1968; Lask, 1977; Paul, 1982; Richman, 1981b; Shirley and Kahn, 1958; Spock, 1949, 1957; Valman, 1981). Advice is often inconsistent. For example, Spock (1949) recommended that parents adopt a firm approach every time the child woke, leaving the infant to cry him/ herself to sleep. Lask (1977) opposed this method. Spock (1949) also argued against taking the child into the parents' bed for any reason. Bax (1980), on the other hand, advocated this practice as a reasonable solution to the problem. Hood (1975) spoke out against taking the child into the parents' bed and recommended that parents should do the minimum necessary to settle their child back to sleep.

The difficulties with these and numerous other suggestions made in the literature are both the lack of empirical investigation and the lack of specific guidelines for parents to follow. 


\section{Behaviour management}

The application of the behavioural approach to the management of infant sleep disturbance offers great potential. The earliest reported application was a case study by Williams (1959). He employed extinction to eliminate bedtime tantrums in a 21-month-old boy. The parents were instructed to put the boy to bed, to leave the room and to ignore the tantrums. On the first night of treatment, the tantrum lasted for 45 minutes. The duration decreased rapidly on subsequent nights and by the tenth night the tantrums had completely disappeared. The author noted that the extinction procedure produced a similar pattern of response to that observed in studies of extinction with non-human subjects.

Until recently, there were no further studies of management with infants. There have been a few studies conducted, applying behavioural principles to children and adolescents with sleeping problems. Yen, McIntire and Berkowitz (1972) reported successful treatment of a 17-yearold insomiac with extinction. Extinction was also used in a study by Bergman (1976) in which a seven year-old boy who slept in his parents' bed was no longer permitted to do so. He was returned to his own bed each time he came through to his parents' room. In the absence of reinforcement the behaviour was soon eliminated. Other studies of behaviour therapy for inappropriate sleeping behaviour in older children have used reinforcement for incompatible behaviour (Kellerman, 1980; Thomas and Smith, 1972), positive routines (Milan, Mitchell, Berger and Pierson, 1981), and gradual reduction of parental attention at bedtime (Anderson, 1979).

Some recent case study literature has appeared recommending behaviour management for infants with sleep problems (Douglas and Levere, 1982; Douglas and Richman, 1982; Inglis, 1976). Although the results of these studies can only provide tentative evidence for the efficacy of the behavioural approach, due to their unsystematic nature, the indications are highly favourable. 
Advocates of the behavioural approach have all recommended training the parents of infants with disruptive sleeping behaviour in the techniques required to modify those behaviours. Parent-training as a means of changing childrens' behaviour is a widely used intervention strategy and extensive reviews have indicated that it is an effective approach to child behaviour management (e.g. Graziano, 1977).

Parent-training is especially appropriate for solving problems of infant sleep disturbance, as sleep behaviour is not readily accessible to intervention by those external. to the family. Furthermore, the evidence reviewed above has demonstrated that parents are very much involved in the maintenance of sleep problems. Therefore, parent-training may offer potential not only for treatment but for the maintenance of treatment gains, since it avoids the problems of generalisation to the natural environment.

A recent publication by seymour et al. (1983) was the first attempt to empirically validate the use of behaviour change procedures in the treatment of night-waking in pre-school children, whose ages ranged from 0-6 years. parents were instructed in

(a) the establishment of stimulus control over behaviour, by adopting a regular bedtime;

(b) extinction procedures, which involved ignoring crying; and

(c) reinforcement of incompatible behaviour, by rewarding sleeping through.

Daily phone calls to parents reinforced parent application of the programme. Results from 193 children who completed the one-month treatment period, show a rapid and sustained improvement. Whereas only one percent of the sample slept through 4 or more nights per week before intervention, 78 percent did so at the end of treatment. The results were maintained at follow-up.

Forty-eight parents were interviewed at the termination of intervention. They reported positive changes in their childrens' daytime behaviour coinciding with learning 
to sleep through and a high level of satisfaction with the programme.

Further investigations, including the present study, that have evaluated the efficacy of behaviour management of infant and pre-school sleep disturbance have been carried out at the University of Canterbury, Christchurch, New Zealand (France and Hudson, 1984; Moesbergen, 1984). The sleep Programme began in 1982 and has received considerable public attention, both through newspaper and television media. Reception has varied from enthusiastic support to harsh criticism. The behavioural strategies that have been evaluated are

(a) extinction,

(b) sedative medication in conjunction with extinction,

(c) reinforcement plus extinction,

(d) reinforcement, and

(e) graduated extinction (the present study).

France and Hudson (1984) employed a non-concurrent multiple baseline design to evaluate extinction in the management of seven infants, aged between 8 and 20 months, with sleep problems. The instructions to parents were similar to those given by seymour et al. (1983) except that reinforcement was omitted for this infant sample. Parents were warned to expect an increase in the variability and frequency of crying at bedtime and during the night as a consequence of extinction. The results of this study were impressive. All subjects showed decreases in both the number and duration of wakings per night from baseline levels. The severity of the sleep problem, as measured by a sleep behaviour scale, also decreased for all subjects during intervention which indicated that the improvement had generalised to aspects of sleep behaviour, other than those explicitly targeted for change. 
Research Issues

The present study addresses questions raised by France and Hudson (1984) from their study of extinction in the management of infant sleep disturbance. One important question raised by their study was whether or not a more gradual approach to management, involving less abrupt reduction of parental attention, would be as effective as extinction. They also questioned whether this alteration to the programme would decrease parental anxiety and increase parental self-efficacy.

These suggestions are based on clinical observations of

(a) the paradoxical effects of extinction,

(b) the resistance of inappropriate sleep behaviour to extinction, and

(c) the reluctance of many parents to use extinction procedures, and on the ethical issues related to the use of extinction. 1

The term extinction, as it is used here, is defined as the removal of a putative reinforcement (parental attention) for inappropriate sleep behaviour. In this definition, extinction is a procedure, not a process, and the outcome of the procedure is response elimination or suppression. This outcome confirms the identification of parental attention as the reinforcing event for the inappropriate behaviour.

\section{Paradoxical effects of extinction}

In both the animal learning literature and the infant operant conditioning literature, so-called 'paradoxical effects' of extinction are evident in behaviour in response

1. The observations were derived from discussions with K.G. France (personal communication, 1983) and the investigator's experience gained as an assistant therapist in France's (1983, 1984) unpublished research. 
to the onset of extinction. Animal studies have demonstrated that when reinforcement is first discontinued, the frequency of behaviour increases before beginning to decline (Reynolds, 1975). The variability, force and duration of responding also increases. These initial effects of extinction are paradoxical in that they produce a temporary change in the response in a direction opposite to the long-term response suppression produced by extinction.

Another possibly paradoxical effect may be evident towards the end of extinction, when responding has almost ceased. There may then be a brief recovery of responding, though typically at a reduced strength, following a brief situational change and/or some respite from the extinction procedure. This may be referred to as spontaneous recovery (Catania, 1968).

Extinction studies with infants have produced patterns of response suppression and elimination that closely resemble extinction curves obtained with animal subjects (Brackbil1, 1958; Williams, 1959). Williams (1959) observed an initial increase in the force and duration of behaviour, in this case bedtime tantrums, after parental attention was removed.

The temporary intensification of behaviour is particularly noticeable in performances that have been maintained on a continuous schedule. Baldwin and Baldwin (1981) gave an example of a child who was continuously reinforced by parental compliance for tantrum behaviour. When extinction began and tantrums no longer produced reinforcement, "not getting her own way" acted as a discriminative stimulus for throwing another tantrum. The child strove harder to gain the previous parental attention. However, if tantrums were consistently ignored then the child would quickly learn that tantrums were no longer effective in obtaining attention and would stop (Baldwin and Baldwin, 1981).

Results from the France and Hudson (1984) investigation of extinction applied to infant sleep disturbance demonstrated that there was occasionally an increase in the 
variability and frequency of the behaviour, more apparent for some subjects than others. The variation amongst infants is likely to be a function of their history of reinforcement, which contributes to the resistance of their behaviour to extinction and the pattern of response elimination.

These paradoxical effects of extinction on infant sleep behaviour are potentially aversive, both to parents and infants. Many parents become anxious if they hear their child crying and may find it unbearable not to attend to it. This raises the ethical question of whether it is acceptable to employ an intervention technique that is likely to increase the child's demands, if parents find this stressful. Furthermore, many parents who present for help with their child's sleeping problem are already exhausted, distressed and anxious.

Apart from the effect on parents, the possibility that extinction may be aversive to infants needs to be considered. The consequences of further stress on parents, many of whom admitted to having felt at risk of abusing their child when exhausted, may have negative repercussions on the infants.

Parents may also be discouraged by the initial deterioration in their child's behaviour. Parents often expect immediate improvement. The phenomenon of a brief recovery of the behaviour may further discourage parents and suggest to them that extinction has not worked. Discouraged parents may become non-compliant, with further adverse consequences detailed below.

In summary, then, it appears that the paradoxical effects of extinction occur with considerable frequency and may be aversive to both parents and infants, hereby raising both practical and ethical issues.

\section{Resistance to extinction}

The resistance of a response to extinction determines the efficiency of the procedure. The rate of decline in the frequency of the response and the number of responses emitted before responding ceases after extinction 
is introduced, depends on its resistance to extinction. changes in the frequency, quality and quantity of reinforcement may all increase resistance to extinction. Of the parameters of reinforcement, it is the schedule of reinforcement that existed prior to the onset of extinction which has been found to be the most important factor in determining resistance to extinction (Kimble, 1961; Reynolds, 1975). Responses reinforced on variable ratio (VR) schedules are more persistent than those with a history of VI, FR and FI schedules after extinction is introduced.

one theory that has been developed to account for the retarded rate of response elimination following partial reinforcement is the discrimination theory (Mackintosh, 1974). Subjects have learned to respond to a situation in which a high proportion of responses are not reinforced, which makes it more difficult to discriminate when extinction is in effect. "After VR reinforcement a truly amazing number of responses at a high, sustained rate may be emitted during extinction" (Reynolds, 1975, p.84). The change from continuous reinforcement to extinction provides an easy discrimination, and responding ceases rapidly after a temporary increase in variability and frequency.

Many inappropriate infant behaviours are difficult to extinguish because they have been intermittently reinforced. For example, a child who has been occasionally reinforced by "getting her own way" for throwing tantrums, will take a lot longer to discriminate when extinction is in effect, than a child who had been consistently reinforced for tantrums.

Undesirable sleep behaviour is most likely to have been reinforced on an intermittent schedule. Many parents report having "left their child to cry" in the past, eventually giving in and attending to the child on some occasions. Some subjects in the extinction study (France and Hudson, 1984) showed persistent patterns of night-waking, that took some time to decrease in frequency. The results suggest that night-waking had a history of intermittent reinforcement for these subjects. 
Furthermore, if the onset of extinction is associated with more intense noxious behaviour and if parents are unable to withhold their attention, the scene is set for the operation of a behaviour trap (Baer and wolf, 1970): withdrawing attention briefly, then restoring it when behaviour is more intense and vigorous than previously sets up a schedule of intermittent reinforcement, and also inadvertently reinforces more intense behaviour. This makes the behaviour

(a) more resistant to extinction in the future, and

(b) may lead to maintenance of the behaviour at the new more intense level.

The difficulties that resistance to extinction represents for parents are similar to those described for the paradoxical effects of extinction. Namely, the potential for increasing parental stress due to the resistance of the inappropriate sleep behaviour and the possibility that parents may be discouraged by this. It is conceivable that a behaviour trap could develop if parents who were stressed or discouraged failed to comply with the extinction instructions. If they eventually attended to their child, creating an intermittent schedule of reinforcement, they may have shaped up an even more resistant response, which could in turn increase their level of stress and discouragement, leading to a vicious cycle. These ethical and practical issues are potential side-effects of extinction and raise questions regarding alternative methods.

Reluctance of parents to implement extinction

Many parents are reluctant to implement extinction procedures which require them to ignore their child's crying and leave the child to fall asleep alone. In the author's experience, the majority of parents say that they have tried leaving their child to cry and that doing this just made it become worse. Some parents described their attempt: "We decided to leave. . [Chris] to it. When he woke we didn't go in, but he kept on crying for nearly two hours. In the end he had got himself so upset that we went in." 
"Leaving the child to cry" is objected to on a number of grounds. Firstly, many parents admit to becoming highly anxious if their child cries, and doubt their ability to implement the procedure. Schmitt (1981) stated that he believes most parents to be quite simply incapable of ignoring their child. Secondly, many parents object to extinction on principle. Usually these parents adhere to the child-rearing philosophy that promotes 100 percent involvement between parent and child. These parents feel that they should be available to their child 24 hours-per-day. They believe that "leaving the child to cry" is wrong because it is denying the child's needs. This issue and that of "sleeping in the parents' bed" have become controversial and a source of disagreement amongst mothers. Appendix A and Appendix B present newspaper and magazine examples of the controversy surrounding the use of extinction.

Thirdly, some parents express concern relating to their belief that their child is waking because of nightmares or night terrors. However, these phenomena are usually discernable from the suddenness and severity of the crying (seymour et al., 1983) and occur very rarely in infants (Werry and Carlielle, 1981).

Feldman and Peay (1982), in their discussion of the ethics of behaviour modification, made the point that clients ought to be able to reject a method that they and the therapist may know is more effective and efficient for an alternative. Since a number of parents are reluctant, and sometimes refuse, to implement extinction there is a clear need for an alternative acceptable to these parents.

\section{Present Study}

\section{An alternative to extinction: Graduated extinction}

The present study was devised as an experimental investigation of a more gradual approach to the management of infant sleep disturbance than extinction. The alternative procedure was devised in response to the issues raised in the preceding discussion of the difficulties with 
extinction. It involved the gradual reduction of parental attention to inappropriate infant sleep behaviour, in a systematic manner until extinction was reached. The procedure has been termed 'graduated extinction' because it is conceptually similar to extinction.

It involves the removal of reinforcement but rather than happening all at once the reduction in reinforcement is gradual.

Graduated extinction as it is used here, is not to be confused with its application to a procedure for extinguishing inappropriate defensive behaviour. "Inappropriate defensive behaviour is frequently extinguished by introducing aversive stimuli at weak intensities that do not evoke avoidance responses, and then gradually increasing their threat value until the most fearsome situations have been neutralized" (Bandura, 1969, p.390). Bandura's definition of graduated extinction refers to a stimulus change procedure combined with extinction. In the present study, graduated extinction refers to the removal of reinforcement gradually, by stepwise decrements until it is totally removed, as in regular extinction.

While extinction has been extensively investigated in the animal operant laboratory, no exact animal counterparts to graduated extinction have been found in the literature. Initially, studies which systematically attenuated the duration or magnitude of primary reinforcement were sought; for example, reductions in the duration of pigeon food hopper presentations. However, Blampied (1984, personal communication) suggested that this may be too simple a view of an appropriate animal analogue. He suggested that the sequence of events typical of nightwaking were better modelled by a chain schedule with sequential components of various behaviours: for example, sleeping; waking; waking and crying; waking, crying and interacting with the parents. The component containing parental attention constitutes the terminal component within which both secondary and primary reinforcers occur. These reinforcers are typically not single discrete events, but often require considerable consummatory behaviour. This suggests 
that the schedules constituting the chain can best be considered variable ratio schedules (VR). In this view, an animal laboratory analogue of the graduated extinction procedure would be a multi-component chain schedule, with a VR schedule in the terminal link. Graduated extinction would occur if the duration of the terminal link was systematically reduced to zero.

Due to the lack of research in both the animal and child operant literature that manipulated reinforcement in this way, there were no guidelines available for designing such a procedure. A number of arbitrary decisions were made due to lack of knowledge regarding the optimal rate or conditions for extinguishing behaviour by this technique.

One month, or 28 days, was decided on as the period of reduction from naturally occurring levels of reinforcement (baseline level) to extinction. This decision was based on France's (1983, personal communication) attempt to use this technique with a mother, fading parental attention out after fifteen days. The attempt was not very successful and France suggested that the time was too short.

An equally arbitrary decision was made regarding the timing and size of the decrements in parental attention. A systematic pattern of successive decrements of oneseventh every four days was chosen rather than criterionbased decrements because of ease of administration. If a criterion of, for example, "no waking" was required at each level of reinforcement reduction, before implementing the next level, it is possible that some children might never meet the criterion as reinforcement was constantly available. The method of consistent reductions regardless of change in infant behaviour was chosen, so that complete extinction would ultimately be achieved for all subjects.

The graduated extinction technique, detailed above, was substituted for extinction in the procedure used by France and Hudson (1984). Otherwise, this study was essentially a replication of France and Hudson, including instructions given to parents regarding the importance of stimulus control. As in their study, the effects of stimulus control were not evaluated independently of the 
modification of parental response to night-waking. Douglas and Levere (1982) suggested that discrimination learning was essential for teaching the infants new and appropriate sleeping behaviours, such as going to sleep alone and in their own cot or bed.

To enhance comparability with France and Hudson's (1984) study, the same dependent variables were examined (as well as additional ones) and most of the same measurement devices employed.

The evaluation of the procedure was based on parental recordings of infant sleep behaviour. The assessment of the reliability of this data was essential before conclusions regarding the efficacy of graduated extinction could be made with any confidence. France and Hudson (1984) used an Esterline Angus event recorder and a voice activated relay to measure the reliability of parental recording of night-waking. A similar method was used in this study because of problems associated with other techniques. Thomas (1982) failed to obtain adequate reliability figures in her study using fathers as a second observer of the infant's sleeping behaviour. She found that fathers inevitably slept through the wakings! The practical difficulties and expense of placing an observer or a time-lapse video camera in the subjects' homes throughout the night, made the collection of reliability figures by these techniques impossible.

\section{Aims of this investigation}

The general aim of this study was to evaluate the management of infant sleep disturbance using graduated extinction. The specific aims of the study were:

(1) To determine whether graduated extinction produced clinically significant changes in a variety of infant sleep behaviours.

(2) To determine whether graduated extinction reduces parental anxiety by avoiding the potentially aversive side-effects of extinction, namely: 
(a) intensification of the undesired behaviour,

(b) resistance of the behaviour to change, and

(c) "leaving the child to cry".

(3) To determine the acceptability of graduated extinction to parents and to assess whether it increases their general child-management skills.

(4) To provide an alternative to extinction.

(5) To compare the efficacy, efficiency and social validity of graduated extinction with extinction in the management of infant sleep disturbance.

(6) To establish whether changes in infant sleep behaviour are durable over time.

In this study one group of infants were exposed to graduated extinction, and one group to extinction. The subsequent changes in the dependent variables were evaluated with primary emphasis on graduated extinction, and the comparison between the two procedures.

\section{Hypotheses}

The following hypotheses were tested:

(1) That graduated extinction would produce significant changes in those aspects of infant sleep behaviour specified as target problems (either by the parents or from analysis of baseline levels of the behaviour).

(2) That changes in infant sleep behaviour would not be apparent immediately after the onset of graduated extinction, but would be gradual and would not show an increase in frequency and duration, even if temporary, from baseline levels.

(3) That parental anxiety would not increase during intervention.

(4) That changes in infant sleep behaviour would be maintained over time. 
(5) That differences would be observed between graduated extinction and extinction groups on the following dimensions;

(a) pattern of response elimination or reduction, (b) parental anxiety levels, (c) acceptability of the procedure to parents. 
CHAPTER TWO

METHOD

The therapeutic programme devised for the present research was developed as part of the University of Canterbury sleep Programme, and is based on the recent work of France and Hudson (1984).

\subsection{SUBJECTS}

Recruitment and selection of Subjects

The subjects of the study were recruited through community health nurses ${ }^{1}$ and newspaper publicity (see Appendix C). Subjects sought were chilaren between the ages of 6 and 24 months, who had sleep problems. They were selected only if their parents reported that one, or more, of the following sleeping difficulties occurred at a frequency which caused parental concern:

(1) Regular night-waking: frequent night-time waking to which parents responded.

(2) Sleep onset latency: recurrent delay in falling asleep after placement in bed.

(3) Bedtime delay: actual bedtime often later than the time preferred by parents.

(4) Sleeping in the parents' bed: either placed into the parents' bed to sleep or brought into their bed after waking during the night.

The subjects were not randomly selected but were selected in order of their application for help through the sleep Programme. On application, parents were enrolled for the therapeutic programme, conditional on their agreement to comply with the research conditions (see Appendix D). No subjects refused to participate and no subjects aropped out after joining the programme. There was no fee for services. In each case the family doctor was informed,

1. Plunket Society Nurses. 
by letter, that the child and his/her parents were participating in the research programme (see Appendix E).

Subject characteristics

The subjects in the study were seven male and five female infants whose ages ranged from 6 to 19 months, with a mean of 12 months. All were Caucasian and lived with both of their natural parents. Parents were aged between 23 and 36 years. In all but one of the families the father was the sole wage earner. The mother took the major responsibility for child-rearing. Subjects typically came from families in the middle-to-higher socioeconomic groups when rated by Johnston's (1983) index of socio-economic status.

All of the subjects in the study slept in a cot, with the exception of subject 11 who slept in a bed. Each child had a room of its own in which to sleep. Further information about the participants is presented in Table 4 .

The quantitative and qualitative aspects of the participants' problems differed from child to child. All parents reported that night-waking was a problem. Many reported additional difficulties with sleep onset latency, bedtime delay and the presence of their child sleeping in their bed. Further information about the target problems identified by parents for each participant is presented in Table 5.

Parental management of night-waking and other sleeping difficulties varied considerably. Most parents had tried medication in the past. Many had tried leaving their child to cry. Currently, most parents either fed their child or reassured it briefly in attempts to get the child to sleep (see Table 6).

\subsection{MEASURES}

Daily Sleep Diary (France and Hudson, 1984)

Booklets of weekly record sheets on which to record their child's daily sleep behaviour were supplied to 
Table 4

Demographic characteristics of subjects

\begin{tabular}{|c|c|c|c|c|c|c|c|}
\hline $\begin{array}{l}\text { Subject } \\
(\underline{N}=12)\end{array}$ & Sex & $\begin{array}{c}\text { Age } \\
\text { (months) }\end{array}$ & $\begin{array}{l}\text { Birth } \\
\text { Order a. }\end{array}$ & $\begin{array}{c}\text { Mother's age } \\
\text { (years) }\end{array}$ & $\begin{array}{c}\text { Father's age } \\
\text { (Years) }\end{array}$ & $\begin{array}{l}\text { Father's } \\
\text { occupation }\end{array}$ & $\begin{array}{l}\text { cio-economic } \\
\text { group b }\end{array}$ \\
\hline 1 & $F$ & 10 & 2 & 26 & 26 & Builder & 3 \\
\hline 2 & M & 19 & 1 & 23 & 23 & Blocklayer & 4 \\
\hline 3 & $\mathrm{~F}$ & 14 & 1 & 30 & 29 & Microbiologist & 1 \\
\hline 4 & $\mathrm{M}$ & 9 & 2 & 29 & 33 & Veterinarian & 1 \\
\hline 5 & M & 6 & 3 & 35 & 36 & Engineer & 1 \\
\hline 6 & $\mathrm{~F}$ & 13 & 1 & 23 & 24 & Welder & 4 \\
\hline 7 & $\mathrm{~F}$ & 12 & 1 & 31 & 34 & Microbiologist & 1 \\
\hline 8 & $F$ & 7 & 1 & 31 & 30 & Manager & 3 \\
\hline 9 & M & 14 & 1 & 21 & 34 & Factory Manager & 3 \\
\hline 10 & $M$ & 9 & 1 & 26 & 26 & Dye setter & 4 \\
\hline 11 & $M$ & 17 & 1 & 28 & 30 & Supervisor & 4 \\
\hline 12 & M & 9 & 2 & 31 & 31 & Farmer $\mathrm{C}$ & 3 \\
\hline
\end{tabular}

a All subjects were youngest children.

$b$ Based on father's occupation.

c Mother worked as a travel consultant. 
Table 5

Sleep problems, their onset and precipitating factors reported by parents for each subject

\begin{tabular}{|c|c|c|c|c|c|c|}
\hline \multirow{2}{*}{$\begin{array}{l}\text { Subject } \\
(\underline{N}=12)\end{array}$} & \multicolumn{4}{|c|}{ Type of Sleep Problem } & \multirow{2}{*}{$\begin{array}{c}\text { Age at onset } \\
\text { (months) }\end{array}$} & \multirow{2}{*}{$\begin{array}{c}\text { Precipitating } \\
\text { Factors (if } \\
\text { any) }\end{array}$} \\
\hline & $\begin{array}{l}\text { Night-waking } \\
\text { (No. per night) }\end{array}$ & $\begin{array}{l}\text { Sleep onset } \\
\text { latency }\end{array}$ & $\begin{array}{l}\text { Bedtime } \\
\text { delay }\end{array}$ & $\begin{array}{l}\text { Sleeping in } \\
\text { parents }\end{array}$ & & \\
\hline 1 & $2-3$ & & & & $0^{a}$ & \\
\hline 2 & $2-5$ & & $\checkmark$ & $\checkmark$ & 0 & \\
\hline 3 & $1-3$ & & $\checkmark$ & & 6 & Holiday \\
\hline 4 & $1-2$ & $\checkmark$ & $\checkmark$ & $\checkmark$ & 0 & \\
\hline 5 & $2-3$ & & & . & 0 & \\
\hline 6 & $2-3$ & & $\checkmark$ & & 9 & \\
\hline 7 & 2 & & $\checkmark$ & & 0 & \\
\hline 8 & $1-2$ & & & & 6 & Teething \\
\hline 9 & 1 & & $\checkmark$ & $\checkmark$ & 6 & Travelling \\
\hline 10 & $0-1$ & & $\checkmark$ & & 6 & Teething \\
\hline 11 & $3-4$ & & & $\checkmark$ & 0 & \\
\hline 12 & 2 & & $\checkmark$ & & 0 & \\
\hline
\end{tabular}

a 0 means that parents reported that the sleeping problem had existed since birth. 
Table 6

Past (P) and current (C) management attempts reported by parents

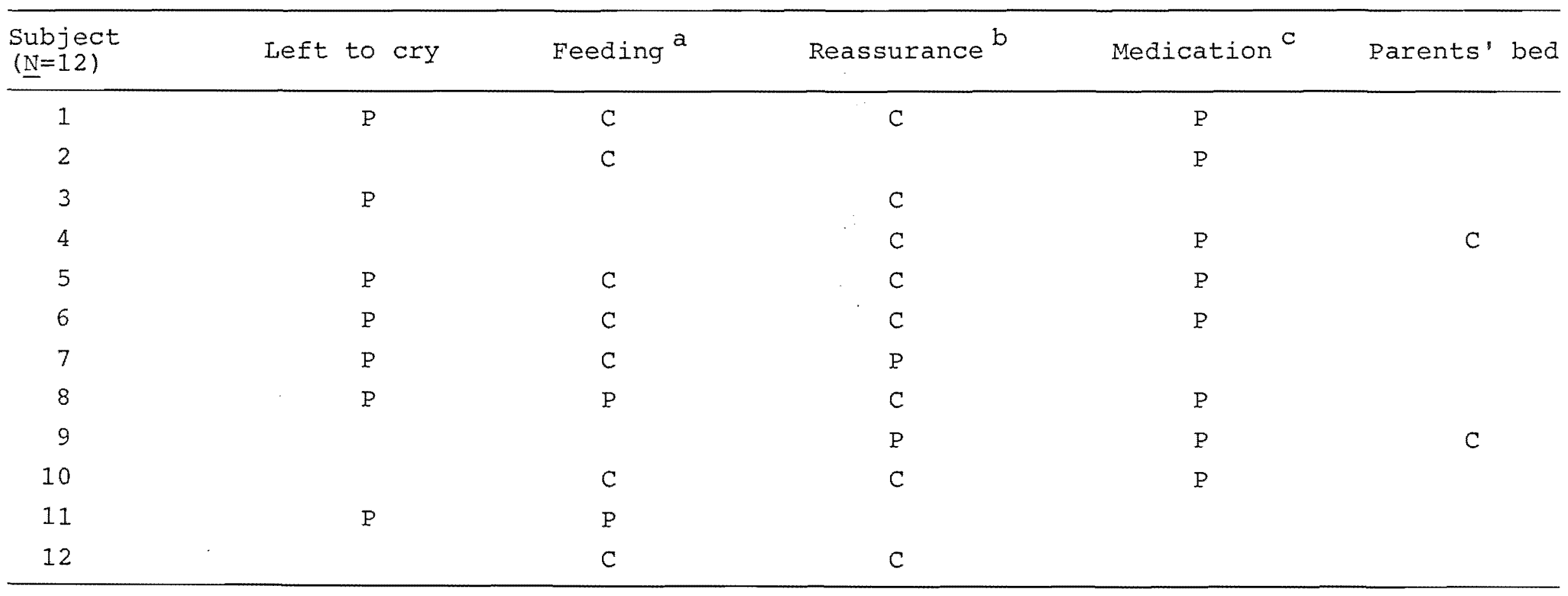

a Includes breast and bottle feeding, as well as drinks of water or orange.

$\mathrm{b}$ Includes patting the child's back, talking, singing, cuddling, turning over, etc.

$c$ Most commonly Phenergan or Vallergan. 
parents, with instructions for their use (see Appendix F). Parents kept a daily record of the following aspects of infant sleep behaviour:

(1) duration and location of daytime sleep/s.

(2) actual bedtime, ideal bedtime and reasons for discrepancy, if necessary (measure of bedtime delay).

(3) time from placement in bed to silence, and the quality of the noise, for example quiet playing, crying or talking (measure of sleep onset latency).

(4) number of night-wakings, and the duration of each.

(5) parental responses to and handling of each waking (measure of self-monitored parental attention).

(6) getting-up time in the morning.

Parents were asked to record night-wakings as they occurred, or first thing the next morning. Weekly Sleep Behaviour Scale

The data recorded by parents were summarised into a weekly score, indicating the overall severity of the sleeping problem. The scale is an adaptation of the scale adapted from Richman (1981a) by France and Hudson (1984) for use in their sleep programme. The composite weekly score covers six areas of sleep behaviour, each rated on a five-point ordinal scale from 0 to 4 . The maximum possible score is 24. A high score indicates a more severe problem. The scale and scoring instructions are presented in Appendix G.

\section{"Deviation from ideal" scale}

Data recorded during the last 15 days of both baseline and intervention were compared with hypothetical "ideal" sleep behaviour, on the following dimensions:
(a) sleep onset latency,
(b) bedtime delay,
(c) child placed into bed awake or asleep,
(e) duration of wakings, and 
child slept in parents' bed or not. (See Appendix H.)

If the infant's actual sleep behaviour was rated as ideal it was scored 0 ; rating of not ideal scored 1 . The highest possible score was five and indicated a marked deviation from the hypothetical ideal.

Structured Interview (France and Hudson, 1984)

The interview, at the end of baseline, covered details about the nature and history of the infant's sleeping problems. Information regarding past and current management strategies for handling sleep disturbance was also elicited. Brief developmental and medical histories were taken, as well as family details including current stresses on the family, family life events over the life of the child and other concerns the parents might have regarding that child (see Appendix I).

\section{3 RELIABILITY}

The reliability of parental recording using the Daily sleep Diary was primarily established by gathering observations through the use of apparatus. The apparatus detected infant crying, which was used as an indication of night-waking. Parental presence near the cot was also recorded, as a measure of parental attention.

Apparatus

An Esterline-Angus event recorder, moving at $7.6 \mathrm{~cm}$ per hour, was used to obtain a continuous record of the entire night's sleep. To measure crying a voice-activated relay (VAR) was used. Noises exceeding a prespecified level, activated one channel of the event recorder. The VAR was calibrated with the amplifier gain switch at a standard setting. With the microphone one metre from a white noise source, the VAR operated at a sound pressure level of 78-80 dB(A), measured by a Dawe Sound Level Meter (Model $1400 \mathrm{E})$.

To measure parental presence next to the cot, a switchmat was placed in front of the cot. Each time a parent stood on the mat, it was automatically registered 
on another channel of the event recorder. In this way a permanent, automatic record of the frequency and duration of occurrences of crying and parental presence was made. (See Appendix J for a photograph of the apparatus.)

Procedure

The apparatus was delivered to the homes of five subjects, randomly selected from the sample. It was used to record the entire night's sleep for a minimum of eight days in baseline and eight days in intervention.

The equipment was set up in the infant's bedroom in the most standard manner possible, allowing for differences in layout from bedroom to bedroom. Where possible the microphone was placed at cot level, about one metre away from the infant's head. The switchmat was placed on the floor directly in front of the side of the cot from which the parents attended to their child. The event recorder and voice-activated relay were placed in as inconspicuous a position as possible. The amplifier gain switch was set to the standard setting and the pens on the recorder checked. Parents were instructed to switch the apparatus on, after putting their child to bed, marking the date and time on the recording paper.

once the machines were removed, the event recorder output was transcribed into numerical values. (For the criteria used in reading the output see Appendix K.) The reliability of parental recording was calculated by determining the point-by-point agreement between parents and the event record.

\subsection{THERAPIST}

The investigator, a 24-year-old woman graduate student, served as the sole therapist in this study. She had previously received training in the application of behaviour modification techniques to sleep problems whilst working as a research assistant in earlier phases of the University of Canterbury sleep Programme. She was concurrently receiving training in clinical Psychology. 


\subsection{EXPERIMENTAL DESIGN AND PROCEDURE}

\section{Experimental Design}

A non-concurrent multiple baseline design across subjects (Watson and Workman, 1981) was used to evaluate the effects of intervention on the sleep behaviour of each subject. Subjects were assigned baseline lengths of $5,4,3$ or 2 weeks based on the order of their presentation to the study. Intervention was implemented for a minimum period of six weeks, and follow-up was conducted two months following the termination of intervention. For details of the number of days spent by each subject in the different experimental phases see Table 7 .

Baseline

Baseline began after the initial telephone contact between parents and the investigator. Parents were sent a booklet of Daily Diary sheets which they were required to keep for the number of weeks of baseline to which they had been randomly assigned. Baseline ended with an appointment which included both the structured interview and the implementation of the sleep programme.

Intervention: Initial Appointment

\section{Attendance}

Intervention began with the appointment which all subjects attended with both parents. Both parents were present so that it could be ascertained that they understood the rationale upon which the procedures were based and were consistent in their implementation of them. Seymour (1983) noted that parents of infants with sleep problems are frequently in conflict over management. The appointment was important for the resolution of these conflicts and to ensure that parents shared the responsibility for dealing with the problem.

The appointment typically lasted for an hour and a half, ranging from one to two hours. 


\section{Assessment}

The appointment began with the structured interview described earlier. It served not only as a data collection method but also as a therapy session, in which clinical judgements regarding the suitability of the therapeutic programme for the particular family were made. Families were assessed to ensure that they met Inglis' (1976) criteria of suitability for a behaviour management approach. All subjects had a history of parental reinforcement for inappropriate sleeping behaviour, had fundamentally positive interactions with their parents and showed no signs of emotional disturbance.

It was ascertained that parents had realistic expectations of their infant's sleep behaviour. Illingworth's (1968) description of normal sleep requirements and the range of individual variability amongst infants, provided a guideline for the selection of appropriate goals, in terms of bedtime, getting-up-time and daytime sleeps to aim for on the programme.

\section{Rationale as applied to parents}

It was determined that parents understood the possible causes of night-waking and their own role in maintaining the problem rather than causing it. If parents had feelings of guilt about having caused the problem, they would have been less likely to be able to implement the programme effectively. The explanation of night-waking and the associated causal and perpetuating factors included the following points:

(1) The vulnerability of infants to night-waking due to the immaturity of the sleep control mechanisms in their brains (Anders, Carskadon and Dement, 1980).

(2) The possibility that certain temperamental characteristics predispose some infants to night-waking (Carey, 1974; Richards and Bernal, 1974).

(3) The reinforcing nature of parental attention for waking and disturbing the parents (Inglis, 1976; Richman, 1981a; Seymour et a1., 1983). For those 
children who had never slept through the night since birth, parental attention had become a necessity as the child had never learned to go to sleep without it. For those children who had reverted to nightwaking, usually after a disruption such as an illness or a holiday, parental attention had perpetuated the waking.

The success of previous research conducted by France and Hudson (1984) using extinction techniques was described. This led to an expectation of success. Some parents in the earlier studies had found it very difficult to leave their child to cry and others had refused to do so.

The present research was designed to study whether a gradual reduction in parental attention would decrease night-waking and other sleep disturbances without the initial increase in frequency and variability of crying behaviour.

\section{Graduated Extinction}

The parents of seven of the twelve subjects participating in the study were instructed in the application of graduated extinction to infant sleep disturbance. The procedures were individually tailored to each infant and parents received a typed protocol of instructions (see Appendix L).

Step 1. The importance of stimulus control over bedtime and settling behaviour was explained to parents. In order to teach their child the temporal stimuli associated with sleep, parents developed a regular bedtime routine and chose a goal bedtime. Parents were instructed to carry out both, consistently and regularly.

Step 2. To ensure that the child learned the appropriate setting stimuli for sleep, parents were required to put their child into its own bed, with its favourite toy if desired, while it was still awake. Many parents were previously accustomed to letting their child fall asleep, either in their arms or playing in the living room, before placing it into bed. The importance of teaching the child to fall asleep alone in the appropriate place was stressed. 
Table 7

Order of presentation to the study for each subject, and the number of days each spent in baseline, intervention and follow-up phases.

\begin{tabular}{|c|c|c|c|c|c|}
\hline $\begin{array}{l}\text { Subjects } \\
(\underline{N}=12)\end{array}$ & $\begin{array}{l}\text { Order of presentation } \\
\text { of subjects }\end{array}$ & $\begin{array}{c}\text { Assigned base- } \\
\text { line length } \\
\text { (days) }\end{array}$ & $\frac{1}{\text { Baseline }}$ & $\frac{\text { length (in days) }}{2}$ & $\frac{3}{\text { Follow-up }}$ \\
\hline 1 & 9 & 14 & 17 & 41 & 7 \\
\hline 2 & 5 & 14 & 17 & $x$ & $\mathrm{x}$ \\
\hline 3 & 4 & 21 & 25 & 57 & 7 \\
\hline 4 & 11 & 21 & 27 & 81 & 7 \\
\hline 5 & 2 & 28 & 43 & 84 & 7 \\
\hline 6 & 3 & 35 & 42 & 77 & 7 \\
\hline 7 & 1 & 35 & 58 & 56 & 7 \\
\hline 8 & 6 & 14 & 20 & $x$ & $x$ \\
\hline 9 & 7 & 21 & 21 & 63 & $x$ \\
\hline 10 & 12 & 28 & 29 & 43 & 7 \\
\hline 11 & 8 & 28 & 35 & 56 & 7 \\
\hline 12 & 10 & 35 & 40 & 42 & 7 \\
\hline
\end{tabular}

$\mathrm{x}$ Denotes missing data 
Step 3. The procedure for reducing parental attention to night-waking required that parents adhere consistently to a pattern of reduction in the time spent with their child during the night. From baseline records the typical amount of time the parents had spent attending to their child on most occasions of waking was measured. This period became the maximum amount of time that parents could spend attending to their child. From the first day of intervention, parents were to reduce the amount of "attention time" one decrement every four days. The decrement was approximately one-seventh of the maximum time. After a month ( 28 days) parents no longer attended to their child. When time was up, they were to leave the room. Parents were alerted to expect occasions when the child would not be asleep when they left the room and that crying was likely. They were cautioned on the dangers of inconsistency. The occasions when the child cried were important opportunities for the child to learn that $\mathrm{s} / \mathrm{he} \mathrm{did}$ not require parental presence to fall asleep. Table 8 details the graduated extinction regimes for the seven subjects.

The practice of taking the child into the parental bed was specifically prohibited during the course of the programme. The type of attention parents gave to their child was not otherwise restricted, but mothers who were breast feeding their child during the night were advised not to.

Step 4. Parents specified the time at which they would like their child to wake in the morning. Waking before this time was to be considered as waking during the night and dealt with similarly. Waking after this time was considered appropriate and dealt with as differently as possible, to aid discrimination learning.

\section{Extinction}

Five subjects were considered unsuitable for the graduated extinction programme and received the extinction programme. Examination of baseline recordings of these five subjects revealed that their parents 
Table 8

Reduction of parental attention time for night-waking, scheduled for each subject in the graduated extinction group.

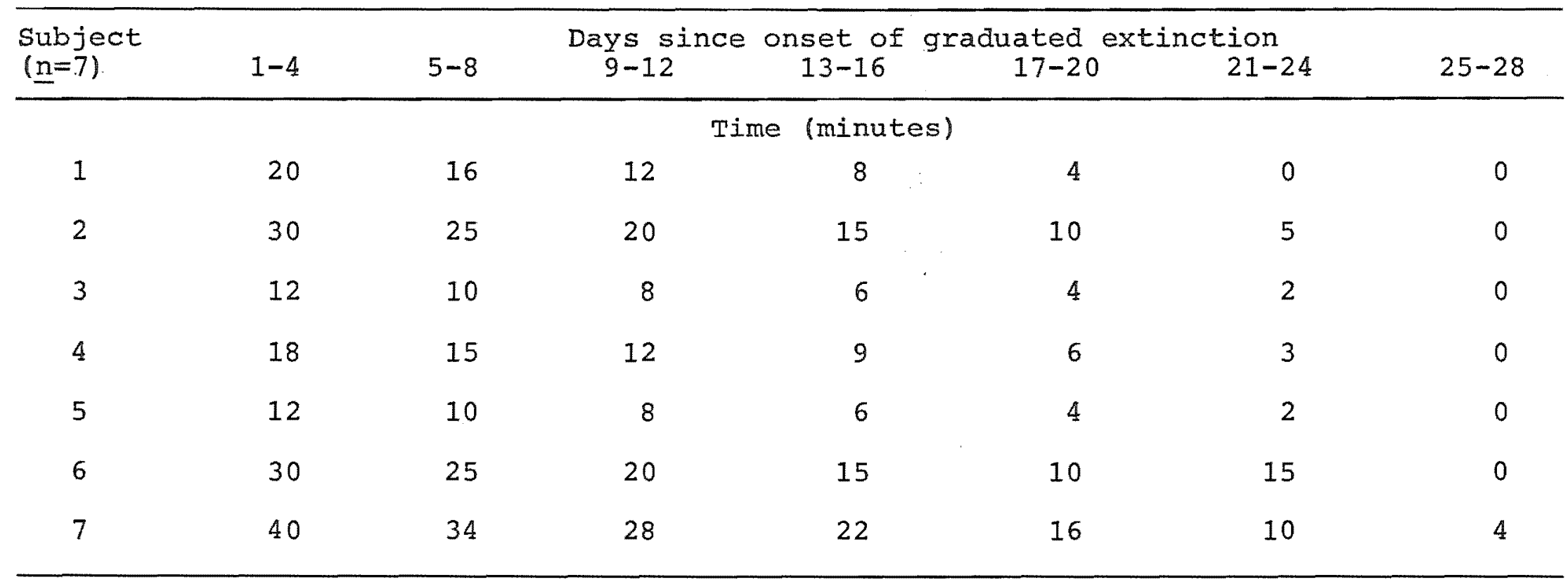


(a) spent very small amounts of time attending to the child, or

(b) took the child regularly into their own bed rather than attending to the child in its own room.

Due to the practical limitations of reducing already small amounts of "attention time" graduated extinction was unsuitable for these subjects. For subjects who were typically taken to their parents' bed, a decision not to implement graduated extinction was made on the basis of the following hypothesis: The change from being in the parents' bed, a state with enormous reinforcement potential for the child, to sleeping alone would represent such a drop in reinforcement level as to approach extinction. If this were the case, then requiring parents to go to the child for a specific period at night might set up a new set of reinforcement contingencies for waking.

The instructions to the parents in the extinction group were identical to those of the graduated extinction group, apart from step 3. Parents were told not to attend to their child after bedtime, unless they became concerned that their child was at risk. If necessary to attend, they were to do so with the minimum of noise, light and reassurance. Subjects $8,9,10,11$ and 12 form this group. Intervention: Continuing Contact

Intervention lasted for a minimum of six weeks and during that time the investigator made regular telephone calls to each family. Initially calls were made daily to discuss progress, offer support and encouragement, and to answer questions. The frequency of calls were reduced after the first week or two, to once every 3 or 4 days, and towards the end of intervention, once weekly. There was no further face-to-face contact, with one exception (Subject 7$)$.

Two weeks after the commencement of intervention, Subject. 7 began to vomit just before or after being put to bed. She also began to cry or scream whenever "bed" was mentioned. After this had occurred on several evenings, 
the parents, distressed by this development, sought and were given an additional face-to-face consultation with the investigator. Analysis suggested that the vomiting was maintained by the intense parental attention which followed it. Parents were advised to deal with the vomiting in ways which minimised their attention. It was also clear to the investigator that the event of bedtime had become a negative occasion for the whole family. Parents were encouraged to substantially increase their positive interaction with the child at bedtime.

Following the consultation, there were three more vomiting incidents, and they did not re-occur during the rest of the study.

\section{Maintenance Instructions}

Parents received maintenance instructions after they had reported a period of 5 to 7 nights of uninterrupted sleep to the investigator during a progress telephone call. Parents were recommended to continue with the sleep Programme until their child's sleeping pattern stabilised. Instructions suggested that should their infant wake after having settled into a stable pattern of sleeping through the night, they should briefly check on him/her. Parents were cautioned to return to the programme if they observed an increase in the frequency of night-waking following an illness or holiday. A brief return to the programme would soon stabilise the sleeping pattern. A letter explaining the above was mailed to all parents, along with a stamped and addressed envelope for the return of data (see Appendix M) . Infant sleep behaviour was not recorded during the maintenance phase.

Follow-up

Parents recorded sleep behaviour for one more week, using the Daily sleep Diary, two months after the receipt of maintenance instructions and the end of intervention recording. 
The following subjective measures were administered to evaluate the clinical significance of changes in infant sleep behaviour and parental responses to the procedure. Flint Infant Security Scale, FISS, (Flint, 1980).

To assess parents" perception of the generalisation of changes in sleep behaviour to other infant behaviour, the FISS was completed on three occasions: during baseline, intervention and maintenance, respectively. Parents were asked to complete the intervention questionnaire ten days after beginning the programme. The next questionnaire was sent out with the maintenance instructions for parents to complete at that point. The scale was adapted from interview form to questionnaire form, so that mothers could easily complete it at home. Mothers were required to underline which of a list of infant behaviours applied to their own child. The list covered eating, sleeping, toileting, social and playing behaviour, as well as behaviour in unfamiliar situations and physical experiences.

Each item underlined was scored either positively or negatively, and combined to form an overall security score. The highest possible score is 0.50 and indicates a high level of security and mental health (Flint, 1980). Flint reported that the normal range of scores on the FISS was from .35 to .44. She suggested that a score below .35 is indicative of poor mental health, and a score below .20 indicates a need for immediate intervention.

State-Trait Anxiety Inventory, STAI, (Spielberger, Gorusch and Luschene, 1970).

To determine whether changes in infant sleep behaviour affected parental anxiety level, each parent completed the STAI, or Self Evaluation Questionnaire, on the same three occasions that mothers completed the FISS. Anxiety scores on both the state and trait dimensions were obtained. The highest possible score on each scale is 80 , indicating extreme anxiety. Knight, Waal-Manning and spears (1983) published norms for the New Zealand population. Combining 
the range of scores two standard deviations from the mean for males in the 20 to 29-year age group, on both state and Trait scales, indicates that most males score between 20 and 47 . For females in the same age group the normal range is between 20 and 54 .

Sleep Programme Evaluation Questionnaire, SPEQ.

To assess parental response to the sleep Programme, the SPEQ was administered at the end of intervention (see Appendix N). A measure of overall satisfaction was obtained from nine items with four-point anchored answers. scores from 9-22 indicated low satisfaction, scores from 23-29 indicated medium satisfaction, and scores from 30-36 indicated high satisfaction.

Individual items and the five open-ended questions of the SPEQ provided an indication of acceptability of the programme to parents, their level of stress associated with its implementation and their perception of its effect on their competence to deal with their child's behaviour, in general.

\subsection{DATA ANALYSES}

The data were analysed to determine treatment effects as follows:

Visual analysis

The raw data for each subject were plotted as line graphs, for the following four variables:

(1) Number of wakings.

(2) Duration of wakings.

(3) Sleep onset latency.

(4) Bedtime delay.

The data for subjects in the graduated extinction group were plotted in a vertical array to enable analysis of the effects of the sequential introduction of intervention on inappropriate sleep behaviour. Data for extinction subjects were displayed in a similar manner. 
Sleeping in the parents' bed was the only aspect of infant sleep disturbance not analysed in this way. The frequency of sleep in this inappropriate location was incorporated into the following composite measures, also plotted for visual inspection:

(1) Weekly sleep Behaviour scores.

(2) Deviation from Ideal scores (plotted for the last fifteen days of baseline and intervention).

(3) Parental responses to infant night-waking (plotted as a weekly cumulative record).

The data obtained from the EISS and STAI for each subject during baseline, intervention and maintenance phases, respectively, were plotted for easy detection of possible trends across phases.

The data were analysed according to Kazdin (1982) and Parsonson and Baer's.(1978) criteria for visual analysis. These authors, amongst many others, have argued that because change in behaviour from baseline to intervention has to be clearly evident and reliable before it is considered significant, the effect will have to be more powerful than that required to produce a statistically significant change if visual analysis is used. The relative insensitivity of visual analysis is valuable for the investigation of treatment effects. A change that is not visible to the naked eye is unlikely to be of sufficient magnitude to be clinically significant (Parsonson and Baer, 1978).

Graphs were produced by package plot 79 on a Burroughs B6900 computer, using a Hewlett Packard Plotter. Statistical Analysis

The C-statistic, a simplified time-series analysis, was used to supplement visual analysis (Tryon; 1982). The C-statistic determines whether the time-series contains any trends. Baseline data are first evaluated for evidence of a trend. If baseline does not contain a significant trend, then treatment data are appended to baseline data and tested with the C-statistic. A significant result is 
evidence that the treatment series, represents a departure from the baseline series.

When baseline data are found to contain a significant trend, the following procedure is recommended:

(a) quantification of the trend and calculation of trend line values;

(b) creation of a comparison series "by subtracting the trend line values associated with the first baseline point from the first treatment point, then subtracting the trend line value associated with the second baseline point from the second treatment point, etc." (Tryon, 1982, p.425). If more treatment than baseline points exist, he suggested that modest extrapolation of the baseline trend Iine is acceptable in order to extend the comparison series; and

(c) application of the C-statistic to the comparison series. A significant result is evidence that the difference between the trends in baseline and treatment phases contains a departure of some kind.

If any of the baseline series were found to contain a trend, significant at the $\underline{p}<0.01$ level, then standard regression analysis was used to quantify the trend. Package Minitab (1983) was employed to obtain the regression equation from which the trend line values were calculated. These values were subtracted from treatment data to create the comparison series, suitable for analysis with the c-statistic. 
CHAPTER THREE

RESULTS

Complete data were collected for $10 / 12$ subjects in this study. Data from Subjects 2 and 8 were unavailable for analysis. (For a dicussion on missing data see Appendix 0.)

\subsection{RELIABILITY}

The agreement between the parental record and the event record was calculated for:

(a) the number of night-wakings,

(b) the number of parental attends, and

(c) the duration of wakings.

Although parents were not required to record the time of night at which night-waking occurred, some did. For these subjects, agreement between parents and apparatus was calculated using time-of-night information also. The reliability of parental recording of each of the above behaviours was calculated using point-by-point agreement. An agreement was scored if the parents and the apparatus had both recorded the occurrence of a behaviour. For those subjects who had recorded time, agreement was only scored if the parents and apparatus had recorded the behaviour simultaneously. An agreement was also scored if parental and automatic recordings agreed on the nonoccurrence of the behaviour during an entire night. A disagreement was scored when either had recorded a behaviour that the other had failed to record. The percentage agreement was calculated by dividing the number of agreements by the number of agreements plus disagreements, multiplied by 100 .

The apparatus/parent agreements summed across the five subjects were (with ranges in parentheses):

(a) Number of wakings - 69\% (40\%-85\%), with the lowest value of $40 \%$ being largely accounted for by differences 
in the sensitivity of the apparatus and the parents. The parents had consistently recorded zero wakings whereas the voice-activated relay (VAR) had recorded sound on several occasions. Without this figure the average agreement was $77 \%$.

(b) number of parental attends $-85 \%(77 \%-93 \%)$.

(c) duration of wakings - 41\% (29\%-56\%) with lower agreement being largely accounted for by differences in apparatus (duration of noise above prespecified DB level) and parental (duration of noise above the parents' threshold of awareness) definitions of duration.

A further check on the reliability of parental recording was conducted by calculating the agreement between parents" written record and verbal report of their child's sleep behaviour during intervention. The information recorded by the investigator during progress telephone calls was compared with the written record for the same day. Where the written record validated the verbal report, an agreement was scored. Where the written record contradicted the verbal report, a disagreement was scored. Pointby-point agreement was calculated for each subject, with an average of $81 \%$ (range $64 \%-96 \%$ ).

Although agreement is reasonable, there is a confounding factor that may have had various effects on different individuals and reduced the level of agreement between verbal and written records. Towards the end of intervention, telephone calls were made less frequently and parents often reported their child's sleep behaviour over the last few days as well as that of the most recent night. Therefore, a factor of recall-accuracy is involved in the verbal report, which is presumably not operative in the written reports which were completed at the time the behaviour occurred or early the following morning.

In summary, then, the mean reliability figures obtained from 5 subjects over baseline and intervention phases calculated by the point-by-point agreement between the parents' record and the automated record were:

(a) $69 \%$ (77\% if the deviant score is removed from the calculation) for number of wakings, 
(b) 858 for the number of parental attends, and

(c) 418 for the duration of waking.

Point-by-point agreement between parents' written record and verbal report during intervention of 10 infants yielded a mean of $81 \%$.

3.2 GRADUATED EXTINCTION AND EXTINCTION: BEHAVIOURAL EFFECTS

The overall behavioural effects of graduated extinction and extinction were examined with respect to the four primary measures of infant sleep behaviour, recorded daily:

(a) number of wakings,

(b) duration of wakings,

(c) sleep onset latency, and

(d) bedtime delay.

The effects of both intervention techniques on each behaviour were examined separately, and then compared. sleeping in the parents' bed was not examined on a separate behavioural measure because it was prohibited during intervention. Changes in this behaviour contributed to the composite sleep behaviour scores presented in the next section, and to measures of parental responses also presented below.

Number of wakings

\section{Graduated extinction}

Number of wakings per night is shown for all subjects in this group in Figure 1 and Table 9. Baseline levels of waking were variable and showed no tendency to stabilise for any subject, except for subject 7. Her waking stabilised towards the end of baseline. The mean number of wakings per night for all six subjects was 1.6 (see Table 9).

Despite variable baseline data there was clear evidence of an overall decrease in the number of wakings from baseline to intervention phases. In most cases the decrease was marked, and accompanied by a decrease in variability of 
Figure 1. Number of wakings per night for subjects in the graduated extinction condition during baseline, intervention and follow-up. 


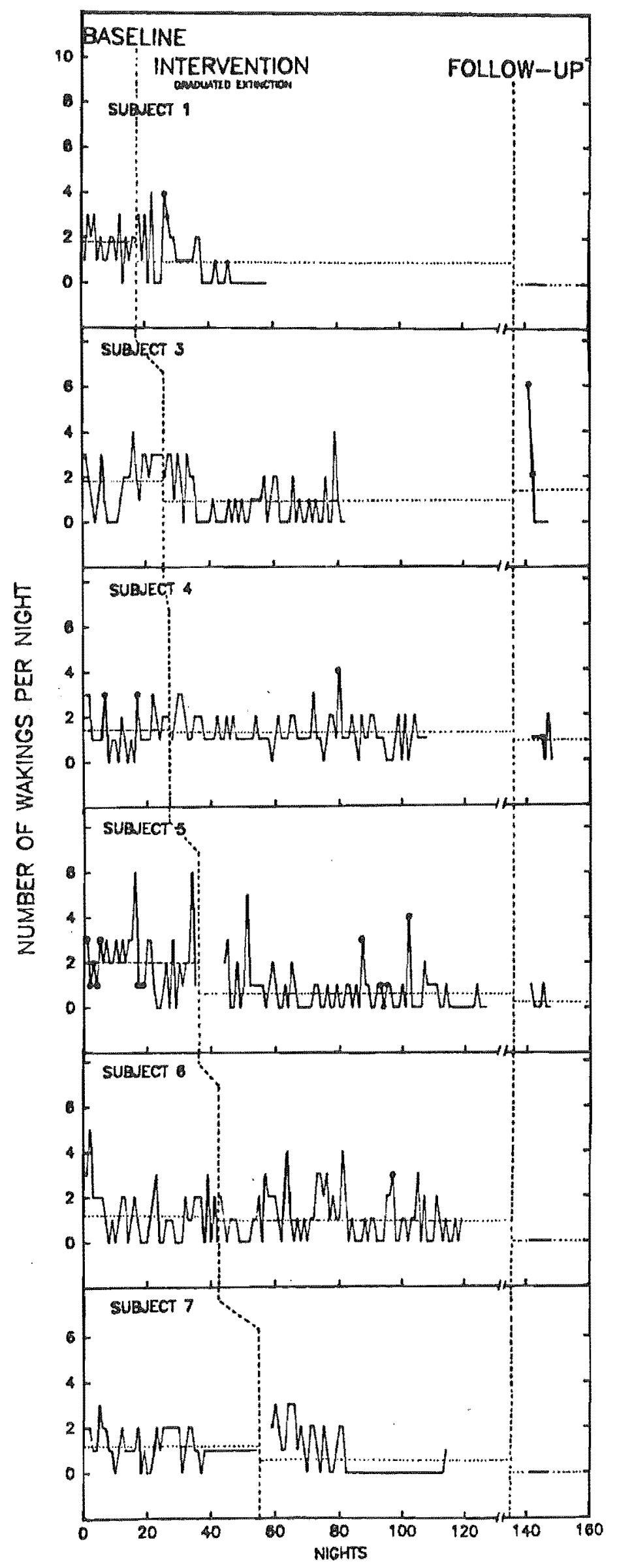

- Denotes nights when the child was unwell. -.-Denotes phase means. 


\section{Table 9}

Means and standard deviations for number of wakings per night for each subject in each experimental condition

\begin{tabular}{ccccccc}
\hline \multirow{2}{*}{ Subject } & \multicolumn{2}{c}{ Baseline } & \multicolumn{2}{c}{ Intervention } & \multicolumn{2}{c}{ Follow-up } \\
& M & $\underline{\text { SD }}$ & $\underline{M}$ & $\underline{\text { SD }}$ \\
\hline $\begin{array}{c}\text { Graduated } \\
\text { extinction }\end{array}$ & & & & & & \\
1 & 1.7 & 0.9 & 0.8 & 1.2 & 0 & 0 \\
3 & 1.8 & 1.2 & 0.8 & 1.1 & 1.4 & 2.5 \\
4 & 1.4 & 1.0 & 1.3 & 0.7 & 0.9 & 0.7 \\
5 & 2.0 & 1.4 & 0.7 & 0.9 & 0.3 & 0.5 \\
6 & 1.2 & 1.1 & 1.0 & 1.1 & 0 & 0 \\
7 & 1.2 & 0.7 & 0.6 & 1.0 & 0 & 0 \\
\hline
\end{tabular}

Extinction

$\begin{array}{rllllll}9 & 0.6 & 0.6 & 0.9 & 1.3 & * & * \\ 10 & 0.2 & 0.4 & 0.1 & 0.3 & 0 & 0 \\ 11 & 3.0 & 1.7 & 1.0 & 0.9 & 0.9 & 1.2 \\ 12 & 1.9 & 0.7 & 0.6 & 0.9 & 0 & 0\end{array}$

* Missing data 
the behaviour. This effect on waking tended to be gradual and in some cases followed an initial increase in the intensity of the behaviour (Subjects 1 and 7). The decrease was maintained at follow-up and in all cases, except subject 3 , further improvements and a concomitant decrease in variability were observed. Subject $3^{\prime} \mathrm{s}$ follow-up mean was inflated due to illness in the first few days of that phase.

Application of the C-statistic (Tryon, 1982) corroborated visual analysis (see Table 10), with the exception of Subject 1. Visual inspection of the trend within subject 1 's intervention phase indicated that although the behaviour finally extinguished, there was an initial period of increased waking. It is possible that the c-statistic is less sensitive when such within-phase trend changes occur.

Although the overall effect of graduated extinction was to produce a decrease in waking, there were exceptions. Subjects 4 and 6 showed no significant changes in the number of wakings per night from baseline to intervention. The fact that a marked decrease in frequency and variability of waking was observed at follow-up for subject 6 , is not necessarily evidence of a treatment effect since maturational factors could have influenced waking in the intervening period.

subject 3, although demonstrating a change in the therapeutic direction, showed an idiosyncratic pattern of response. Initially a substantial decrease in the number of wakings was observed, but this was followed by an upward reversal in trend. The parents explained this deterioration in a letter accompanying subject $3^{\prime} \mathrm{s}$ data. The family were on holiday when it occurred and the parents said: "We did not feel that we could leave her [Subject 3] as we were on holiday and had other people staying with us." Follow-up data showed that the level of improvement acquired before the holiday was regained.

Subjects 1,5 and 7 showed unequivocal improvements in waking. Subject 5's behaviour showed continued lability, but due to the marked decrease in mean and variability and 
Table 10

Statistical evaluation of the presence of changes due to intervention using the C-statistic (Tryon, 1982)

\begin{tabular}{|c|c|c|c|c|c|c|c|c|}
\hline \multirow[b]{2}{*}{ Subject } & \multicolumn{2}{|c|}{$\begin{array}{c}\text { Number of } \\
\text { wakings }\end{array}$} & \multicolumn{2}{|c|}{$\begin{array}{c}\text { Duration of } \\
\text { wakings }\end{array}$} & \multicolumn{2}{|c|}{$\begin{array}{c}\text { Sleep onset } \\
\text { latency }\end{array}$} & \multicolumn{2}{|c|}{$\begin{array}{l}\text { Bedtime } \\
\text { delay }\end{array}$} \\
\hline & $\mathrm{B}^{\mathrm{a}}$ & $B+I^{b}$ & B & $B+I$ & B & $B+I$ & B & $B+I$ \\
\hline $\begin{array}{l}\text { Graduated } \\
\text { extinctior }\end{array}$ & & & & I & & & & \\
\hline 1 & & & & $\mathrm{x}$ & & & & \\
\hline 3 & $\mathrm{X}$ & $\mathrm{X}$ & $\mathrm{x}$ & $X$ & & & & \\
\hline 4 & & & & $\mathrm{X}$ & & $\mathrm{X}$ & & $\mathrm{X}$ \\
\hline 5 & & $\mathrm{X}$ & & $\mathrm{X}$ & & $\mathrm{X}$ & & $\mathrm{X}$ \\
\hline 6 & & $\mathrm{X}$ & & & & & & $\mathrm{X}$ \\
\hline 7 & $\mathrm{X}$ & $x$ & . & $x$ & & $\mathrm{X}$ & $\mathrm{X}$ & $x$ \\
\hline
\end{tabular}

Extinction

9

10

11

12
$\mathrm{X}$

$\mathrm{X}$

$\mathrm{X} \quad \mathrm{X}$

$\mathrm{X}$

$\mathrm{X}$

$\mathrm{X}$

$\mathrm{X}$

Note: $\mathrm{x}=\mathrm{C}$-statistic significant at the $\mathrm{p} \leq 0.01$ level.

a significant trend in baseline

b significant departure from baseline trend in intervention 
the evidence of decreasing trend, this did not detract from evidence of treatment control.

\section{Extinction}

Baseline data, presented in Figure 2 and Table 9, indicated that although night-waking had been a target problem for all subjects, it was extinguished during baseline for subject 10. There were no occurrences of waking during the last 18 nights of baseline. Baseline levels of waking for the other three subjects in this group were variable, intensely so for subjects 11 and 12 . The mean number of wakings for these three subjects was 1.8 .

An overall decrease in the number of wakings per night between baseline and intervention phases was observed (see Figure 2 ).

Subjects 11 and 12 showed marked decreases in waking, whereas Subjects 9 and $10^{\circ}$ showed no changes. Where decreases occurred they were maintained at follow-up. The C-statistic supported visual analysis (see Table 10). Subjects 11 and 12 showed significant changes in behaviour as a result of intervention. These results were significant at the $\underline{p} \leq .01$ level.

Subject 9's results show that although treatment may have produced some long-term decrease in waking, the initial increase in intensity and variability of waking and a subsequent peak in responding later on in treatment, preclude a positive conclusion of treatment effect. The initial increase in night-waking was associated with the onset of extinction, after which a downward trend occurred. The second peak in waking was associated with a change in sleep location mid-way through intervention. Subject 9 was moved from a cot to a single bed. Waking increased for a short period, then showed another downward trend towards the end of intervention. The durability of the decrease in behaviour could not be determined due to the lack of follow-up data for this subject.

Subject $10 \mathrm{\prime}$ s results, which showed no change in behaviour which could be related to intervention, were 
Figure 2. Number of wakings per night for subjects in the extinction condition during baseline, intervention and follow-up. 


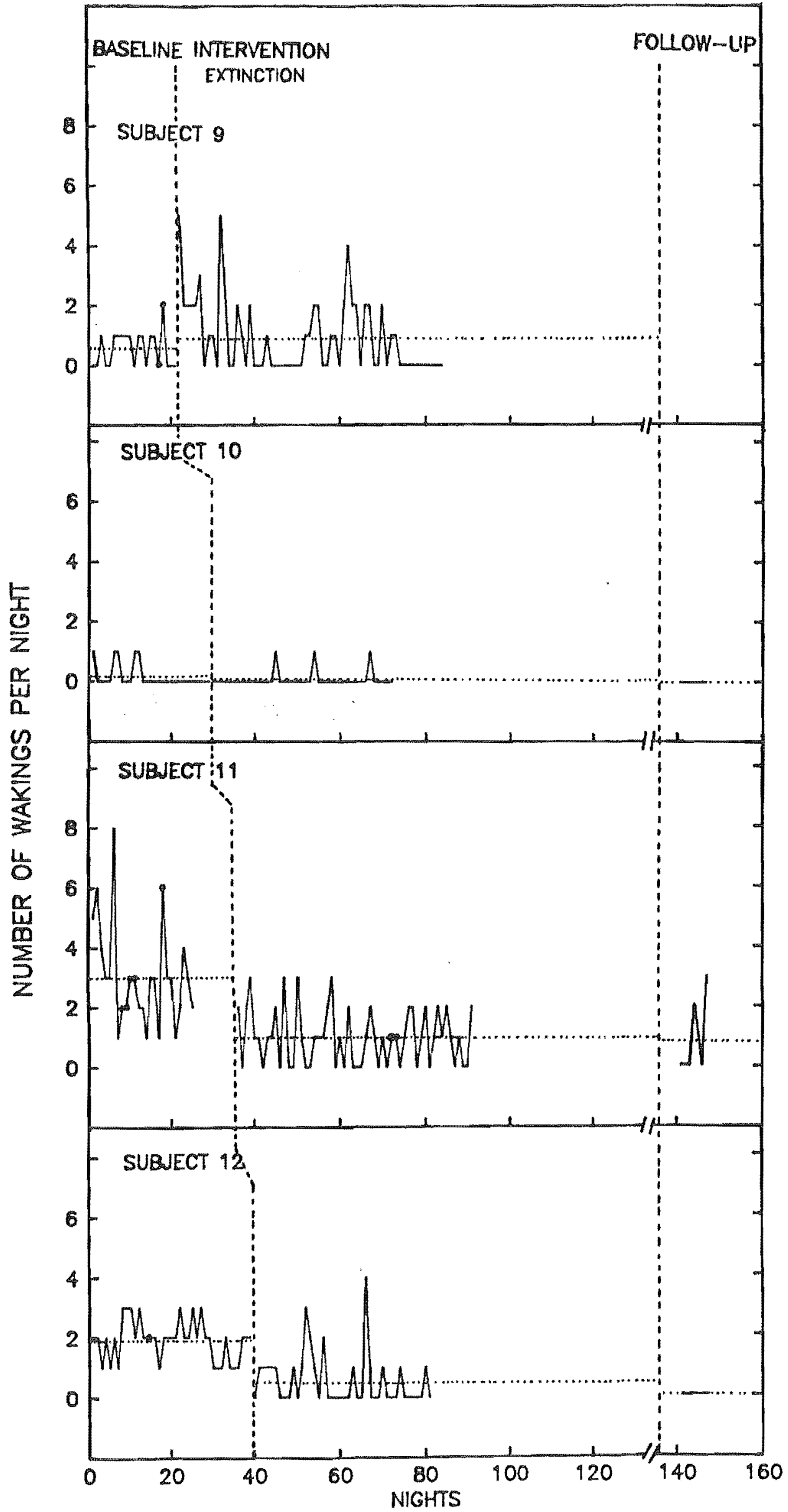

- Denotes nights when the child was unweld. -m-Denotes phase means. 
Figure 3. Duration of wakings per night (minutes) for subjects in the graduated extinction condition during baseline, intervention and follow-up. 


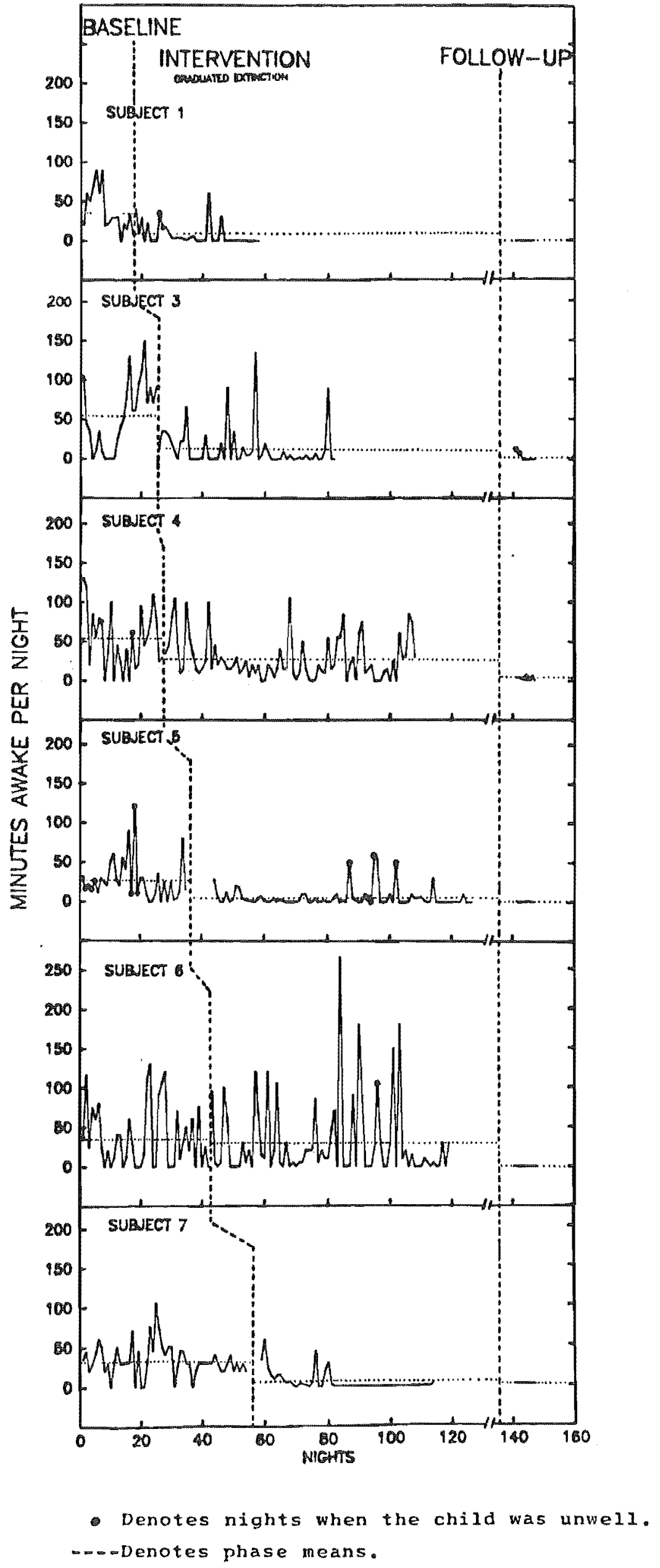


Table 11

Means and standard deviations for duration

of wakings per night (minutes) for each

subject during each experimental condition

\begin{tabular}{llllll}
\hline Baseline & & Intervention & Follow-up \\
Subject & $M$ & $\underline{S D}$ & $\underline{M}$ & $\underline{\text { SD }}$ & $\underline{S}$
\end{tabular}

Graduated

extinction

$\begin{array}{lrrrrrl}1 & 38.5 & 27.1 & 7.4 & 13.7 & 0 & 0 \\ 3 & 54.4 & 44.1 & 13.4 & 25.8 & 2.9 & 5.0 \\ 4 & 52.5 & 38.6 & 27.8 & 27.3 & 4.0 & 2.8 \\ 5 & 27.3 & 26.8 & 5.7 & 12.3 & 0.3 & 0.5 \\ 6 & 36.6 & 39.8 & 31.2 & 51.5 & 0 & 0 \\ 7 & 33.6 & 20.1 & 5.6 & 12.1 & 0 & 0\end{array}$

Extinction

$\begin{array}{rrrrrrl}9 & 4.3 & 5.6 & 4.4 & 11.6 & * & * \\ 10 & 11.7 & 31.7 & 0.7 & 2.8 & 0 & 0 \\ 11 & 41.4 & 33.0 & 10.4 & 19.4 & 2.3 & 3.4 \\ 12 & 48.5 & 27.9 & 6.9 & 13.8 & 0 & 0\end{array}$

* Missing data 
at follow-up. There were several subjects who showed further decreases at follow-up and reduced variability. The C-statistic generally supported visual analysis (see Table 10). The only discrepancy involved subject 4 . According to the C-statistic, graduated extinction produced a change in the duration of waking significant at the $\underline{p} \leq .01$ level. Yet this effect was not discernible to the naked eye.

closer analysis of each subject's individual response to graduated extinction revealed a number of equivocal features. For example, although duration of waking decreased and finally extinguished during intervention for subject 1 , the presence of a slight downward trend in baseline weakens the demonstration of control. Subject $3^{\prime} \mathrm{s}$ data showed the same pattern of reversal towards the end of intervention apparent in her data for the number of wakings, which was associated with the family going on holiday. Subject 4 showed no change in the duration of wakings from baseline to intervention phases.

Subject 5 showed a decrease in the duration of wakings, but this was a weak effect due to the presence of a slightly increasing trend towards the end of treatment. However, these longer wakings were associated with the child experiencing another of his frequent bouts of ear infection and represent an inflation unrelated to the graduated extinction procedure. There was no therapeutic change observed in subject 6's data. This subject showed an increase in the variability during intervention and a number of extremely long wakings. Subject 7 showed a marked decrease in the duration of wakings. Following a gradual reduction in the time awake each night there was a brief return to baseline levels before waking ceased altogether.

\section{Extinction}

Duration of wakings per night for extinction subjects is shown in Figure 4. Baseline data showed the same pattern of variation between subjects as was evident from the number of wakings. Subject 9 woke regularly but for short periods of time. Subject 10 no longer woke by the end of baseline. 
Figure 4. Duration of wakings per night (minutes) for subjects in the extinction condition during baseline, intervention and follow-up. 


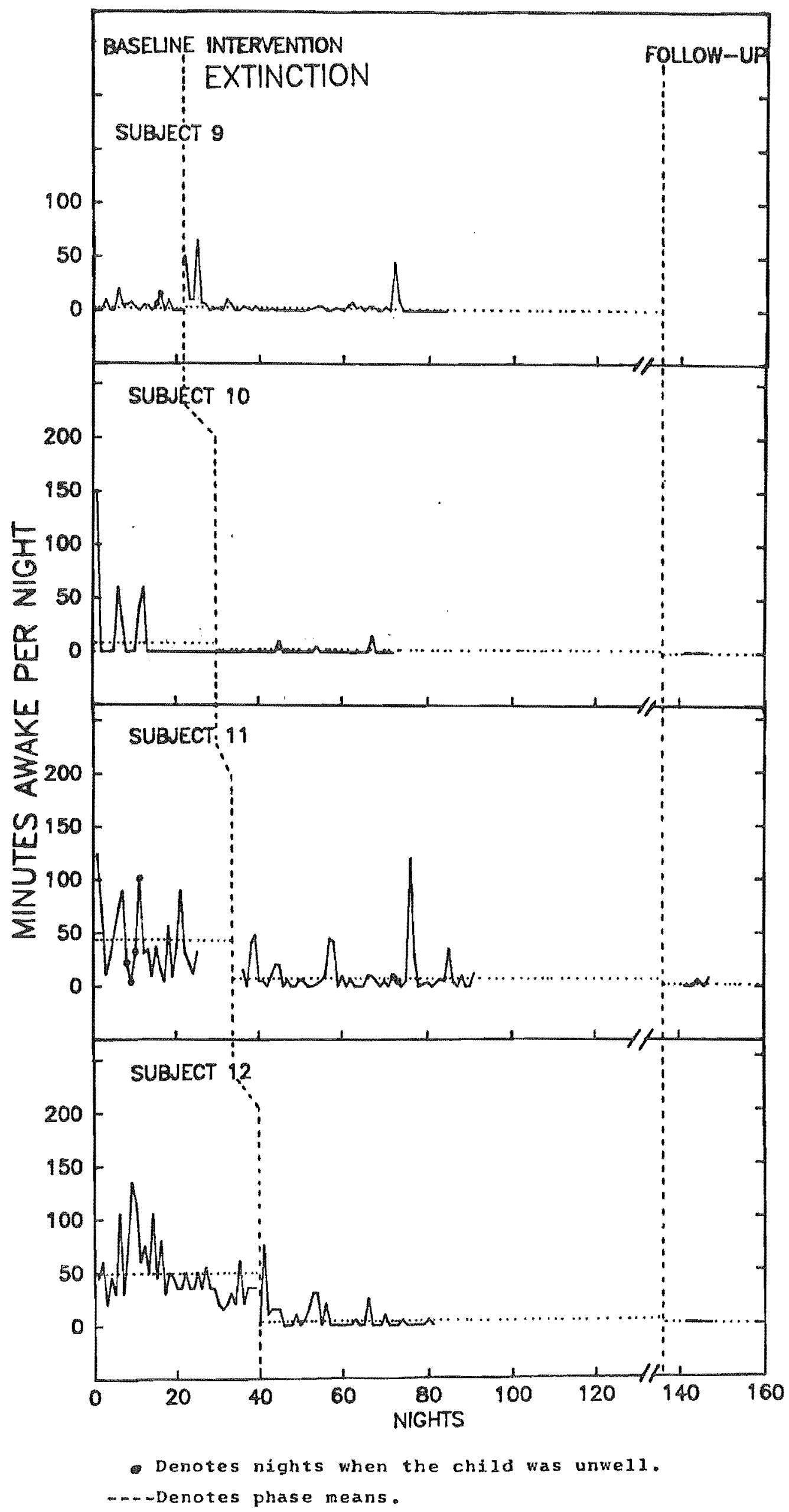


Subjects 11 and 12 had highly variable baseline data, with fairly high mean durations. A slight downward trend was evident for subject 12 (See Table 11 ). The mean for Subjects 9,11 and 12 was 31.4 minutes awake per night during baseline.

Overall, although the evidence is not unequivocal, there is a case for a mild treatment effect. All subjects, with the exception of Subject 9, showed small decreases in the mean amount of time awake per night between baseline and intervention phases. Further decreases in intensity and variability were evident at follow-up.

Supplementary analysis using the C-statistic (see Table 10) found significant effects for subjects 10, 11 and 12 ( $\underline{p} \leq .01)$, which does not provide convincing proof of clinically significant effects but clearly indicates that a small, but consistent, decrease in the duration of wakings was evident.

Subject 9 showed an increase in the duration of waking from baseline to intervention, with a small decrease perceptible towards the end of intervention. The downward trend, although visible, was both too small and too delayed to justify the conclusion that any positive effect was related to treatment. The increase in the duration of waking paralleled the pattern observed when extinction was applied to night-waking. An initial increase in duration was associated with the onset of extinction, and a further increase with the transfer from a cot to a single bed.

Subject 10 showed no change in duration. This was predictable from the baseline series which showed that subject 10 had stopped waking before intervention was ever implemented.

Subject 11 showed a small decrease, but the overlap in scores and the sustained variability during intervention minimised the demonstration of experimental control.

Subject 12 showed a decrease in the duration of waking across phases, but since a downward trend was evident during baseline it was not clear that treatment produced changes greater than might have resulted in the absence of treatment. 


\section{Comparison}

A clear decrease in the duration of wakings was observed in the graduated extinction time-series. The results from extinction subjects were less impressive, but in the same direction. There were no patterns of response characteristic to either intervention technique, nor any distinguishing features.

Sleep Onset Latency (SOL)

Prolonged sleep onset latency, measured by the number of minutes from placement in bed to silence, was not a common presenting problem for subjects in this study. For many subjects the behaviour virtually never occurred during baseline, due to the fact that these subjects were placed into bed only after they had fallen asleep in some other location.

\section{Graduated extinction}

Sleep onset latency per night is shown for these subjects in Figure 5. Baseline data confirmed that sol did not occur frequently nor intensely for the majority of subjects. Subject 4 was the exception. This subject showed the greatest variability and intensity in sleep onset latency at baseline. The behaviour was one targeted for change by his parents. Subjects 3 and 7 were placed into bed asleep. Subjects 1,5 and 6 were placed into bed awake but went to sleep quickly (see Table 12).

overall, there was no evidence of change in the duration of sleep onset latency per night between baseline and intervention phases. A trend towards an increase in sol was evident for several subjects. Although this change was in a non-therapeutic direction, analysis of the results for individual subjects indicated that where sol was problematic, graduated extinction produced decreases in its duration.

Subject 4 , whose baseline level of responding was the most variable and prolonged, showed a marked decrease in SOL per night between baseline and intervention phases. The decrease was maintained at follow-up. The visual 
Figure 5. Sleep onset latency per night (minutes) for subjects in the graduated extinction condition during baseline, intervention and follow-up. 


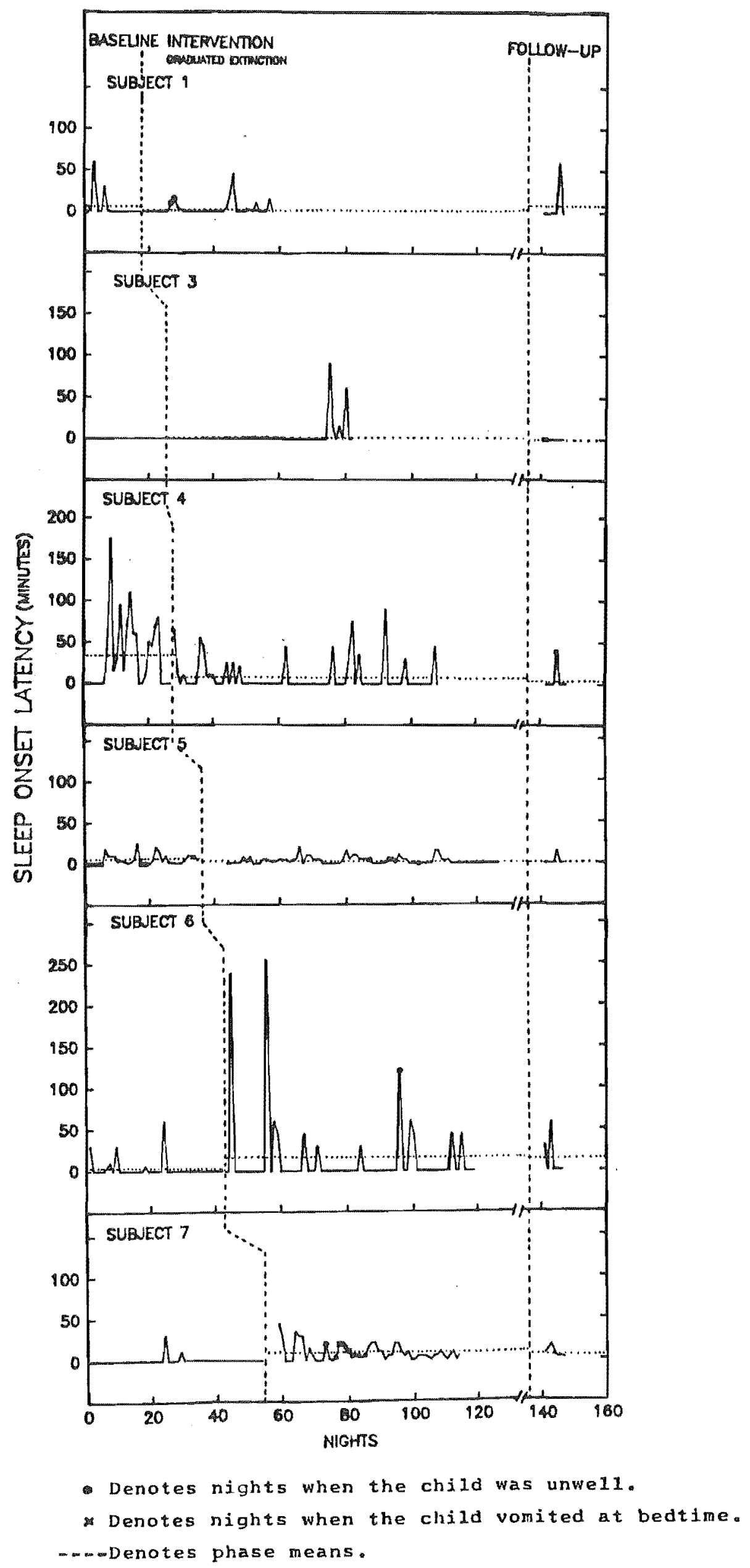


Table 12

Means and standard deviations for sleep onset latency per night (minutes) for each subject during each experimental condition

\begin{tabular}{|c|c|c|c|c|c|c|}
\hline \multirow{2}{*}{ Subject } & \multicolumn{2}{|c|}{ Baseline } & \multicolumn{2}{|c|}{ Intervention } & \multicolumn{2}{|c|}{ Fo11ow-up } \\
\hline & $\underline{M}$ & $\underline{S D}$ & $\underline{\mathrm{M}}$. & $\underline{S D}$ & $\underline{M}$ & $\underline{S D}$ \\
\hline \multicolumn{7}{|c|}{$\begin{array}{l}\text { Graduated } \\
\text { extinction }\end{array}$} \\
\hline 1 & 5.8 & 15.8 & 3.2 & 8.3 & 8.6 & 22.7 \\
\hline 3 & 0 & 0 & 3.2 & 14.4 & 0 & 0 \\
\hline 4 & 34.6 & 44.6 & 8.6 & 19.1 & 5.7 & 15.1 \\
\hline 5 & 5.5 & 6.4 & 3.1 & 4.2 & 2.1 & 5.7 \\
\hline 6 & 3.4 & 11.1 & 13.3 & 43.3 & 12.9 & 23.6 \\
\hline 7 & 0.7 & 4.3 & 9.2 & 10.3 & 5.3 & 5.5 \\
\hline \multicolumn{7}{|c|}{ Extinction } \\
\hline 9 & 0 & 0 & 6.4 & 19.7 & * & * \\
\hline 10 & 10.2 & 12.7 & 6.9 & 11.9 & 0 & 0 \\
\hline 11 & 15.9 & 9.5 & 13.0 & 21.3 & 15.7 & 16.7 \\
\hline 12 & 0 & 0 & 6.7 & 4.6 & 2.1 & 3.9 \\
\hline
\end{tabular}

* Missing data 
evidence of decrease was confirmed by the c-statistic, which was significant at the $\mathrm{p} \leq .01$ level (see Table 10). subject 5 also showed a significant decrease in SOL, but this was not visually apparent.

Other subjects, whose baseline levels of SOI were of low intensity and frequency, either showed slight increases in SOL per night during intervention or no change. The increases were insignificant according to the C-statistic, apart from Subject 7 (see Table 10).

\section{Extinction}

Baseline data, presented in Figure 6, showed that extinction subjects had infrequent occasions when sleep onset was delayed. Subjects 9 and 12 were regularly put into bed asleep. Subjects 10 and 11 showed some variability in the behaviour, but the mean duration was not large for either subject (see Table 12).

overall, there was no change in the duration of sleep onset latency per night between baseline and intervention phases (see Eigure 6). No change was evident at follow-up either. Slight increases in sol were observed in the time-series of subjects 9 and 12 , found to be statistically significant at the $\mathrm{p} \leq .01$ level for subject 9 .

\section{Comparison}

No differences between the responses of subjects in either condition were observed. Where the child had been put to bed asleep during baseline, small increases in sleep onset latency between phases were apparent for both graduated extinction and extinction subjects. Although insufficient evidence was available to provide convincing demonstration of treatment control, it appeared that where SOI was variable and intense, and therefore a "problem", intervention was effective in producing a decrease in the duration of SOL. Such was the case with Subject 4 .

\section{Bedtime Delay}

\section{Graduated extinction}

Bedtime delay per night is shown for graduated 
Figure 6. Sleep onset latency per night (minutes) for subjects in the extinction condition during baseline, intervention and follow-up. 


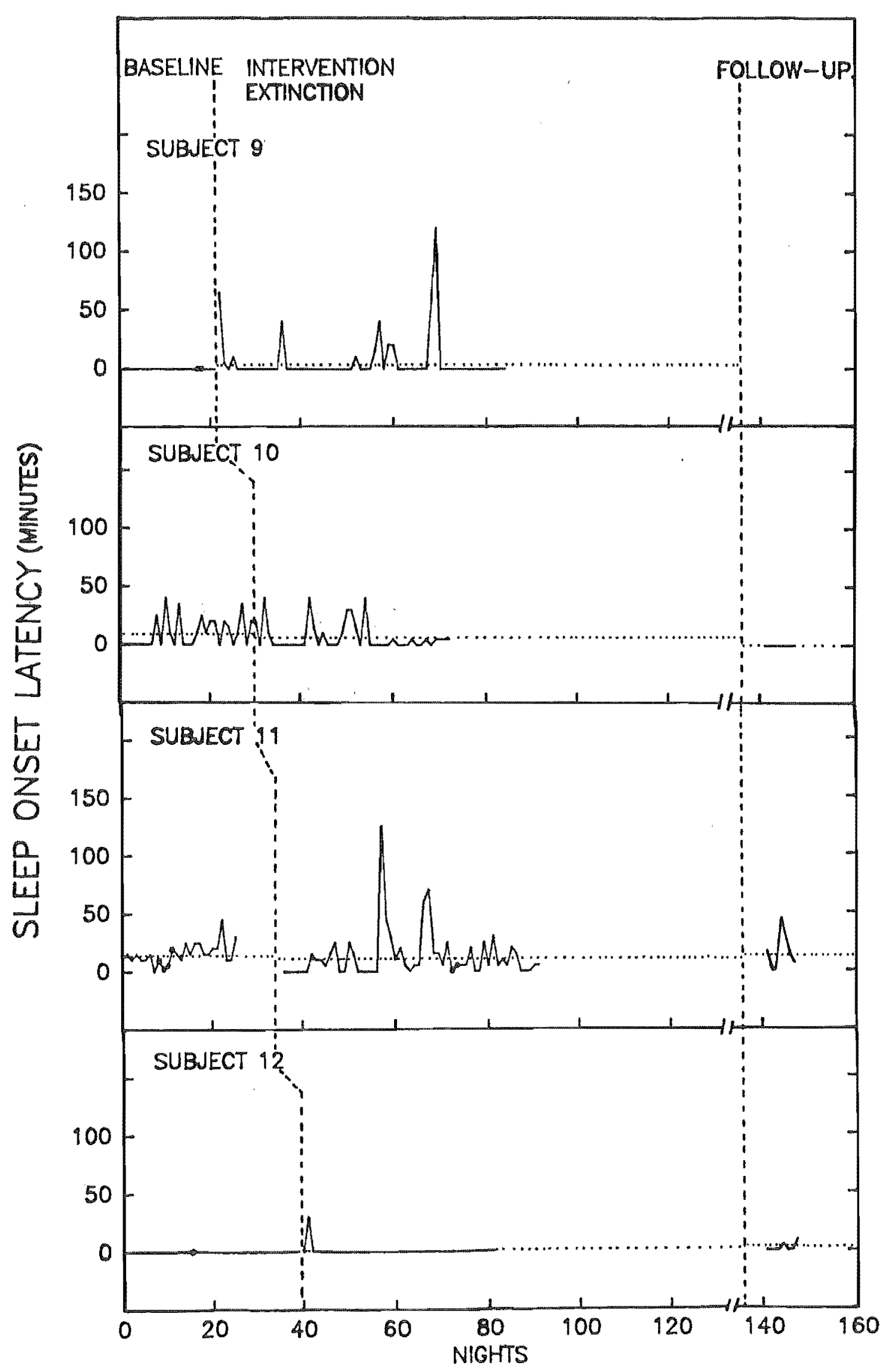

- Denotes nights when the child was unwell. $-\infty-\infty$ Denotes phase means. 
extinction subjects in Figure 7. All subjects, except subject 1 , had highly variable baseline data, indicating that the majority of infants in the study were frequently put into bed later than the parents preferred. The mean number of minutes of bedtime delay during baseline was 35 (see Table 13).

All subjects, except subjects 1 and 3 , showed marked decreases in the amount of bedtime delay per night between baseline and intervention phases. The decrease in level of the behaviour was abrupt and was accompanied by a decrease in variability. The decreases were maintained at follow-up. The C-statistic supported visual analysis (see Table 10).

Subjects 1 and 3 were the only two subjects not to show clear changes in bedtime delay associated with treatment. Subject 1 showed a relatively low rate of responding at baseline which did not decrease further during intervention. Subject 3 showed an initial decrease in bedtime delay following the implementation of treatment, but due to a reversal of this trend towards the end of graduated extinction the demonstration of treatment control was reduced. A further decrease in bedtime delay at follow-up suggested that the upward reversal was temporarily related to the family's holiday occurring at that time.

\section{Extinction}

Bedtime delay per night for these subjects is shown in Figure 8. It was highly variable for all subjects, except subject 11, during baseline. The mean number of minutes delay for all four subjects was 63.3 (see Table 13).

Al1 subjects, except subject 11 , showed marked decreases in bedtime delay per night between baseline and intervention phases. An abrupt level change with a concomitant reduction in variability was observed. The decreases were maintained at follow-up. [Visual analysis was confirmed by statistical analysis (see Table 10).]

\section{Comparison}

The same pattern of abrupt decreases in level and variability of bedtime delay was characteristic of most subjects in both treatment conditions. 
Figure 7. Bedtime delay per night (minutes) for subjects in the graduated extinction condition during baseline, intervention and follow-up. 


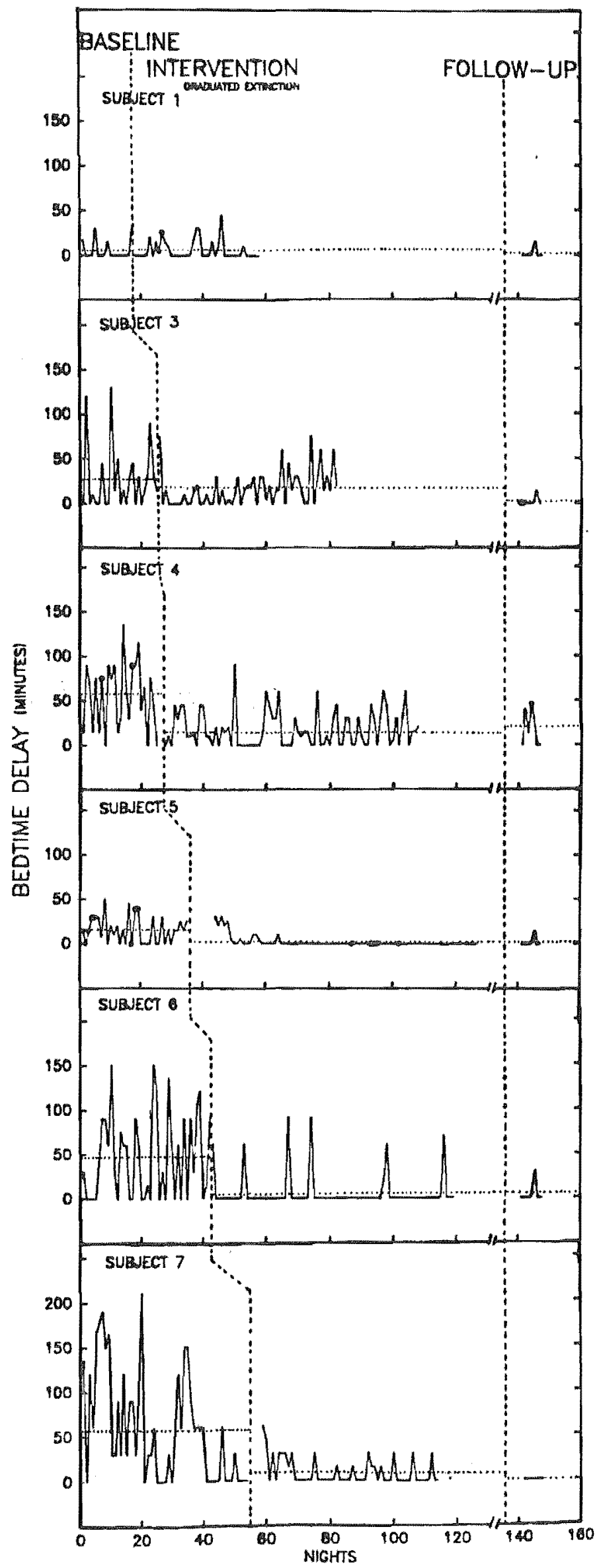

- Denotes nights when the child was unwell. - - Denotes phase means. 
Table 13

Means and standard deviations for bedtime delay per night (minutes) for each subject during each experimental condition

\begin{tabular}{|c|c|c|c|}
\hline \multirow{2}{*}{ Subject } & Baseline & Intervention & Follow-up \\
\hline & $M \quad S D$ & $M \quad S D$ & $M \quad S D$ \\
\hline
\end{tabular}

Graduated

extinction

1

$5.4 \quad 10.7$

6.0

10.7

2.1

5.7

3

$26.8 \quad 36.9$

16.4

19.6

2.1

5.7

4

$58.0 \quad 37.9$

17.8

20.5

18.6

19.7

5

$15.4 \quad 15.1$

2.0

6.3

2.1

5.7

6

$46.4 \quad 48.0$

5.8

19.8

4.3

11.3

7

$57.7 \quad 61.0$

8.8

14.5

0

0

\section{Extinction}

\begin{tabular}{rrrrrrr}
9 & 81.3 & 28.1 & 0.3 & 2.5 & $*$ & $*$ \\
10 & 84.8 & 42.3 & 43.6 & 25.7 & 6.4 & 8.0 \\
11 & 1.0 & 2.9 & 3.0 & 6.6 & 0 & 0 \\
12 & 86.2 & 53.7 & 5.1 & 9.1 & 10.0 & 22.4 \\
\hline
\end{tabular}

* Missing data 
Figure 8. Bedtime delay per night (minutes) for subjects in the extinction condition during baseline, intervention and follow-up. 


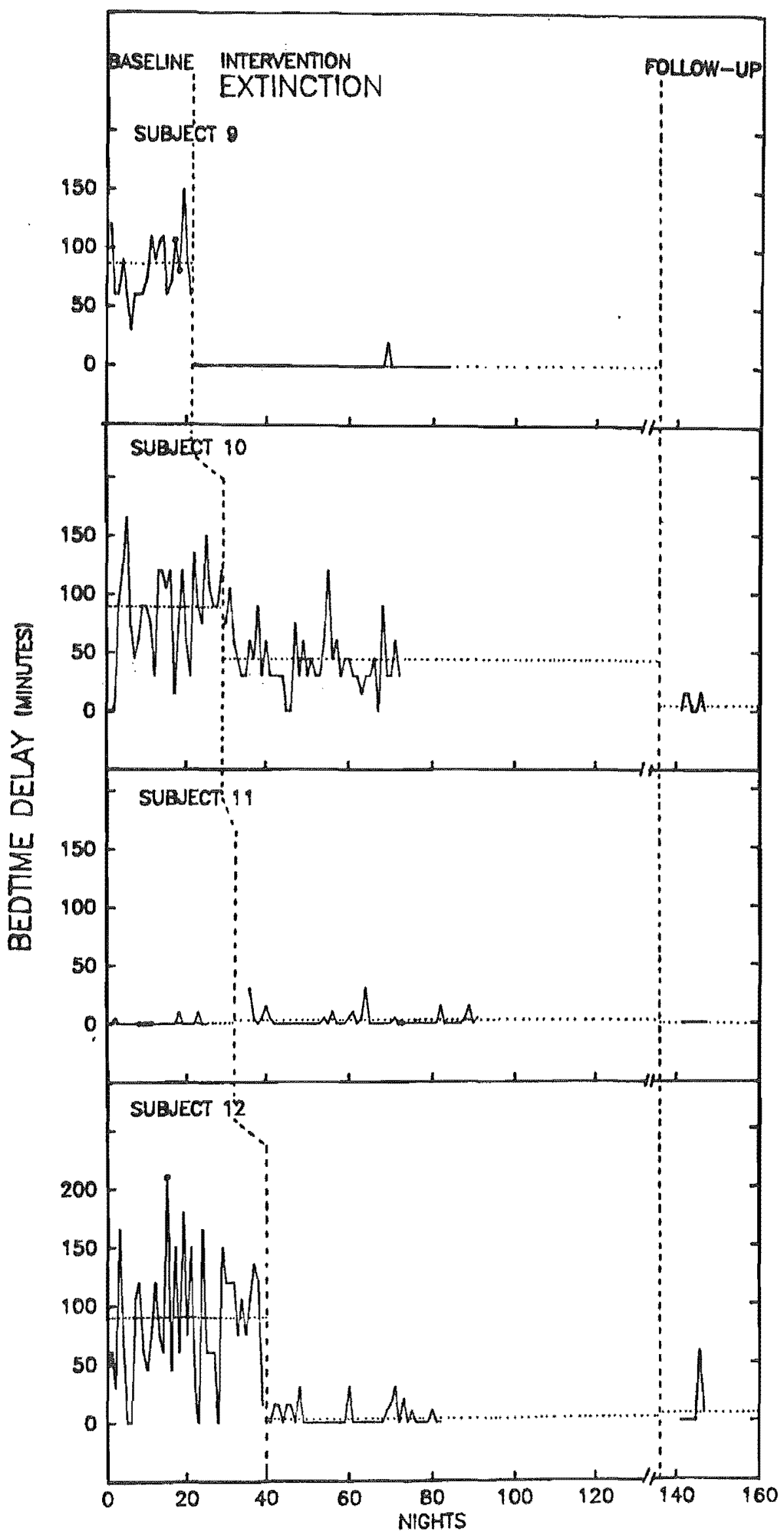

- Denotes nights when the child was unwell. -.-Denotes phase means. 
Each infant in the study was a participant because of his/her disturbed sleep. However, the exact nature of these disturbances differed from subject to subject. In order to assess the impact of intervention on global aspects of infant sleep disturbance, the following composite measures were examined to determine whether overall changes were observed from baseline to intervention. Firstly, changes in the severity of the sleeping problem were examined with the weekly sleep Behaviour scale. secondly, changes in the subjective quality of the infants' sleep behaviour were assessed with the Deviation from Ideal scale. Included in both of these measures were the various behaviours already examined, as well as sleeping in the parents' bed. Improvement in composite scores was enhanced if infants were moved into their own cot and left there all night.

\section{Sleep Behaviour Scale}

\section{Graduated extinction}

All subjects showed a tendency for sleep behaviour scores to decrease between baseline and intervention phases (see Figure 9) but the demonstration of experimental control was not convincing.

Subjects $1,3,5$ and 6 did not show appreciable changes from baseline to intervention, but all showed considerable improvement at follow-up. The downward trend in subject 1's baseline data made any conclusion of treatment effect doubtful, due to the difficulty of assessing whether the decrease during intervention was greater than would have occurred without intervention. Subject 3 showed a marked decrease in severity of the sleep problem initially, with a deterioration towards the end of intervention. This represented an artificial inflation due to the family going on holiday with friends and temporarily abandoning the programme. Subject $5^{\prime \prime s}$ improvement was slow and small, indicating weak experimental control. Subject 6 showed no change which could be related to intervention. 
GRADUATED EXTINCTION

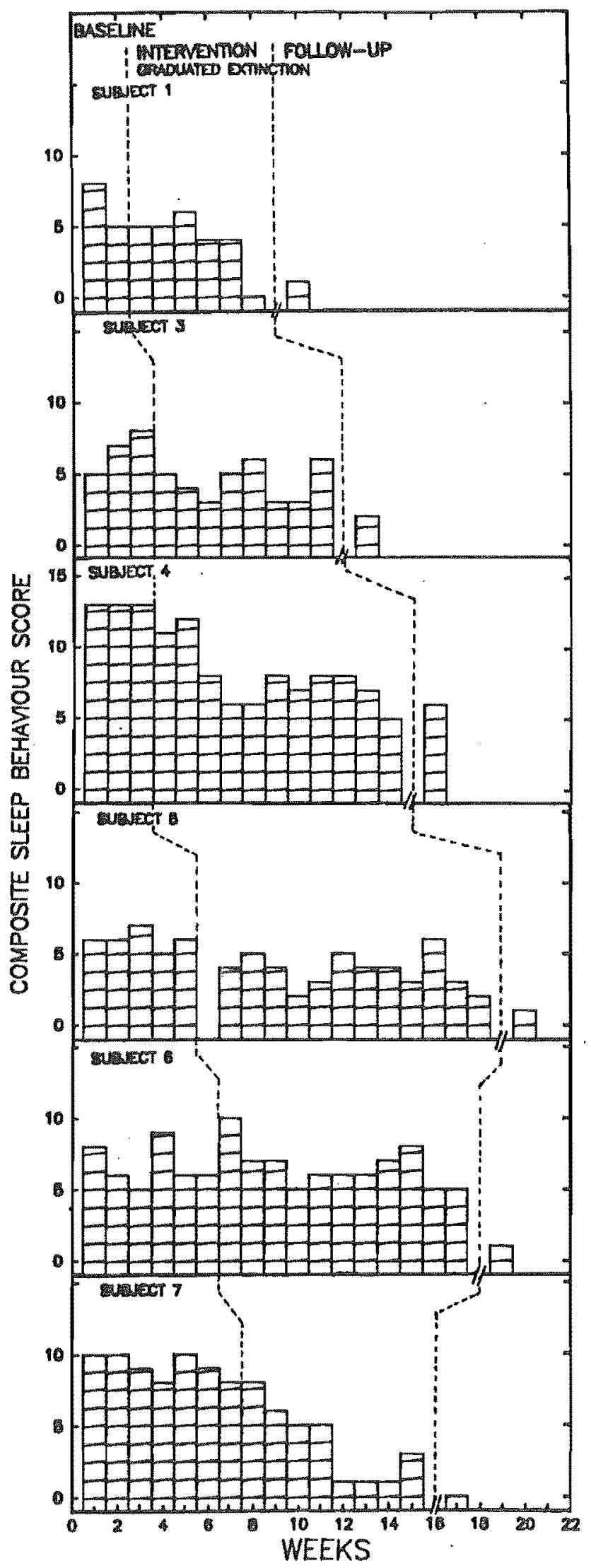

Figure 9. Composite weekly scores on sleep Behaviour Scale for subjects in the graduated extinction condition during baseline, intervention and follow-up. 
Subjects 4 and 7 showed marked decreases in sleep behaviour scores between baseline and intervention phases. The magnitude of decrease in this score for subject 7 was greater than would have been predicted from changes in the separate sleep behaviours already examined. This additional improvement was accounted for by the fact that after the onset of graduated extinction, subject 4 was no longer taken into his parents' bed, an event which had occurred frequently during baseline. Subject 7's rapid decrease in score indicated a marked improvement in all aspects of sleep behaviour.

\section{Extinction}

A11 subjects showed improvements in sleep behaviour scores between baseline and intervention phases (see Figure 10). Apart from subject 10, the decreases were marked and of a greater magnitude than expected from separate behavioural effects. Subject 9, particularly, showed additional improvement associated with a change from sleeping in the parents' bed to sleeping alone. Improvements were maintained at follow-up.

\section{Comparison}

The mean sleep behaviour scores for each treatment condition are presented in Figure 11. Both groups showed a slight improvement between baseline and intervention phases. However, the small downward trend evident in the baseline averages for both groups meant that the downward trend during intervention was less impressive than it might have been. The effect was particularly weak for graduated extinction subjects. The improvement was gradual and insufficiently different from the baseline trend. Extinction subjects had a mean score that showed a more abrupt decrease, indicating that treatment was effective in producing improvement faster than would be expected from the baseline trend. The mean scores for each group have adequately summarised the overall trends evident in individual subjects and the confidence that can be placed in the conclusions. 
EXTINCTION

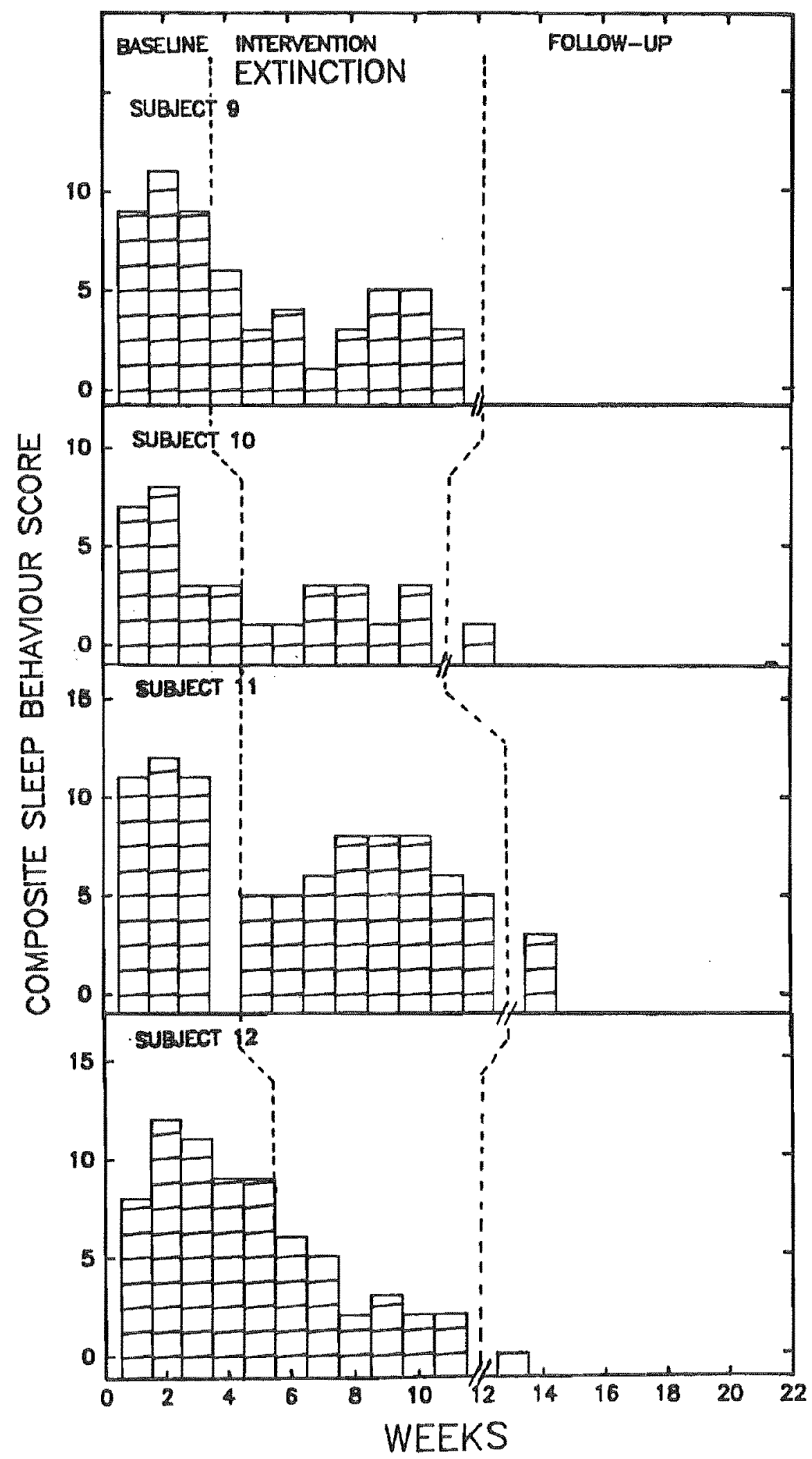

Figure 10. Composite weekly scores on Sleep Behaviour Scale for subjects in the extinction condition during baseline, intervention and follow-up. 


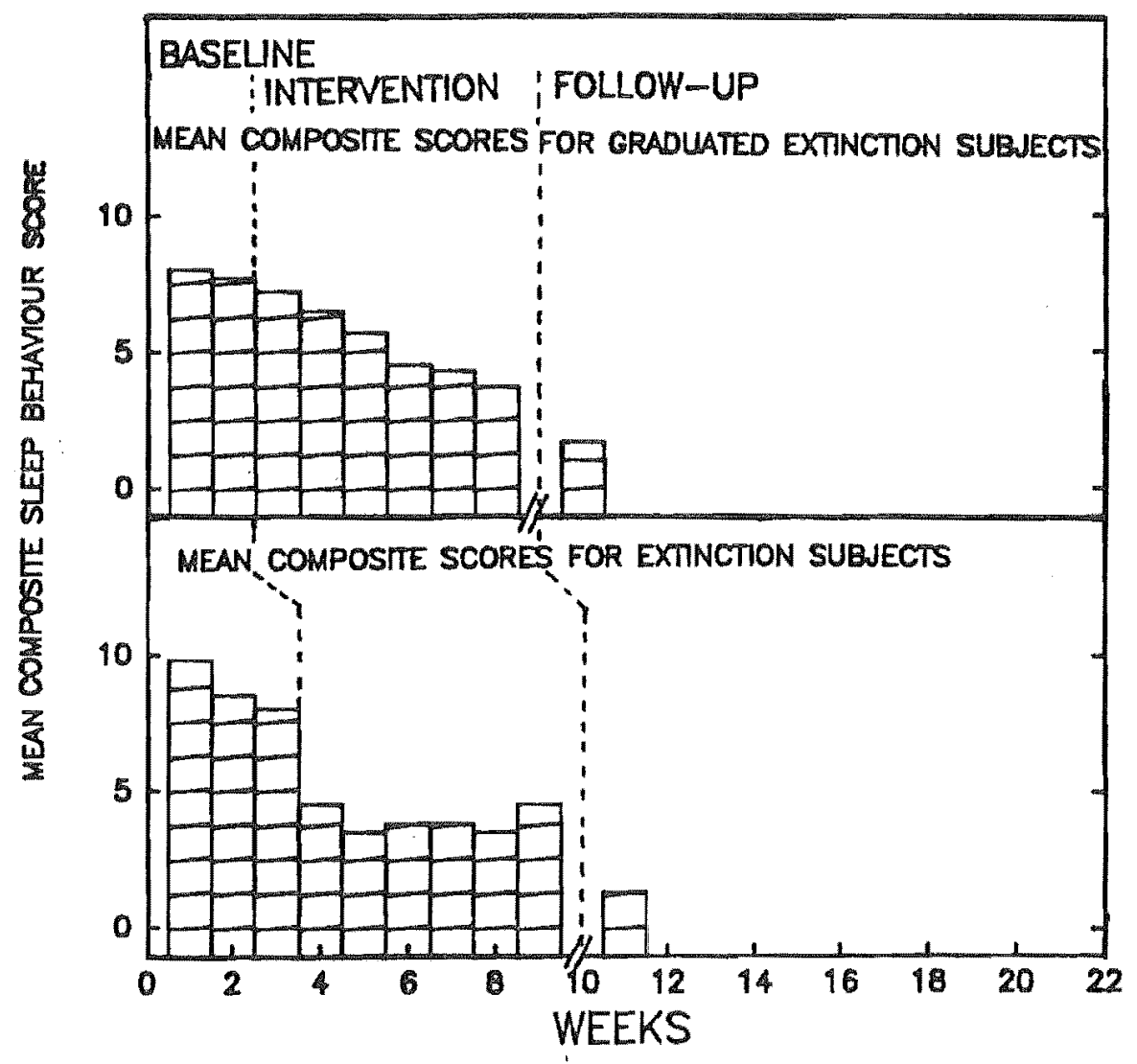

Figure 11. Mean composite weekly scores on sleep Behaviour scale for graduated extinction and extinction subjects during baseline, intervention and follow-up. 


\section{Graduated extinction}

There was an overall improvement in deviation scores between the end of baseline and the end of intervention (see Figure 12). Most subjects showed marked decreases in their deviation from so-called ideal sleep behaviour indicating considerable improvement in the quality of their general sleep behaviour. Subjects 4 and 6 showed no significant improvement on this scale.

\section{Extinction}

A11 subjects showed improvements in deviation scores from the end of baseline to the end of treatment (see Figure 12). The improved quality of sleep behaviour was marked, except for subject 10. His sleep behaviour was less deviant from the ideal at baseline and consequently showed only a mild improvement.

\section{Comparison}

Both groups showed equally convincing improvement in deviation scores (see bottom-right panels of Figure 12). There were no distinguishing features of either group.

\subsection{PARENTAL RESPONSES}

The cumulative number of self-monitored parent responses to night-wakings per week during baseline, intervention and follow-up are shown for all subjects in Figure 13. These were examined for changes in the rate of parental responding. The distribution of the type of parental responses to night-waking made during baseline and intervention are presented in Table 14. These were examined for changes in the type of attention parents administered when responding to the infant's waking.

\section{Graduated extinction}

Overall, the number of parental responses to nightwaking per week decreased between baseline and intervention phases (see Figure 13). The slope of the cumulative curve 
Figure 12. Composite daily scores on the Deviation from Ideal Scale for each subject during the last fifteen days of baseline and the last fifteen days of intervention.

Mean data for each group are shown in the two panels at bottom right. 


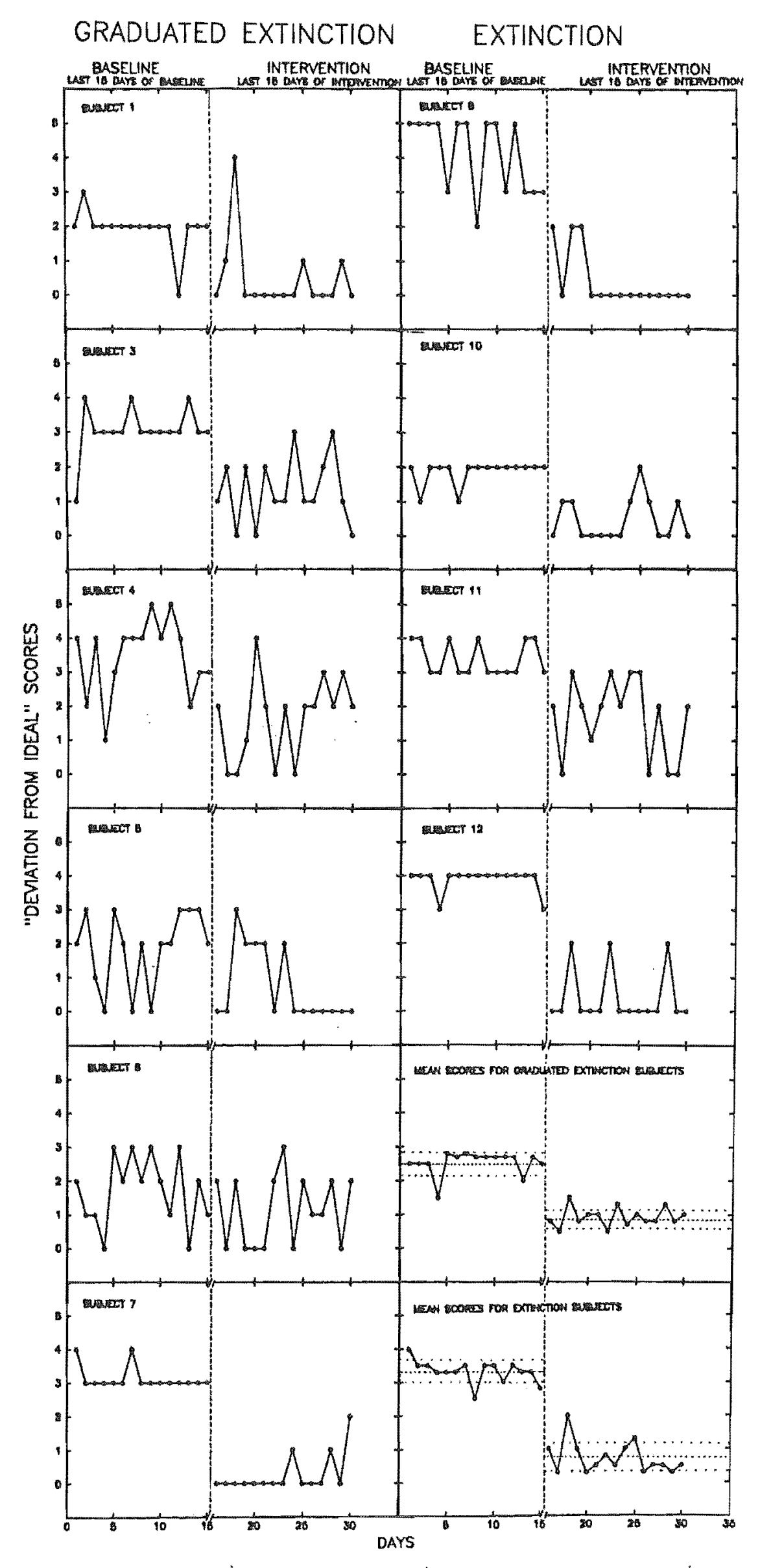

22.

....Denotes phase means.

$\ldots-$ Denotes standard deviation about mean. 
Figure 13. Cumulative number of parental responses to each subject's waking during baseline, intervention and follow-up. Mean data for each group are shown in the two panels at bottom right. 
83.

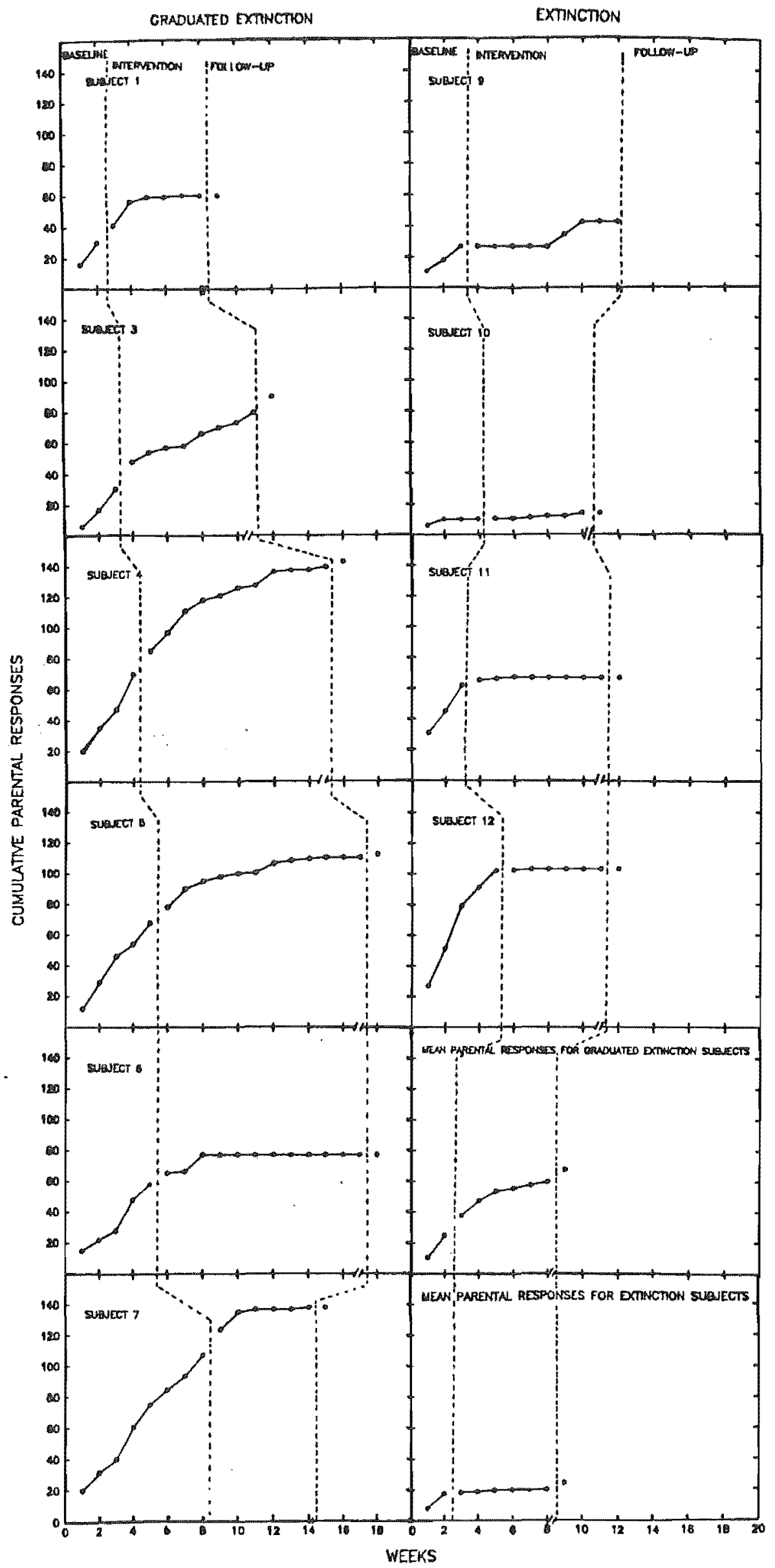


Table 14

Distribution of the types of parental response to infant night-waking during baseline and intervention

\begin{tabular}{|c|c|c|c|c|c|c|}
\hline \multirow[t]{2}{*}{ Group } & \multirow{2}{*}{$\begin{array}{l}\text { Number of } \\
\text { parental } \\
\text { responses } \\
\text { (Weekly M) }\end{array}$} & \multicolumn{5}{|c|}{ TYPE OF PARENTAL RESPONSE (percent of total) } \\
\hline & & Nappy Change & Feeding & Reassurance & Medication & Parents Bed \\
\hline \multicolumn{7}{|l|}{$\frac{\text { Graduated }}{\text { extinction }}$} \\
\hline Baseline & 76.5 & 28 & 40 & 19 & 10 & 3 \\
\hline Intervention & 33.5 & 25 & 23 & 48 & 2 & 2 \\
\hline \multicolumn{7}{|l|}{ Extinction } \\
\hline Baseline & 37.7 & 6 & 60 & 7 & 9 & 18 \\
\hline Intervention & 1.7 & 40 & 20 & 10 & 30 & 0 \\
\hline
\end{tabular}

Note: Each type of parental response is presented as a percentage of the total number of responses made by parents in each treatment condition. 
for each subject showed a tendency to flatten out after intervention, indicating a decrease in the amount of parental attention. Parental responses decreased very gradually for the first few weeks of intervention and then decreased rapidly, until the curve flattened out completely, for most subjects. These decreases were maintained at followup.

Subjects 3 and 4 's parents showed a decrease in their rate of responding to waking from baseline to intervention, but they never actually ceased responding altogether. The slower rate of responding was maintained at follow-up.

Examination of the distribution of parental responses before and after intervention, presented in Table 14, indicated that there was a shift between baseline and intervention phases towards less time-consuming responses by the parents. Feeding was used less often, relatively fewer nappies were changed, and relatively more "reassurance" responses were made. The reassurance response ranged from cuddling the child to turning the child over or tucking it in. Although responding did not cease for some parents in the graduated extinction group, the shift away from the more time-consuming responses was significant.

\section{Extinction}

All subjects' parents showed a decrease in the number of times they responded to night-waking per week between baseline and intervention phases (see Figure 13). The effect of treatment was abrupt and produced a complete cessation of parental responding for most subjects. Little change was observed in subject 10 's parental response curve, as parental responding had virtually ceased during baseline. Subject 9 showed a second increase in the number of parental responseshalf-way through intervention, associated with the transfer of this child to a single bed. He repeatedly got out of bed and disturbed his parents, who responded by taking him back to bed. Parental responding ceased rapidly after the parents shut his door, thus preventing him from coming into their room demanding attention. 
The distribution of parental responses between baseline and intervention for extinction subjects shows a shift away from feeding and taking the child into the parents' bed, and a relative increase in nappy changing (see Table 14). However, due to the infrequency of parental responses during intervention the relative percentages were somewhat meaningless. The percentages were derived from ten responses, the total number of responses made by all four parents during the first six weeks of intervention.

\section{Comparison}

There was a markedly different pattern of parental responding evident in the two intervention conditions. The extinction group showed a rapid and abrupt cessation of parental responding following the introduction of intervention, whereas the graduated extinction group showed a gradual reduction of parental responding eventually resulting in total removal of attention for most subjects. However, two cases showed continued, although decreased, parental responding to infant night-waking. Total extinction was never achieved for these subjects.

\subsection{SOCIAL VALIDATION AND ACCEPTABILITY}

The clinical significance of the changes in infant sleep behaviour and the acceptability of the techniques employed were examined with respect to both graduated extinction and extinction. The treatment conditions were evaluated and compared across experimental phases for their effects on

(a) infant security scores, measured by the FISS;

(b) parent anxiety scores, measured by the STAI; and

(c) Sleep Programme Evaluation Questionnaire responses. Flint Infant Security Scale, FISS.

\section{Graduated extinction}

The security scores for all subjects are shown in Figure 14 for baseline, intervention and maintenance administrations. All subjects showed an increase in score from baseline to maintenance, indicating improvement in general 
behaviour and mental health as perceived by parents (Flint, 1980). Most of these increases were small and not convincing, but they clearly demonstrated that graduated extinction did not produce a deterioration in general behaviour.

An individual result worth noting is that of Subject 2, since this is the only parent-recorded data available for this subject. An increase in score from baseline to intervention indicates that subject 2 showed improvement in his general behaviour as a result of graduated extinction.

Subject 4 had an extremely low baseline score of 0.13 which was below the figure of 0.20 which Flint (1980) suggested was indicative of very poor mental health and the need for immediate intervention. The score had improved considerably by the end of intervention, bringing subject 4 out of Flint's "requiring-concern" category.

\section{Extinction}

All subjects showed an increase in security scores between baseline and maintenance phases (see Figure 14). Subjects 9 and 12 both had extremely low baseline scores, indicative of concern according to Flint (1980), which improved markedly following intervention. Although improvement was not so convincing for subjects 10 and 11 , the direction of change was at least positive.

\section{Comparison}

The mean scores across experimental phases for subjects in both conditions are shown in Figure 14. Although there was inter-subject variability, the overall trend in both groups was upward. The average score on each successive administration of the FISS was higher than the previous one. This indicated that the majority of mothers perceived an improvement in the general behaviour of their child following exposure to either graduated extinction or extinction.

State-Trait Anxiety Inventory, STAI

Fathers and mothers of each subject completed the STAI independently on the three occasions (baseline, 


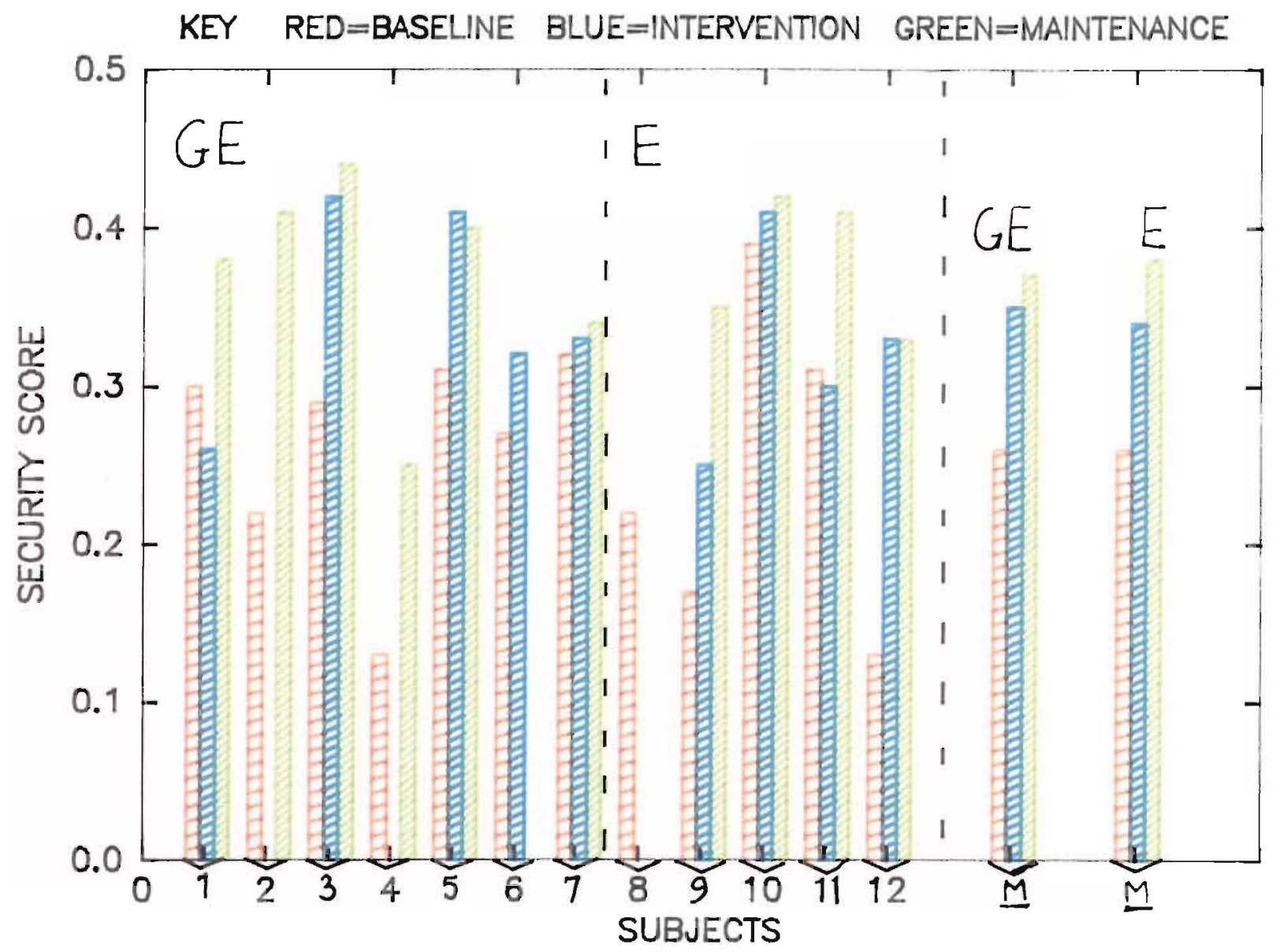

\footnotetext{
GE Denotes graduated extinction

E Denotes extinction
}

Figure 14. Security scores obtained on the Flint Infant security scale for each subject during baseline, intervention and maintenance phases. Mean data for each group are shown in the two columns at the far right. 
intervention and maintenance). The A-State and A-Trait scores for the fathers of all the subjects are presented in Figure 15, and for the mothers in Figure 16.

\section{Graduated extinction}

Overall there was little evidence of trend in fathers' (see Figure 15) or mothers' (see Figure 16) scores on either the A-state or A-Trait scales. Where changes in scores from baseline to intervention to maintenance were observed they tended to be downward, indicating a decrease in anxiety level. Graduated extinction was clearly not associated with an increase in parental anxiety level.

subject 4's father was the only one to show an increase in anxiety following intervention. Subject 2 's father, for whom baseline data alone were available, was the only father to score above the normal range for New zealand males in his age group (Knight et al., 1983) indicating a high level of anxiety prior to entering the programme.

Subject 2's mother, for whom baseline and maintenance scores were available, showed a change in direction opposite to that of the rest of the mothers. Her maintenance score on the A-State scale showed a marked elevation which was beyond normal range (Knight et al., 1983) indicating an increase in anxiety. Although uncertain, the increase was likely to be related to this woman's recent marital separation rather than the sleep programme.

\section{Extinction}

Overall, there was no change in anxiety scores between baseline, intervention and maintenance phases for either fathers (see Figure 15) or mothers (see Figure 16). If any trend in the data existed, which was doubtful, it was towards a decrease in anxiety levels on both the state and trait dimensions. A few minor increases evident in data from subject 9's father and subject 10's mother were insignificant. Clearly there was no increase in parental anxiety aroused by the extinction procedure. 
Figure 15. A-State (top) and A-Trait (bottom) scores obtained on the State-Trait Anxiety Inventory by fathers of each subject during baseline, intervention and maintenance phases. Mean data for each group are shown in the two columns at the far right. 

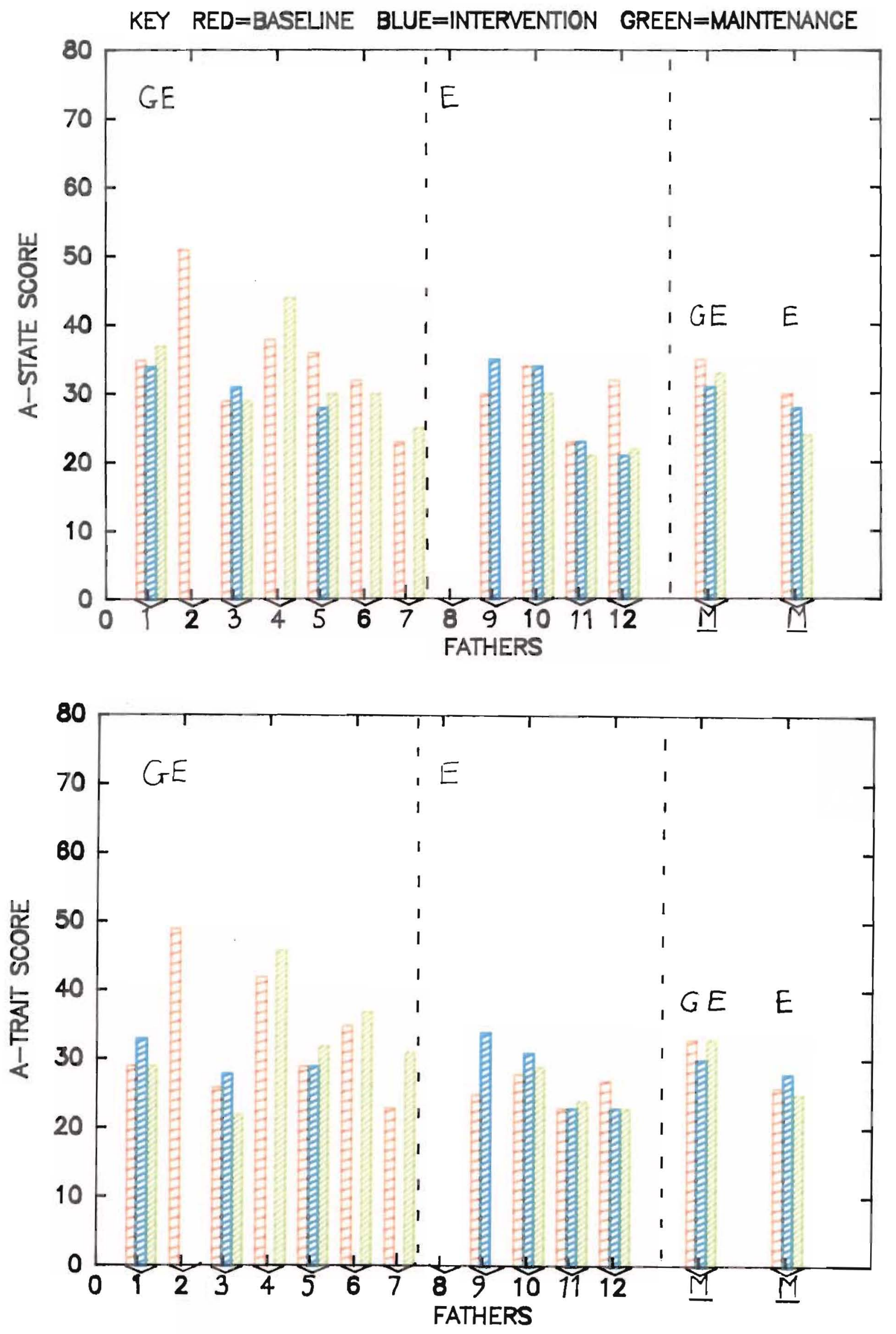

GE Denotes graduated extinction

$E$ Denotes extinction 
Figure 16. A-State (top) and A-Trait (bottom) scores obtained on the State-Trait Anxiety Inventory by mothers of each subject during baseline, intervention and maintenance phases. Mean data for each group are shown in the two columns at the far right. 
KEY RED=BASELINE BLUE=INTERVENTION GREEN=MAINTENANCE
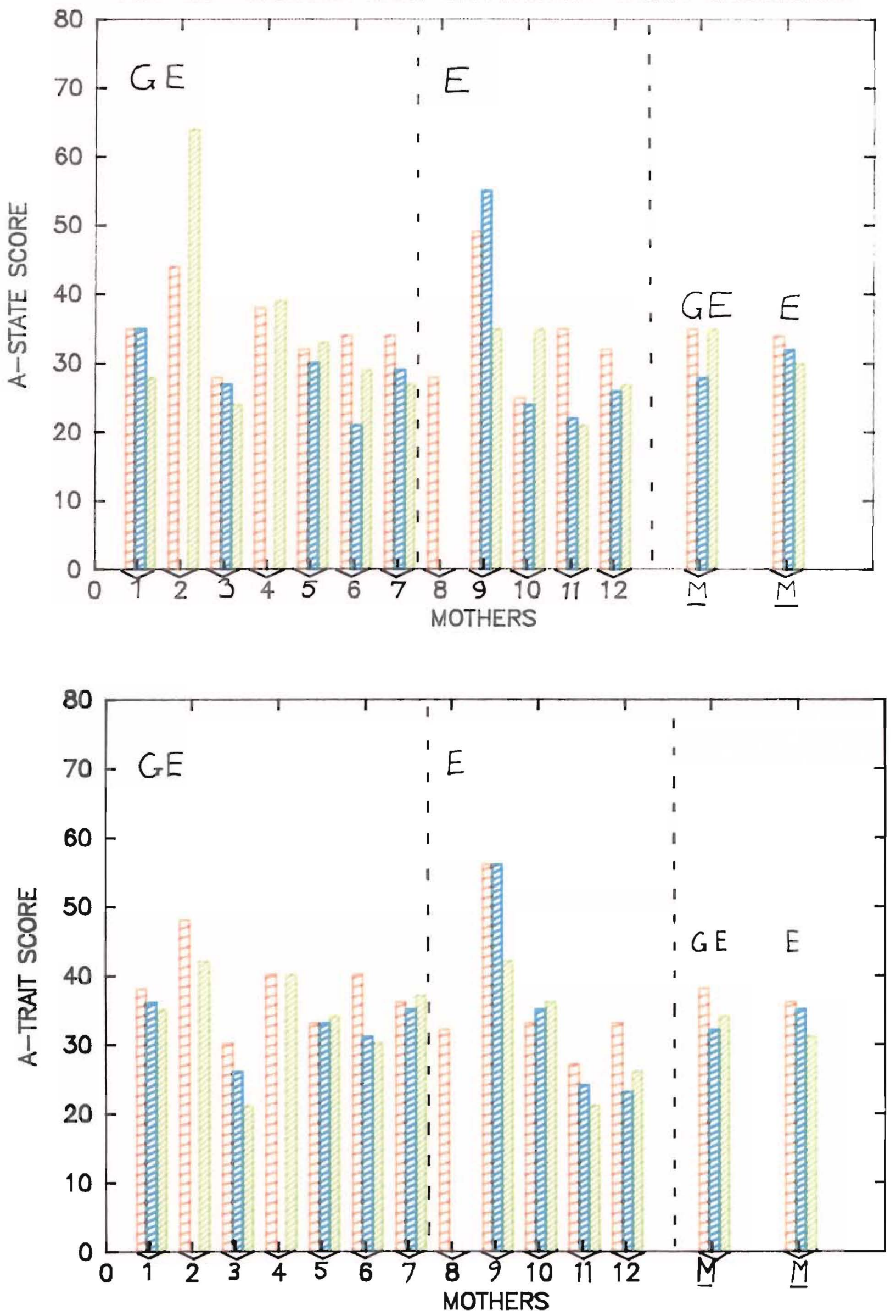

GE Denotes graduated extinction

$E$ Denotes extinction 
No increase in parental anxiety associated with either graduated extinction or extinction procedures was manifest. There were no distinguishing features between the two treatment conditions and both showed similar slight overall decreases in mean anxiety (see Figures 15 and 16).

Sleep Programme Evaluation Questionnaire, SPEQ

The return rate for the SPEQ was high. of the 10 subjects ( 6 graduated extinction, 4 extinction) for whom intervention effects have been analysed, all parents bar one completed the SPEQ. Subject 6's father declined to reply to the questionnaire. He said that he preferred not to comment as he had not been involved with the implementation of the programme.

\section{Item analysis and averall satisfaction}

All parents reported a medium to high level of satisfaction with the programme. The mean total score on the SPEQ was 30.6 (highest possible score is 36), indicating a high degree of general satisfaction. There was no difference in reported satisfaction between graduated extinction $(\underline{M}=29.6$, range 25-35) and extinction $(\underline{M}=$ 31.9, range $28-35$ ) subjects.

Item analysis revealed that most items received positive responses from the vast majority of parents. Mean scores for these items fell between 3.4 and 3.7 , where a score of 4 indicated the highest level of satisfaction for each item. Parents were:

(a) generally satisfied with the quality and amount of help they received,

(b) satisfied that they had got what they wanted from the programme,

(c) confident that it had fulfilled their needs and that they would recommend the programme to friends in need of similar help, and 
(d) of the opinion that they would come back to the programme if they had a similar problem again.

The item which received the greatest spread of replies was Item 6: "Have the services you received helped you to deal more effectively with other difficult child behaviour?" Ten parents selected the responsechoice indicating that the programme had not helped them in this way, whereas 9 parents found it somewhat or very helpful with other child behaviour (M $($ item 6$)=2.6$, $\underline{S D}=.83)$.

Item $9(\underline{M}=3.4, \underline{S D}=0.7)$ which required parents to rate their level of stress associated with implementing the sleep programme produced interesting results. It was the only item to which parents in the two treatment conditions responded distinctly. The parents of subjects in the graduated extinction condition generally reported a slightly higher degree of stress than parents of subjects in the extinction condition. Six of 8 parents who employed extinction described the programme as non-stressful, whereas only 3 of 11 parents who used graduated extinction did so. The other 7 parents in the graduated extinction group found the programme somewhat stressful ( $\underline{n}=5)$ and moderately stressful $(\underline{n}=2)$, whereas only two parents in the extinction group reported any degree of stress.

Content analysis and parental evaluation

The content of the five open-ended questions appended to the SPEQ was analysed. A few minor points of dissatisfaction were revealed but the majority of comments provided further evidence of parental satisfaction with the programme.

All parents in both treatment conditions responded positively when asked to comment about the instruction protocol explaining the intervention procedure. All found it easy to follow and well explained. One parent added: "We were aided in our understanding by the excellent verbal explanation at the initial interview." (Subject 12 's mother.) 
The majority of parents who were instructed in the application of graduated extinction, when asked to comment on the technique, replied in favour of a more gradual method and preferred it to the "leaving-your-child-to-cry" method. Subject 3 's father summed up the general attitude when he said "it was the better method for us as we felt it was less stressful on [our daughter]". Subject 1's parents were unique in that they both felt that the technique was too slow and that they could have more quickly decreased their attention time by using larger decrements. Most parents responded positively to the progress and support telephone calls made by the investigator. For example, Subject 6's mother wrote: "The telephone support given was of great help, . . I was given encouragement to carry on with the programme." Not all subjects were as satisfied. Subject 4's parents complained that the calls were irregular and would have liked them arranged for a certain time each day. Subject 5's father complained that the calls occurred too often at dinner time. One parent commented that the calls became too infrequent towards the end of intervention and said she felt left alone (Subject 5's mother), whereas another suggested that calls could have been reduced in frequency towards the end (Subject 3's father).

Comments regarding the keeping of daily records of infant sleep behaviour were varied. In all cases it was the mother who collected the data and all found that it became tedious towards the end of intervention. For example, subject 11's mother wrote "When I first made the records I was amazed how often I was getting up, rather frightening in fact, however I did get a bit sick of it towards the end." These sentiments were echoed by a number of mothers who found the records useful to look back on but that they later became a chore. One parent was somewhat annoyed at having to spend his now-peaceful evenings, after success with the programme, completing questionnaires.

The final open-ended question was an invitation for general comments and criticisms of the programme. A few examples of comments received will provide a flavour of 
parents' reactions to the outcome of intervention.

"The programme has altered our lifestyle more dramatically than any other single event, since her [their child's] birth. I no longer feel guilty, tired, etc. We also have far better ideas re management of her behaviour in general" (Subject 7's mother).

"Very pleased with the response" (Subject 1's father).

"It's excellent to have a full night"s sleep" (Subject 12's father).

"My feeling is that the programme succeeds through (a) sound common sense (a characteristic not always applied by exhausted parents), (b) by $100 \%$ consistency, and (c) by recording the child's sleep" (Subject 5's mother).

Some parents gave advice:

"Bedding should be taken into consideration. I, for one, have found that [our child] prefers light coverings at night" (Subject 11's mother).

"I would suggest that any physical cause for poor sleeping should be noted initially and possibly investigated" (Subject 5"s mother, whosechild had a series of ear infections during the programme).

one parent described unfulfilled expectations:

"At the start I had great hope that my daughter would be sleeping through the night at the end of the programme. . . I feel a little let down that she is not.. [But she has] gone from waking up five times a night most nights down to sleeping through four nights per week, and waking 1 to 2 times for only 5 minutes (but going back to sleep on her own) the other nights. I feel this is a satisfactory sleep pattern and might only be the best she will ever sleep" (Subject 6's mother). 


\section{DISCUSSION}

\subsection{SUMMARY OF RESULTS}

Earlier research into the management of infant sleep disturbance (France and Hudson, 1984; Seymour et al., 1983) has clearly shown that extinction by withdrawal of parental attention is an effective treatment. It has also shown in a number of cases that some aversive side-effects of extinction occurred early in treatment, making the problem temporarily worse. Furthermore, a number of parents were found to be reluctant to use extinction because they were unwilling to abruptly withdraw all attention from their child. Graduated extinction was developed as a treatment method which, it was hoped, would eliminate or reduce the short-term side effects of extinction, and be acceptable to those parents unwilling to use extinction procedures. This study was a systematic investigation of the graduated extinction method.

The interpretation of the results of this study is not easy because of the large number of variables used. Also, the data from each subject have their own individual and distinctive features which makes any overall summary difficult to achieve. Nevertheless, a general trend of clinically significant improvements in sleep behaviour from baseline to intervention was clearly demonstrated for treatment by graduated extinction, supporting the principal hypothesis. Subjects given extinction also showed significant improvement. This study, then, also replicates findings of France and Hudson (1984) and Seymour et al. (1983). Negative changes resulting from either treatment were minor and were far outweighed by changes in the therapeutic direction. The graduated extinction procedure, like extinction, was found to be effective in reducing the frequency of the four primary targets for change, and in improving other aspects of sleep-related behaviour. These improvements were maintained or further improved over time, as predicted in hypothesis four. 
Graduated extinction was not successful in avoiding the aversive side-effects of extinction, so the second principal hypothesis was not supported. Occasionally, a temporary increase in problem behaviour was observed following the onset of graduated extinction, making the problem temporarily worse. Since the paradoxical effects of extinction described earlier (Chapter one) do not occur for the majority of extinction subjects either (see France and Hudson, 1984), there is no advantage to be gained from graduated extinction in this respect.

In an attempt to summarise the overall effect of intervention the results for each subject were tabulated (see Table 15), with emphasis placed on those dependent variables targeted for change in each case. Intervention was described as an overall "success" for an individual subject if more than half of the target behaviours and at least one of the composite measures showed clinically significant improvement. Alternatively, intervention was designated as successful if both composite measures were judged improved to a clinically significant degree. The judgement of a clinically significant improvement was made if the change in behaviour resulting from treatment was large enough to be clearly evident upon visual inspection (Parsonson and Baer, 1978). Changes that were statistically but not clinically significant were excluded.

The procedures investigated in this study produced a successful outcome, according to the above criteria, in eight out of ten subjects (Subjects 1, 3, 5, 7, 9, 10, 11 and 12). Treatment was not successful for subjects 4 and 6 , both of whom received graduated extinction. Although the "success-rate" for graduated extinction was lower than extinction, the number of significant changes in target behaviours was higher for graduated extinction than for extinction; 14 out of 18 and 6 out of 9, respectively.

The aspect of infant sleep disturbance which was a presenting problem for all subjects in the study was nightwaking. Since this was also the reason for which subjects were referred to the study and was the behaviour which parents found most distressing, night-waking was specifically 
Table 15

The effects of intervention on each behavioural measure for each subject

\begin{tabular}{|c|c|c|c|c|c|c|c|}
\hline Subject & 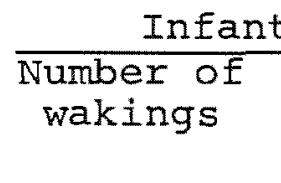 & $\begin{array}{c}\text { Sleep Behavi } \\
\text { Duration of } \\
\text { wakings }\end{array}$ & $\begin{array}{l}\text { Sur Measures } \\
\text { Sleep onset } \\
\text { latency }\end{array}$ & $\begin{array}{l}\text { Bedtime } \\
\text { Delay }\end{array}$ & $\begin{array}{c}\text { Composite Meas } \\
\text { Sleep Behaviour } \\
\text { Scale }\end{array}$ & $\begin{array}{l}\text { ures } \\
\text { Deviation } \\
\text { from Ideal } \\
\quad \text { scale }\end{array}$ & $\begin{array}{l}\text { Parental } \\
\text { responses }\end{array}$ \\
\hline \multicolumn{8}{|c|}{$\begin{array}{l}\text { Graduated } \\
\text { extinction }\end{array}$} \\
\hline 1 & $+*$ & $+*$ & 0 & 0 & 0 & + & + \\
\hline 5 & $+*$ & $+*$ & 0 & $+*$ & 0 & + & + \\
\hline 6 & $0 *$ & $0 *$ & 0 & $+*$ & 0 & 0 & + \\
\hline 7 & $+*$ & $+*$ & 0 & $+*$ & + & + & + \\
\hline \multicolumn{8}{|c|}{ Extinction } \\
\hline 9 & $0 *$ & 0 & 0 & $+*$ & + & + & + \\
\hline
\end{tabular}

* Denotes those infant sleep behaviours targeted for change for each subject

+ Denotes improvement between baseline and intervention phases

0 Denotes no change between phases 
examined. Subject 10 was excluded because baseline data showed that his night-waking had ceased prior to the onset of intervention. of the nine remaining subjects, nightwaking improved significantly in 6 out of 9 subjects (not for subjects 4,6 and 9 ).

To summarise, graduated extinction was clearly an effective treatment. Using a multiple-baseline design, a reduction in infant sleep disturbance was observed concomitant with the introduction of treatment. Those positive changes were maintained or further improved over time. Subjects 4 and 6 who did not show significant overall improvement are exceptions. The utility of graduated extinction for all subjects is therefore questionable. Although sufficient evidence exists to clearly demonstrate the efficacy of extinction for managing infant sleep disturbance, the lack of significant changes for night-waking for subject 9 shows that extinction is also not uniformly effective for all subjects.

\subsection{CONSTRAINTS ON THE INTERPRETATION OF RESULTS}

The confidence that one can have in this favourable interpretation of the present results is a product of the reliability of parental recording, the degree to which the requirements of the multiple-baseline design are met, and the sensitivity and ecological validity of the variables used. These issues are considered below.

Reliability of parental recording

The accuracy of parental recording was extremely difficult to assess. Due to a number of problems encountered in the collection of the reliability data, reliability estimates can only be considered tentative. of course, the problems experienced are not unique to the study but occur in the whole field of intervention in family settings. The inaccessibility of behaviour that occurs in the home, especially behaviour occurring at night during sleep, means that it is not easily monitored by those outside the family system. Previous research has shown that even family 
members have low agreement on the occurrence of night-waking. For example, Thomas (1983) found that fathers inevitably slept through most of their child's wakings and could not be used to determine the accuracy of the mother's recording. The major sources of inaccuracy in the present study of reliability were

(a) participation of parents in making both the primary recording and the mechanical reliability checks,

(b) mechanical problems with the apparatus used, and

(c) the arbitrariness of the criteria used to transcribe the apparatus-derived event record into numerical values.

The need to rely on parents to operate the apparatus reduced the credibility of the results produced, because it confounded the demonstration of recording reliability with parental reliability in machine-operation. Parents occasionally forgot to switch the apparatus on, forgot to write the date and time on the recording paper after placing their child in bed, or neglected to inform the investigator that the apparatus had failed. One method of reducing this problem would have been for the investigator to visit the subjects" homes at bedtime in order to operate the apparatus. However, both the practical difficulties of frequent evening visits and the invasion of the family's privacy meant that this alternative was not seriously considered. The apparatus used in this study was both prone to mechanical failure and to human interference. For example, on one occasion the paper path on the Esterline Angus event recorder jammed and prevented further recording. On another occasion the marker pens dried up preventing ink flow. Human interference could reduce the accuracy of the monitoring system by altering the sensitivity of the Voice Activated Relay (VAR). Since the amplifier gain switch on the VAR could not be locked in position, it became an easy target for young children and was moved from the standard setting at some stage in most homes. The effect of increasing the sensitivity was to increase the likelihood that extraneous 
noises such as dogs barking and cars passing activated the event-pens.

Since the transcription from the event record to numerical values involved discriminating between those penexcursions that represented infant crying and those that represented extraneous noises using arbitrary criteria, a further source of error was introduced. Arbitrary criteria were unavoidable if the event records were to be scored without knowledge of the parental record, a minimum requirement of the reliability assessment. obviously, no criterion for the interpretation of pen excursions could adequately distinguish night crying from extraneous noises.

These problems could possibly be overcome if an observer were placed in the subject's room or by more sophisticated technical devices, for example infra-red video recordings. These methods would record infant nightwaking directly. Nevertheless, the potential advantages must be weighed against the invasion of the family's privacy and the cost.

France and Hudson (1984) in their study of reliability, using a similar procedure, found that parent and event records were correlated with a mean $r=.82$ for the number of wakings, and mean $r=.66$ for the duration of wakings. For the sake of comparability with their study it may have been desirable for this study to have used correlational methods to calculate reliability, but these were avoided due to criticisms that they lead to inflated estimates of reliability (Wampold and Holloway, 1983). Point-by-point agreement was used in preference because it preserves the sequential nature of the data. But whatever method of calculation is used, the reliability of parental accuracy is likely to be underestimated due to the practical problems involved. The only direct comparison of videotaped recordings and parental diaries found that they agreed over 90 percent of the time (Jacklin, Snow, Gahart and Maccoby, 19801 .

A feature of this study which represents an improvement from France and Hudson's (1984) work, was the inclusion of the switchmat for the assessment of the reliability of 
parental self-monitoring of attention. There were fewer sources of inaccuracy in the automated assessment of parental attends because nothing other than the parents' weight was likely to activate the switchmat during the night. The higher agreement between the parent and event record for parental attends reflects this. However, it would have been possible for the parents to avoid stepping on the switchmat, had they so desired.

other factors possibly detrimental to reliability were decreased sensitivity to infant night-waking as the behaviour improved and parents became used to uninterrupted sleep, and boredom with recording. All of the mothers reported that keeping daily diaries for a long period became tedious. Boredom is likely to be associated with a decreased concern for accuracy. Again, the problem cannot be obviated without technical advances in home-based observation systems.

In conclusion, estimates of the reliability of parental recording, although far from ideal, are adequate given the limits of available resources. The plausibility of parental recording is enhanced by the similarity of effects evident in the time-series for the same infant across different variables. For example, subject 3 showed an idiosyncratic reversal in trend towards the end of intervention in each behaviour. If the parents had been making recordings by guesswork, no consistent pattern would have been likely to have been evident.

other constraints on interpretation

The interpretation of the present study is constrained not only by the quality of the data, but by ambiguities in the inferences which can be drawn from the multiple-baseline design used and the dependent variables employed. First, ambiguities result from the non-uniform implementation of intervention to each subject. Second, ambiguities result from the variety of the dependent variables assessed. Third, the measurement procedures used do not necessarily convey the impact on family life of improvements in infant sleep behaviour. Fourth, the high variability of baseline data 
may have interfered with the detection of a treatment effect (Kazdin, 1983). Nonetheless, the magnitude and type of change that occurred, as well as the concomitant decrease in variability, suggests that variability did not interfere significantly with the inferences made. Fifth, the non-random allocation of subjects to treatment conditions and the sample size in each group limit the between-group comparisons possible. However, the additional comparison with previous extinction studies (France and Hudson, 1984; Seymour et al., 1983) ensures a considerable degree of confidence in the comparison between extinction and graduated extinction. The first three of these points are elaborated below.

\section{Implementation of intervention}

In all parent-training research, the research is only as good as the degree to which parents comply with the procedures they are trained to implement. A multiple-baseline design which compares a treatment across different subjects and/or settings requires that all subjects receive identical treatment. The exact identity of all treatments cannot be guaranteed when parents are responsible for their application. However, it has been argued that so long as the independent variable (treatment) is monitored, then infringement of the identity requirement does not detract from the utility of the design (Moreland, Schwebel, Beck and Wells, 1982; Peterson, Homer and Wonderlich, 1982).

Parental compliance with the procedures in this study was measured by

(a) the self-monitored data of parental responses to night-waking,

(b) the changes in bedtime delay, and

(c) transcripts of telephone calls to parents.

Measurement of parental responses to night-waking from baseline to intervention showed that the majority of parents complied with the requested reductions in attention in graduated extinction and removal of attention in extinction. A lower compliance level was evident for some 
subjects, although all parents showed some decrease in the number of responses they made during intervention.

A low level of compliance was often associated with extraneous factors that influenced both parent and child behaviour. For example, subject 3's parents showed an increase in the number of responses they made to waking towards the end of intervention, associated with going on holiday. The parents decided not to implement the programme whilst on holiday with friends. The degree to which extraneous factors influenced parental efficiency in implementing the procedures varied from subject to subject. As France and Hudson (1984) noted from their results, the impact that illness had on infants' progress was related to the parents' ability to discriminate illness from non-illness, and to tailor the programme accordingly. Whereas some parents stopped using the procedures when their child was sick or they were on holiday (e.g. Subjects 5 and 3 , respectively), other parents showed consistency and an ability to cope with temporary aversive side-effects with minimal impact on improvement. For example, Subject 7, whose parents sought extra consultation when their child began vomiting, efficiently dealt with the problem whilst continuing to implement the procedures consistently. When parents lapsed into baseline levels of attention to night-waking this became, in effect, an informal reversal of the treatment, and the concomitant change in behaviour is evidence for the potency of parental attention as the variable maintaining the problem behaviour.

A clear association between parental compliance and improvements in infant sleep was demonstrated. Subject 4 , whose parents continued to respond to night-waking throughout intervention (although less frequently), showed no improvements in night-waking. That brief inconsistencies had a detrimental effect on infant night-waking, was also demonstrated in subject 9's response to intervention. Initially, when the parents complied with extinction instructions, a decrease in the number of wakings was observed. Mid-way through intervention the child was transferred from a cot to a single-bed and increased waking was observed. 
The parents responded to the child, who wandered out of his bedroom into theirs, by getting up and taking him back to bed. It was not until the parents consistently implemented extinction again, by shutting his door, that his waking began to decrease.

In both extinction and graduated extinction, failure to withdraw attention as prescribed is parental non-compliance, and is detrimental to the effectiveness of the intervention. Subject 6's parents demonstrated a more subtle form of noncompliance, which is not evident in gross measures of parental responses such as those shown in Figure 13. Closer examination of the parental records showed that these parents were inclined to advance the programme too rapidly. They prematurely applied extinction to some night-wakings then reverted to the prescribed duration of attention for other wakings. This set up a schedule of intermittent reinforcement which accounts for the apparent lack of improvement. An intermittent schedule produces behaviour that is highly resistant to extinction (Kimble, 1961) so that even when parents finally ceased attending to their child on any occasion, the indistinct discrimination between the intermittent reinforcement schedule and extinction resulted in little apparent change in behaviour.

Although bedtime delay was primarily treated as a variable of infant sleep disturbance, it could alternatively be considered as a measure of parental compliance. Bedtime delay was a measure of the delay between the child's actual bedtime and the time the parents considered ideal or appropriate. If the children in this study had been older and responsible for going to bed on their own, bedtime delay would have been a child-related dependent variable. However, since the children were under two years, their bedtime was likely to be controlled by their parents. Bedtime delay, as it occurred during baseline, could be conceptualised as an interaction between parent and infant behaviour. If the child was excited and wakeful, most parents did not attempt to put him/her to bed before they detected signs of weariness. Instructions to parents required that they chose a regular bedtime which they were required to stick to, 
regardless of whether the child was tired or not. Therefore, changes in this variable more accurately reflect parental compliance with the stimulus control aspects of the procedures than infant behaviour. A dramatic decrease in bedtime delay was evident for all subjects, showing that parents generally complied with the instructions.

Some of the parents (Subjects 3 and 4) who were noncompliant in their withdrawal of attention to night-waking also showed relatively low decreases in bedtime delay, indicating poor compliance with stimulus control aspects of treatment as well.

Telephone calls to parents throughout intervention ensured some control over their consistency in implementing the programme. For example, in the case of subject 9, whose parents moved him into a single bed and then started taking him back to bed when he climbed out, the investigator was able to suggest to the parents that they shut his door to re-implement extinction. However, there were parents who seemed unable or unwilling to comply with instructions despite regular reminders and support. Looking over the transcripts of the telephone calls to parents, the number of nights on which subject 4's parents complied was discernibly lower than for other subjects. Subject 5 's parents showed more occasions of non-compliance than the majority but these were consistently associated with subject 5 's recurrent bouts of ear infection.

In conclusion, parental compliance with the instructions was essential for improvement in infant sleep disturbance. Temporary deterioration in both infant sleep beháviour and parental compliance was often associated with extraneous factors, such as illness or holidays. The suggested role of parental attention in maintaining infant night-waking (France and Hudson, 1984; Richman, 1981b; Seymour et al., 1983; Thomas, 1983) was clearly supported. A greater level of non-compliance was apparent for parents implementing graduated extinction than extinction. High levels of compliance with extinction were reported by France and Hudson (1984) and Seymour et al. (1983) and this study confirms this. Seymour et al. (1983) reported that $95 \%$ of 
their large sample implemented extinction successfully. This raises the question of why graduated extinction received lower parental compliance than extinction.

There are several possible explanations for the lower compliance rates of parents implementing graduated extinction. Firstly, it is a more complex programme requiring considerable concentration and self-monitored behaviour from the parents. Secondly, the schedule of gradual reduction of attention may implicitly sanction parental attention, making it more difficult for parents to implement full extinction when necessary. Furthermore, parental responding to child behaviour continues to be reinforced during graduated extinction. Thirdly, graduated extinction was developed to cater for parents who do not wish to ignore their child's crying, yet the procedure still resulted in crying. parents may have found the programme more difficult to follow because they had expected to avoid the crying. Parents who self-select for graduated extinction may thus be less compliant with treatment instructions in any circumstances in which their child continued to cry.

\section{Adequacy of the dependent variables}

No matter how effective a treatment is, nor how perfectly the requirements of an experimental design are met, no piece of research will be successful unless the dependent variables used are appropriate, and sufficiently sensitive to behavioural change.

A multivariate study such as this one has both advantages and disadvantages. Against the benefits of multiple indices of change and replications of treatment effects are set the costs of the increased likelihood of inconsistency between variables. Any attempt to determine the overall outcome for any subject, as the "success-rate" calculated earlier, which treats all variables equally, is bound to be misleading. For example, sleep onset latency, measured as the time from placement in bed to silence, was incapable of reflecting the underlying change in behaviour and quality of life for the family. Yet non-significant results on this variable were compared with non-significant results 
on other variables which were clearly more sensitive to the underlying behaviour.

Sleep onset latency was a variable that showed no improvement for the majority of subjects. Yet systematic changes were apparent in the qualitative aspects of this behaviour. Infants who had previously only gone to bed asleep, or very late, were now going to bed at a regular time, being put into bed awake and falling asleep on their own. One parent described the improvement in her lifestyle thus: "Now I can do three hours study at night as [Subject 7] is in bed". Other parents were able to go out and leave their child with a babysitter for the first time.

other measurement procedures also failed to adequately reflect the impact on family life resulting from infant sleep disturbance. For example, subject 9 showed no significant improvements in either of the night-waking variables, yet closer analysis of the data showed that baseline levels of waking were as low as they were only because the child slept in the parents' bed each night. The data did not reflect the changes in lifestyle resulting from intervention. The child was now sleeping in his own bed enabling the parents to enjoy conjugal relations without the necessity to break their own sleep by getting up in the night.

The collection of social validation data was an attempt to evaluate the social and ecological effects of intervention which were not adequately assessed by dependent variables. The flint Infant security scale showed that parents perceived a slight improvement in their infant's mental health as a result of intervention. This suggests, that for some subjects at least, the procedures showed generality across response measures. Some parents confirmed the improvement in their child's everyday behaviour, describing their child as "happier", "less grizzly" and "less demanding". Parents in both extinction studies noticed similar improvements in their child's demeanour concomitant with improvement in sleep. Several parents also reported increased confidence in managing their child's inappropriate behaviour, generally, and felt that the programme had taught them skills which they were able to apply to everyday child management. 
Parental perception of the significance of the improvements in infant sleep behaviour showed that even where clinically non-significant or small changes were evident in the dependent variables used, parents reported satisfaction and qualitative improvements in lifestyle as a result of intervention. For example, subject 6 showed no significant improvements in night-waking yet her mother was satisfied with progress as she no longer had to interrupt her sleep to attend to the child. All parents reported a high degree of satisfaction with the sleep programme and its outcome. However, the data obtained from parental responses to the sleep Programme Evaluation Questionnaire, SPEQ, must be interpreted with caution because of likely distortion from acquiescence and social desirability (Lebow, 1982). Parents' replies were not anonymous and they knew that the investigator was receiving the questionnaires, which increases the likelihood that parents gave "grateful testimonials".

The finding that graduated extinction was highly acceptable to parents (supporting hypothesis five) who said that they preferred the gradual method because it was "less traumatic than leaving the child to cry" is subject to the same demand characteristics as satisfaction estimates. Although parents may idealogically prefer the graduated extinction procedure, other findings suggest that a favourable attitude towards the procedure is insufficient. Firstly, parents instructed in graduated extinction procedures reported that they found the programme stressful more often than those parents instructed in extinction. Secondly, parents complied less often with graduated extinction than extinction procedures. It seems, then, that graduated extinction may appeal to parents because they are reluctant to "leave their child to cry". But perhaps due to its increased complexity and the extra demands placed on parents to concentrate on and monitor their own behaviour, graduated extinction may be more stressful and difficult to implement. In contrast, seymour et al. (1983) found that even though many parents initially objected to extinction for various reasons, once the procedures were explained, 95\% of them 
implemented them successfully. It is not, therefore, surprising that the proposed reductions in parental anxiety associated with graduated extinction as opposed to extinction, predicted in hypothesis five, were not confirmed.

In summary, then, the dependent variables of the study differed in their sensitivity to changes in family well-being. Social validation measures emphasised parental satisfaction and improvements in the quality of Iife associated with intervention. In all cases children were now going to bed at a regular time, the frequency of their waking during the night had diminished, and parents were able to enjoy conjugal relations uninterrupted by the necessity to attend to their child. Again it can be said that while the dependent variables used in the study were not ideal, especially in their ecological validity and sensitivity to changes in quality of life, they were sufficiently sensitive to permit robust conclusions to be drawn about the effectiveness of graduated extinction.

\subsection{CLINICAI EVALUATION OF GRADUATED EXTINCTION}

The efficacy of graduated extinction and extinction have been clearly demonstrated, as well as their relative efficiency. However, efficiency and efficacy are not the sole criteria upon which a clinician should base his/her decision regarding the appropriate behaviour management strategy. Feldman and Peay (1982) emphasize the importance of taking the client's preference for treatment into consideration. A client should be able to reject a method that they know is more efficient for reasons of personal preference, so long as the available alternative is of demonstrated effectiveness. In this context, therefore, graduated extinction is a useful contribution to the management of infant sleep disturbance.

From a clinician's point of view, a number of suggestions can be made that may enhance the utility of extinction. Since parental compliance with the procedures is the most significant factor influencing treatment outcome the 
clinician could maximise compliance by

(a) warning parents that even though their infant is unlikely to cry initially, there will come a time when they will have to ignore some crying;

(b) teaching parents how to cope with extraneous factors, such as illness and holidays, so that they have minimal impact on the infant's progress;

(c) contracting with parents prior to the onset of intervention that they will not alter their child's sleep location whilst on the programme;

(d) insisting that parents make a long-term commitment to the procedures; and

(e) ensuring that parents do not expect fast improvement which may lead to discouragement.

From a clinical perspective, the investigator would not recommend graduated extinction as the treatment of choice unless parents very strongly objected to extinction. This recommendation is based on clinical experience as well as evidence of its lower efficiency and compliance rate. Graduated extinction requires more therapeutic involvement on the part of both the therapist, to sustain parental compliance, and the parents, to implement the procedure. Extinction has the advantage that it is a more direct, "short-sharp", method which provides unambiguous and clearly defined guidelines to parents. Instead of a complex regime of attention-reduction which requires considerable self-discipline and concentration, parents know that, after having applied extinction, attention is no longer appropriate at all.

Although further research is necessary to elucidate for whom which treatment would be the most effective, it is unlikely that parents who are in conflict over the implementation of the procedures would successfully apply either procedure. It may be useful for future management studies to include one of the standard assessments of marital status to assess this. Iikewise, parents who are extremely reluctant to leave their child to cry and find it highly stressful 
and self-select graduated extinction for this reason would probably find compliance with either procedure difficult. Finally, there are two aspects of the graduated extinction procedure that were not evaluated in the present investigation which could usefully be addressed by future research. Firstly, the effect of stimulus control training on infant sleep behaviour has not been determined independently of graduated extinction. It seems likely that attention to the stimulus control aspects of infant sleep behaviour contributes to the effectiveness of the procedure by teaching the infants the setting stimuli for sleep at bedtime, which generalises to night-time wakings. Secondly, after discussion with parents it became apparent that the arbitxary decision to reduce attention systematically over twenty-eight days during graduated extinction did not suit all subjects equally. The question of what might constitute an optimal rate of reduction for which infants remains for future investigation.

\subsection{CONCLUSIONS}

This study has investigated graduated extinction in the treatment of infant sleep disturbance. The procedure was found to produce significant improvements in infant sleep behaviour. There was little difference in the efficacy of graduated extinction and extinction. However, the superior efficiency of extinction was shown. Subjects exposed to extinction in this study and in previous research (France and Hudson, 1984; Seymour et al., 1983) showed more rapid improvement than subjects exposed to extinction.

The most significant finding in regard to the efficacy of both procedures was that parental compliance accounted for more individual subject improvement than the type of intervention. The two treatment conditions met with different degrees of parental compliance. Some parents instructed in graduated extinction procedures showed lower compliance. It was concluded that extinction was the treatment of preference unless parents strongly objected to its use. 
REFERENCES

Anders, T.F. (1979), Night-waking in infants during the first year of life. Pediatrics, 63, 760-864.

Anders, T.F., Carskadon, M.A. and Dement, W.C. (1980). Sleep and sleepiness in children and adolescents. Pediatric Clinics of North America, 27, 29-43.

Anders, T.F. and Weinstein, P. (1972). Sleep and its disorders in infants and children: A review. Pediatrics, 50, 312-324.

Anderson, D.R. (1979). Treatment of insomnia in a 13-yearold boy by relaxation training and reduction of parental attention. Journal of Behavior Therapy and Experimental Psychiatry, $10,263-265$.

Anderson, O.W. (1951). Psychologic aspects of pediatrics: The management of "Infantile Insomnia". The Journal of Pediatrics, 38, 394-401.

Baer, D.M. and Wolf, M.M. (1970). The entry into natural communities of reinforcement. In $R$. Urich, $T$. Stachnik and J. Mabry (Eds.) Control of Human Behavior: Vol.2 From Cure to Prevention (pp.319-324). Illinois: Scott, Foresman.

Baldwin, J.D. and Baldwin, J.I. (1981). Behavior Principles in Everyday Life. New Jersey: Prentice-Hall.

Bandura, A. (1969). Principles of behavior modification. New York: Holt, Rhinehart and Winston.

Basler, K., Largo, R.H. and Molinari, L. (1980). Die entwicklung des schlafver hallens in den ersten funf legensjahren. Helvetica paediatrica Acta, 35, 211-223.

Battle, C.U. (1970). Sleep and sleep disturbance in young children: Sensible management depends upon understanding. Clinical Pediatrics, 9, 675-682.

Bax, M.C.O. (1980). Sleep disturbance in the young child. British Medical Journal, 10 May 1980, 1177-1179.

Bergman, R.L. (1976). Treatment of childhood insomnia diagnosed as hyperactivity. Journal of Behavior Therapy and Experimental Psychiatry, ㄱ, 199.

Bernal, J.F. (1973). Night waking in infants during the first 14 months. Developmental Medicine and Child Neurology, 15, $760=769$.

Blurton-Jones, N., Ferreira, M.C.R., Farquar Brown, M. and MacDonald, L. (1978). The association between perinatal factors and later night waking. Developmental Medicine and Child Neurology, 20, 426-434. 
Brackbill, Y. (1958). Extinction of the smiling response as a function of reinforcement schedule. Child Development, 29, 115-124.

Carey, W.B. (1974). Night waking and temperament in infancy. Journal of Pediatrics, 84, 756-758.

Catania, A. (1968). Contemporary research in operant behaviour. Illinois: Scott, Foresman.

Chavin, w. and Tinson, S. (1980). Children with sleep difficulties. Health Visitor, 3 , 477-480.

Dorsel, T.N. (1978). Crying: Easily established, but difficult to eliminate. Journal of Clinical Child Psychology, $7,156-160$.

Douglas, J. (1983, November 1). Sleep problems in children. Update, pp. 1239-1244.

Douglas, J. and Levere, P. (1982). Behavioural management of sleep disturbance in young children. Unpublished manuscript, Department of Psychological Medicine, The Hospital for sick Children, Great ormond street, London.

Douglas, J. and Richman, N. (1982). Sleep management manual. Unpublished manuscript, Department of Psychological Medicine, The Hospital for Sick Children, Great ormond Street, London.

Feldman, M.P. and Peay, J. (1982). Ethical and legal issues. In A.S. Bellack, M. Hersen and A.E. Kazdin (Eds.), International Handbook of Behavior Modification and Therapy (pp.231-262). New York: Plenum Press.

Fergusson, D.M. (1982). The Christchurch child development study: The first four years. Christchurch, New Zealand. Concord Press.

Fergusson, D.M., Shannon, F.T. and Horwood, L.J. (1981). Night waking in the first two years of life. Unpublished manuscript, Christchurch clinical School, Christchurch Hospital, Christchurch, New Zealand.

Flint, B.M. (1974). The Flint Infant Security Scale. Toronto: University of Toronto Press.

France, K.G. (1982, May). Infant and preschool sleep disturbance: The rowdy majority: Overview and future directions. Paper presented at the meeting of the Australian Behaviour Modification Association, Surfer's Paradise, Australia.

France, K.G. and Hudson, S.M. (1984). Extinction in the management of infant sleep-disturbance: An experimental analysis. Unpublished manuscript, Department of Psychology, University of Canterbury, Christchurch, New Zealand. 
Graziano, A.M. (1977). Parents as behavior therapists. In M. Hersen, R.M. Eisler and P.M. Miller (Eds.), Progress in Behavior Modification: Vol.4 (pp.251-298). New York: Academic Press.

Guilleminault, C., and Anders, T.F. (1976). Pathophysiology of sleep disorders. Part II: sleep disorders in children. Advances in Pediatrics, 22, 151-174.

Hirschberg, J.C. (1957). Parental anxieties accompanying sleep disturbance in young children. Bulletin of the Meninger Clinic, 21, 129-139.

Hood, L. (1975, June). Nightwaking. Parents Centres, pp. 14-15.

Illingworth, R.S. (1951). Sleep problems in the first 3 years. British Medical Journal, $1,722-728$.

Illingworth, R.S. (1966). Sleep problems of children. Clinical Pediatrics, $5,45-48$.

Illingworth, R.S. (1968). Sleep problems of the toddler. The Practitioner, 200, 345-350.

Inglis, S. (1976). The nocturnal frustration of sleep disturbance. The American Journal of Maternal Child Nursing, $1,28 \overline{0-287}$.

Jacklin, C.N., Snow, M.E., Gahart, M. and Maccoby, E.E. (1980). Sleep pattern development from 6 through 33 months. Journal of Pediatric Psychology, $5,295-303$.

Jenkins, S., Bax, M. and Hart, H. (1980). Behaviour problems in pre-school children. Journal of Child Psychology and Psychiatry, 21, 5-17.

Johnston, R. (1983). A revision of socio-economic indices for New Zealand. Wellington: New Zealand Council for Educational Research.

Kazdin, A.E. (1982). Single-case research designs. New York: Oxford University Press.

Kellerman, J. (1980). Rapid treatment of nocturnal anxiety in children. Journal of Behavior Therapy and Experimental Psychiatry, 11, 9-11.

Kimble, G.A. Condıtioning and Learning. (2nd ed.). London: Methuen.

Knight, R.G., Waal-Manning, H.J. and Spears, G.F. (1983). Some norms and reliability data for the state-Trait Anxiety Inventory and the zung Self-Rating Depression Scale. British Journal of Clinical Psychology, 22, 245-249. 
Lancioni, G.E. (1980). Infant operant condition and its implications for early intervention. Psychological Bulletin, 88, 516-534.

Larsen, D.I., Attkisson, C.C., Hargreaves, W.A. and Nguyen, T.D. (1979). Assessment of client/patient satisfaction: Development of a general scale. Evaluation and Program Planning, 2, 197-207.

Lask, B. (1977). Emotional and behaviour problems in childhood. Midwife, Health Visitor and Community Nurse, 13 , $384-389$.

Lebow, J. (1982). Consumer satisfaction with mental health treatment. Psychological Bulletin, 91, 244-259.

Mackintosh, N.J. (1974). The Psychology of Animal Learning. Iondon: Academic Press.

Milan, M.A., Mitchell, Z.P., Berger, M.I. and Pierson, D.S. (1981). Positive routines: A rapid alternative to extinction for elimination of bedtime tantrum behavior. Child Behavior Therapy, $3,13-25$.

Minitab (1983). Minitab Inc., 215 poud Laboratory, University Park, P.A., 16801, U.S.A.

Moesbergen, K. (1984, August). Effects of extinction and token reinforcement on sleep disturbance in pre-school children. Paper presented at the meeting of the New Zealand Psychological Society, University of Massey, Palmerston North, New Zealand.

Moore, T. and Ucko, L.E. (1957). Night waking in early infancy. Archives of Disease in Childhood, 32, 333-342.

Moreland, J.R., Schwebel, A.I., Beck, S. and Wells, R. (1982). Parents as therapists. Behavior Modification, $6,251-276$.

Parsonson, B.S. and Baer, D.M. (1978). The analysis and presentation of graphic data. In T.R. Kratochwill (Ed.), Single subject research: Strategies for evaluating change (pp.101-165). New York: Academic Press.

Patterson, G.R. (1976). The aggressive child: Victim and architect of a coercive system. In E.J. Mash, I.A. Hamerlynck and L.C. Handy (Eds.), Behavior Modification and families (pp.267-316). New York: Brunner/Mazel.

Patterson, G.R. and Reid, J.B. (1973). Intervention for families of aggressive boys: A replication study. Behavior Research and Therapy, 11, 383-394.

Paul, F.M. (1982). Sleep disturbances in young children. The Singapore Family Physician, 8, 111-113. 
Peterson, L., Homer, A.I. and Wonderlich, S.A. (1982). The integrity of independent variables in behavior analysis. Journal of Applied Behavior Analysis, 15 , $477-492$.

Ragins, N. and Schachter, J. (1971). A study of sleep behavior in two-year-old children. American Academy of Child Psychiatry, 10, 464-480.

Reynolds, G.S. (1975). A primer of operant conditioning (rev. ed.). Illinois: Scott, Foresman.

Richards, M.P.M. and Bernal, J.F. (1974, February 28). Why some babies don't sleep. New Society, pp.509-511.

Richman, N. (1981a). A community survey of characteristics of one-to-two-year-olds with sleep disruptions. Journal of the American Academy of Child Psychiatry, 20, $\overline{281-291 .}$

Richman, N. (1981b). Sleep problems in young children. Archives of Disease in Childhood, 56, 491-493.

Richman, N. Stevenson, J.E. and Graham, P.J. (1975). Prevalence of behaviour problems in 3-year-old children: An epidemiological study in a London borough. Journal of Child Psychology and Psychiatry, 16, 277-287.

Roberts, K.E. and Schoellkopf, J.A. (1951). Eating, sleeping and elimination practices of a group of two-and-one-halfyear-old children: Part III, sleeping practices. American Journal of Diseases in Children, 82, 132-136.

Russo, R.M. Gururaj, V.J. and Allen, J.E. (1976). The effectiveness of Diphenhydramine HCL in pediatric sleep disorders. The Journal of Clinical Pharmacology, 16, $284-288$.

Schmitt, B.D. (1981). Infants who do not sleep through the night. Journal of Developmental and Behavioural pediatrics, $\underline{2}, 20-23$.

Seiler, E.R. (1972). Sleep problems in children. The Practitioner, 208, 271-276.

Seymour, F.W., Bayfield, G., Brock, P. and During, M. (1983). Management of night-waking in young children. Australian Journal of Family Therapy, 4, 217-223.

Shirley, H.F. and Kahn, J.P. (1958). Sleep disturbances in children. Pediatric Clinics of North America, 5 , 629-643.

Snow, M.E., Jacklin, C.N. and Maccoby, E.E. (1980). Crying episodes and sleep-wakefulness transitions in the first 26 months of life. Infant Behavior and Development, 3 , 387-394. 
Spielberger, C.D., Gorsuch, R.L. and Lushene, R. (1970). State-Trait Anxiety Inventory: Manual. Palo Alto: Consulting psychologists press.

Spock, B. (1949). Chronic resistance to sleep in infancy. Pediatrics, 4 , 89-93.

Spock, B. (1957). Sleep problems in the early years. Postgraduate Medicine, 21, 272-274.

Thomas, E.P. (1982). Night waking in pre-school children: An assessment and intervention. Unpublished master's thesis, University of Waikato, Hamilton, New Zealand.

Thomas, J.D. and Smith, O.A. (1972, August). Parents' use of behaviour modification techniques. Paper presented at Symposium on Applied Operant Research, New Zealand Psychological Society, New Zealand.

Tryon, W.W. (1982). A simplified time-series analysis for evaluating treatment interventions. Journal of Applied Behavior Analysis, 15, 423-429.

Valman, H.B. (1981, August 8). Sleep problems. British Medical Journal, 283, $422-423$.

Wampold, B.E. and Holloway, E.L. (1983). A note on interobservor reliability for sequential data. Journal of Behavioral Assessment, 5, 217-225.

Watson, P.J. and Workman, E.A. (1981). The non-concurrent multiple baseline across-individuals design: An

extension of the traditional multiple baseline design. Journal of Behavior Therapy and Experimental psychiatry, 12, 257-259.

Wenar, C. (1963). The reliability of developmental histories. Psychosomatic Medicine, 25, 505-509.

Werry, J.S. and Carlielle, J. (1981). Common sleep problems in children under five. Unpublished manuscript, Department of Psychiatry, School of Medicine, University of Auckland, New Zealand.

Williams, C.D. (1959). The elimination of tantrum behavior by extinction procedures. Journal of Abnormal and Social psychology, 59, 269.

Yen, S., McIntire, R.W. and Berkowitz, S. (1972). Extinction of inappropriate sleeping behaviour: multiple assessment. Psychological Reports, 30, 375-378. 
APPENDIX A

GETTING CHILDREN TO SLEEP

To attend or not to attend? That is the question debated by several Christchurch mothers in a sequence of Letters to the Editor sparked off by this article, which appeared in the Christchurch Press on May 21, 1984.

\begin{tabular}{|c|c|c|c|c|}
\hline 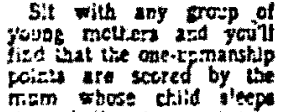 & $\begin{array}{l}\text { JULIA WATSON, } \\
\text { study of babies" }\end{array}$ & "Observer," con & & 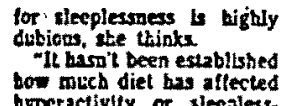 \\
\hline 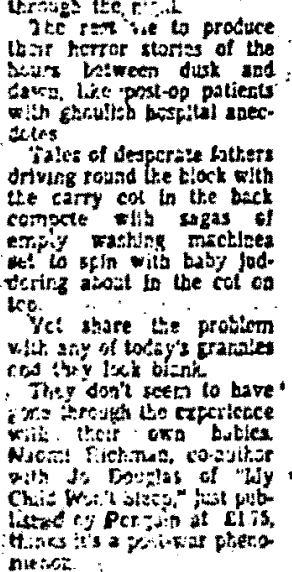 & 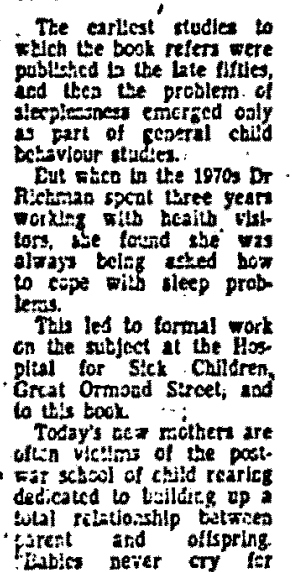 & 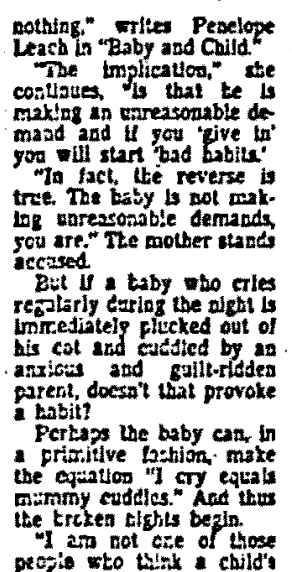 & 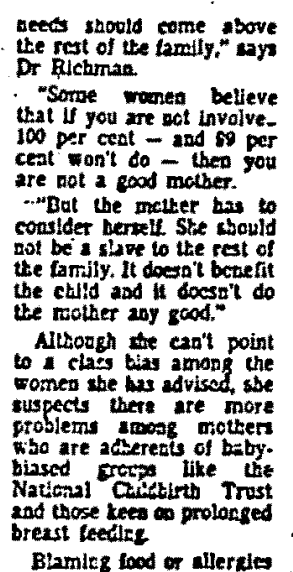 & 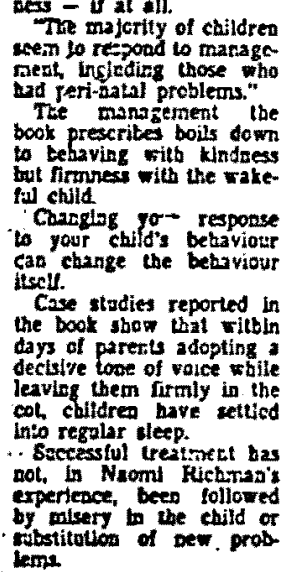 \\
\hline
\end{tabular}


(1) \& (2). May 25, 1984.

\section{Getting children} to sleep

Sir, - What a curious attitude our society has towards sleep. ("Hush now, baby," "The Press," May 21). Parents whose child bas very talt skin do not expose her to large amounts of sunshine to toughen her up. They provide a sun hat or sunsereen cream Parents that or suns whese child is allergic to a particuhim to eat it to train him out of the allergy. diet. Parents whose child is exceptionally lall do not cram ber into too-small clothes to get her out of the habit of growing. Yet parents whose child wakes irequently at night are advised to ignore him, to train him out of the habit. Chlidren are expected to conform to a pattern that suits some but not others, and the parents who try to meet their individual child's individual needs are deemed to be making excessive sacrifices. Why? - Yours, etc.

CATHERINE GLUE.

May $22,1984$.
Sir, - Perish the thought that might be an "adherent of baty. bigsed groups ..." ("The Press." May 211. If look me years o molhering, lour children and count lees remedies later, in vain at tempt to solve the sleep problem. It was simple in the end. Finally. I was able to accept emotionally my child's dependency and feel her need for noctumal contact. Wel. also a night-waker and anxious, into my bed, worked. We all slept Six months later, the five-year-old decided independently to returm hor bed, and sleeps all night. The three-year-old now sleeps all night. mostly in my bed. Dccasionally ste chooses to sleep (all night) in her oxn bed. Baby-biased groups pro mote long term, the interests of the child towards todependence. Yours, etc.

CHRISTINE D

ROWLANDS

May 21. 1924.
(3). May 29, 1984.

Sir-Catherine Glue's assertion. that Imoring chlldren's cryigg in the night is anslagous to teeding a child who has an allergy with the food she is allerglc to is patent consezize. I am a parent myself, and have used this technlque on both wy children successfully, I love my chlldren fust as much as anpone else but I do not cope well vith broken sleep Ef hit after night As for having them in bed with me, as for baving them in bed with me, sleep with a chlld wriggling and ycking between us. I suppose my burbind conid move to a separate bed, but my idea of marriage has my busband in our bed, not my lercnt ways of dealleg with thls problem, but I wonder if advacates of "lamily beds" can solve it? Yours, etc.

$$
\text { T. E. MOON. }
$$

May 25,1084 .

(4). May 31, 1984.

\section{Gettiag children} to sleep

Sir-Most poople embart on manriage with ther assumption that both partears bave. Identiliatle necds, and both shewid as! far as possible bave tham mat sadly, most go into parenthood with litile idea of what a chllo's aeeds might really be When children fail to meet our preconcelved expectations we try to change the children rituer than the expectations A couple's need for the phrsical and emotional intimicy of a shared bed is widely accepted as Importint, yet depend. accepted as Importint, yet dependeat children are denied thls, and their protests Ignored. The "farnily a bed designed for twol Many. pareats install an extra bed adjotnIng their onn thes allowing everyone's needs, rather than lettling the ves of the varents overide those of the children-Yours, etc. CATHERINE GLUS

May 29, 1034

Add Hospltal art-Ball

\section{(5). June 1, 1984.}

\section{Getting children}

to sleep

Sir, - Whether or not chlldren Feed to sleep with their parents is dctatable. They certsinly desire it but then childres cesire' all kinds of things that responsible parents are not going to give them. Most parents would have experienced screams of rage and frustration when they prevent beir child from having or doing somathing it has set its beart on. Sleeping throush the night in their oun beds is just the same, and no parents ueed feel any more guilty than they would if they denied their chind a chocolate bar every time they went to the shop. As for creating irdependent children, my dxugher is very independent and confident but I have sean several children of the same age who have been breastfed same age wo have been breasted
for a gurnber of years and who sleep with mum and dad who will not leave mun's side. - Yours. elc.

Say
(6). June 4, 1984.

\section{Getting children to sleep}

Sir,-How tragic to lump to gether a child's desire to be comforted in times of anxiety and her dealre for ichocolite har. The child tho screams from fear and lanelines in her solltary bedroom. and is always noswered but who gcreams for chocolate bars and is often imored lesrns that human love is more important liso lurury tood. The child whose cries are Ignored, if inconvenient to her parents, regardless of what she is crying lor, learns that her leelings are not important. The wisest statement I have beard about inde. pendence is "True independence is aot 'not beediag belp', but knowing bow to ask for belp when you do bow to ask for belp when you do need it." To do this, a person must" feelings, and trust that others will care about ler. Such trust can best be developed by a childhood bis. tory of asklog for help and receiv. ing it-Yours elc.

CATHERINE GLUE.

June 1, 1984. 
(7). June 5, 1984 .

\section{Getting children}

to sleep

Sir, - We have a child who slept badly irom an early we. By six rionths she was ; waking six times a night. Having her sleep with us had no effect on. the number of times she woke. While we may have been "answering her every need" during the night, being chronically tired ourselves meant that we were unable to function adequately as parents during the day. There must be a balance between the child's needs and the parents, both par: ties' quality of life being important. To solve our problem we used the excellent sleep programme offered by the university. Our child still wakes briefly most nighis, but has gained the independence to cope happily by berselt. crying only when in genuine distress. We have energy now lor ber and the rest of our lives. She has happier days resulting from her bealthier sleep. ing pattern and the added routine in our lives - Yours, etc.

M. B. Moss and

ALISON LOCKE

June 4,1984 .

\section{(8) \& (9). June 6, 1984.}

\section{Gefting children \\ to sleep}

Sir-My personal growth through mothering three children has involved changes in expecta. tions. In helpless despair we lowed our. Iirs child (at about is montus) to cry-it-out when we failed montus to cry it-out when we failed
to get him to sleep. Our expecta. tions were in transition with oü second child and at times I resisted ber need of my. closeness only to arrive yet again at the acceptance of ber need. Our expectations totally revised, it has seemed so easy to follow our third child's cues and meet ber needs. She sleers in our ealarged bed when she Indicates a readiness for sleep. When she wakes she usually breast-feeds back to sleep. There are numerous varia. tions on the "family bed." My husband has a separate bed. Inl. tially 'I found this enormously threatening, until we realised its possibilities as our "love nest" trom which I can return to sleep with our child or children-Yours, ete. c. GRIFFITHS

June $2,1984$.
Sir, - The crucial issue in the "getting children to sleep" controversy (June 1, is one of children's dependency needs and emotional development. Chtidren are, by their state; not independent. Adults may achieve emotlonal maturlty of which independence is one aspect. Most educationalists and psychologists generally define "inlancy" as lasting until about 'the' age of seven. Children deprived in in* fancy, in ways appropriate to them individually, have their growth to: wards independence halted or dis. torted. Conflict between being told "what is right" and what parents "Ieel to be right" is usually unre. solved. Invariably it is the chlidren who pay the price and 'the cycle of emolional deprivation continues for another generation. I/syropathise with parents struggling to recog rise and meet children's depend ency needs. I am still struggling with mine. However in breaking the culitural conditioning, interfor. ing, with my biologically-based instinct. to "mother" my children, 1 feel I am at least progressing, Yours, etc. CHRISTINE b. ROW.
LANDS.

June 1.1984 .

\section{(10). June $7,1984$. (11). June $8,1984$.}

\section{Getting children to sleep}

Sir, - Catherine Glue thinks that Ignoring children's crying at night is teaching them that their needs are unimportant. I cannot agree. What it teaches them is that other peaple have needs as well. such os a need for a night's sleep and that their desire to be with zoum is not always as strong as mum's need for a night's sleep. As for always trusting other people if you are a woman it is far safer to learn that you can rely on yoursell to cope with problems than rely on anyose else, especially a mac. Most women are already too dt pendent. I want my daughters to be strong and self-reliant. I also thinis parents bave a difficult enough job without people implying thai a! the world's social problems can be blamed on parents who make chii. dren sleep at night. - Yours, etc.,

$$
\text { T. E. MOUN. }
$$

June 4. 1984.

\author{
Gețing children \\ to sleep. \\ Sir,-M B. Moss and Alison \\ Locke (May 5) Wighlight the rea] \\ anguish of parents whose broken \\ nights interfere with their daytime \\ functioning. The problem is all too \\ functioning. The problem is all too
common. Yel it ultimately comes \\ back to expectations and accept. \\ ance. On the rare occasions when \\ our first child woke at night (once \\ or twice a night, for two of three \\ nights in suecession. when ill or \\ teething), we were exhausted for \\ days afterwards. Our second child \\ as well as going to bed around \\ midnight, woke Irequently every \\ night for his flrst two years. Yet 1 \\ never felt anything resembling the \\ exhaustion I had had with our first. \\ It seems that tiredness comes not \\ from the amounti of time spent \\ awake each night, but from the \\ amount of time spent tense and \\ angry. Learning to see a few ball. \\ hours of wakefulness each night as \\ interludes rather than intrusions \\ made, an immense difference to \\ rie.-Yours, etc. \\ CATHERINE GLUE \\ June 6,1904
}

\section{(12). June 9, 1984 .}

\section{Getting children to sleep}

Sir: - I am amazed and angered by the pure selllessnuss that so many women have dis. played recently regarding the issuc of getting children to sleep. Whi must pomen constantly regard themselves as a service industry th be used and discarded at ofhers convenience? Certainly, children need adequate purenting. love apd shelter, but to devote one's self $2 t$ hours day to one's child(ren) and on the way deny the originil marital relationship of husband and wite by dllowing a chilt to sleep in one's own bed and, in.onr case mentloned, banishing the hus band to a separate bed, sevins it me to be tolally ridiculous. Why are so many women dwereed when their ehildren loive home? Why do so many wromen momplam ot "empiy nest syndrome't One's ro lotionship with one's child(ren) is, 1 belicve. quality not quantmy. $P$ er haps children who connot sliep their mothers were secure. Whole pcople. - Yuurs, atc.

SHARON E IICNTE:H

June $6,198:$ : 
(13), (14)\& (15). June 11, 1984.

\section{Getting children} to sleep

Sir,-Surely, whether a mother allows her child to sleep in her bed is not the deciding factor of how much she cares for ber child. The child is only one member of a unit called a tamily, and the child's needs must be balanced against the rest of the lamily's. If parents cannot sleep with chlldren next to them for fear of squashing them. because they turn and kick too. much, they. should train them to sleep in their own beds. A tired mother cannot give the same care and attention. No employer wants a tired husband. If the parents find they enjoy the child sharing the bed and it strengthens their bond the practice suits the family unit. If there is more than one child another weight bas to be balanced. Each mother copes in the. way that she is able, and the only important oucome is for a child to feel loved and wanted - Yours, etc. R. W. HOSKINS

June $6,1984$.

Sir,-Sacrificing a child's need to the parent's need as $T$. Moon indicates ("The Press," June 7) does not ensure independence in the child. Resulting self-rellance is born out of compliancy rather than "choice. Yes, our culture reinforces and maintains dependency and pas. sivity in women, unnedessarily, as it does independence and power in men. Through feminism, women have come into feeling awarenes with their own unresolved depend. ency needs. Men's liberation movements allow men the realisation that their independence, strength and self-reliance is a facade. Underzeath, men are fragile, vulnerable, "little" and afraid, Surely the parental task is to provide the environment whereby their child's dependency needs are metappropriately, and at the right time, in childhood. Hopefully the child become-adult will be ernotionally mature, independent, yet able to enter an interdependent relation. ship, to differentiate between sexual and sensual needs, to give and receive different types of lover and receive different types of
able to parent.-Yours, etc. CHRISTINE D. ROW. LANDS:

June 7,1084 ;

Sir.-T. E. Moon's letter made me feel very sad., Can she really believe it is healthy to distrust other people? There is no slame in dependency: we are all dependent on each other. I, too, want my daughter to be strong, but 1 see this as more complex than sellsufficiency. My daughter, like me, has parents who have always loved her intersely, but not always in ways appropriate to her. She may, like me, respond inappropriately to becoming a parent herself. If this happens, I want ber, as I did, to have the trust to go to someone. and say. "I am afraid; I feel and say. "I am afraid; I feel fort; I need something I cant name, I only know a need it desperately." The trust to - reach out for help is perhaps the most important thing we can give her. "No man is an island"-no woman eithep,-Ycurs. etc.

$$
\text { CATHERINE GLUE. }
$$

June 7,1904

\section{(18). June 12, 1984.}

Sir,-T. E. Moon's attack upon Catberine Glue's new thinking is society's way of stamping out independence ("The Press," June 7). I give full support to Catherine's idea not to care for and put yourself before others. I hope that parents read my letter before solving their children's sleeping problems with a dose of reasoning Society's rules for bringing up children are wropg and silly. Pro ducts of Euch rubbish are reflected in children's behaviour - for 'instance, a child crying when it is isolated from its mother. A child who does not bave mother standing over it all the time stands a better chance at sleeping than a child who does and cannot face reality. The answer to why a child awakes crying for no apparent physical reason is also related to mother dependency. The unconscious reason for this is that the child comes to a point in the dream where his mother is not there. - Yours, etc., G. N. SMITH.

June $10,1984$.
(16)\& 17). June 12, 1984

\section{Getting children to sleep}

- Bir, - Cartstine D. Rowlands and Calberine Glue have now written anmber of letters implying that children who aleep through the vilght in their :own bods orow on -rith all corts of emotional prob kems. Where is the evidence? SayIng It bappens is hardly enough I lept through the night as a child in son own bed and as an edult I am emotionally mature, Independent. yet able to eater an interdependent relationship, to differentiate be tween serual and sensual needs to give and recelve different types of love, etc "I cannot uoderatand why Tamily bed idvocates are zo dog." matic Their way he the only way for everyone They toem to be Utre erusading ctiristan: : 100ting" for converts. Thelr attltude that they only are good pareats is offensive It's about time they ceased to see this Issue In terms of blect and white and realined there are. grey arens. - Yours, etc,

T. MOON.

June.11, 1984

Sir; - tharoa E Ituater; refer. ring to hull-time mothering as service industry" and denial of the marital relationship, misses the point Marriage is never static condition, and need not be as restrictive as Sharon Runter would like. A couple who bave chosen to produce a baby find - whatever kind of parents they are - that their marriage is radically changed. Some struggle to maintain it as it was before the child's birth, but this is neither possible - for the parents nor desirable for the chlld. An infant is intensely dependent and has complex needs: parents who come to terms with this reality can allow their relationship to grow and develop, and include their child. Children are not a disruptive by-product of marriage: they can be sccepted as a fulfilment of the relationship and a shared joy for both partners. Yours, etc.

$$
\text { CATHERINE GLUE. }
$$

. June 9, 1984. 
(19)\& (20). June 13, 1984.

\section{Getting children to sleep}

Sir,-Sharon Hunter (June 9) is critical of mothers who share their beds with their children. I wonder whether she personally knows any? To many of us, meeting the nighttime needis of our children is just part of the reality of 24 -hour parenting. Indeed, it takes "secure and whole people," as she puts it. to not feel threatened by the idea of giving to our children in this way. Parents who try to understand and meet the needs of their chiloren do not feel "used and discarded." They see, as the years go by, what a valuable investment selfless loving is. They can bappily release their children to adulthood withyut the pain of the "empty nest syndrorne," knowing they have done the best possible job in helping the next generation to wards security and wholeness. By the way, most family beds are very large and husband and wife usually sleep together like anyone else. Yours, etc.

ROSE ISDALE

June 9,1984 .

Sir,-For the harrased parents who are trying to get children to sleep: an old remedy is to make a pillow of hops. It seems that the aroma has a pacifying effect on young and old alike. Try it. Yours, etc
E. BROOKES, Hawarden.

June 11,1984 .

\section{(21) \& (22). June 14, 1984.}

\section{Getting children} . to sleep

Sir, - My original objection was to prople in positions of authority stating that leaving children to cry is an acceptable solution to "slecp problems." This is like saying that If is acceptable to hit or ridicule chldren. All these are understand. able reactions by trustrated and desperate parents - they are not desirable "techniques." A baby can. not comprehend that his mother loves him - or cven that she exists - if she is not within reach of his physical senses. Curiously, one correspondent sees it as "banishment" respondent sees it as "banishment"
when a grown man sleeps, alone, when a grown man sleeps, alone, choice in the malter, slees alone. The child's parents are his only resource. I believe meeting a child's urgent needs leads to more stable adults: I know from my own experience that it leads to more relaxed childen and parents. Yours, etc.

CATIERTNE GLUE

June 12,1984 .

Sir.-As a competent father who once won a nap-changing contest on Plunket night, I wish to submit that to induce children to sleep, four basic rules apply; deal with hunger. discomforl (dirty naps), need for security, or teething problems. The first three are all controllable, teething is a cookie. controllable, teething is a cookie snack. Iresh dry naps. a hottie maybe a rock in the cradle or a cuddle from mum Teething roster is called for, mum on ton. days Hednesdays and Fridays and days, indmesclas and dad on Tuesdays, Thursdays and Saturdays. Sundays. toss up. A selt adjusted problem corrected by pas. sage of time. - Yours. etc.

W. JACKSON

(23)\& $\& 4)$. June $16,1984$. June 12. 1984

\section{Getting children to sleep}

Sir, - In reply to $\mathrm{T}$. Moon (June 12), the issue is bow a child comes to sleep through the night in its own bed, and the "family bed" controversy is only one aspect. The point $I$ have consistently developed in this debate, is that the parental task is the recognition, acceptance and meeting of their child's dependency beeds, whatever they are-appropriately, individually and at the right time; in childhood. We are, perhaps, discussing parenting styles. Fundamental to my style, developed with parenting experience and my own emotional growth, is the blend of my intellectual aim to be a loving, caring, responsible parent, with my emotonal capacity. I am not judging. I do not profess to be "good." I reiterate however, that he child, especially in infancy, is in a fragile state, and adults needs ideally should be delayed while meeting the more immediate needs of the child. - Yours, etc., CHRISTI
LANDS.

June $12,1984$.

Sir, - Rose Isdale would now have us believe that doing the best possible job as parents consists only of baving your children in your bed. How easy. No having to deal with temper tantrums as infants. Do not hear their reading. or help them with their maths. As for the teen-age years that should be really good. I suppose kioss who have slept in their parent's beds do not get acne or painiful menstrua. tion, do not have emotional difficulties or problems adjusting to sexuality. As parents we all face these problems and deal with them as best we can. Most of us deal with them better after a good night's sleep and are better parents when we and our children sleep at night in our own beds. - Yours, etc,

T. E. MOON. 
Article in the Listener magazine, oct 13-19, 1984. (pp. 23-24).

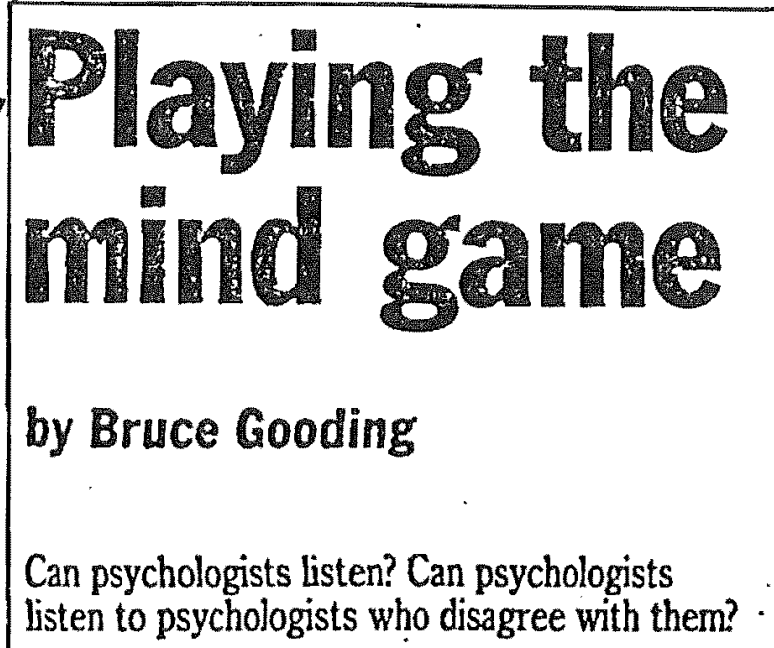

F YOLR BABY perxistenty make (1) Ind ones through the night, John 3 tirllund is one of the peaple you Finght ask for help. The Palneerston clini tor ming habies in his home Thu wame city has been hosing a coly. enct at per

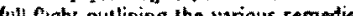
atulabit to parenis who are plagued by

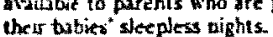

$H_{t}$ is intempied: "Excuse me. Why do $y$ ou label the behavioural approsich as "Let "an ar"?"

hithlind responds" "I behere it is ercurate to call that option let "em a)....

The questioner doesn't think so: "I

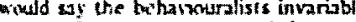
use reinulatenkent. a revard for non cring behaviour, as well as extinction."

Exturcton hay wound derpente wothtion to the probiems created by cring bubs. Hoxever, in psjuchological proan. "extinitinn" siniply means takine moxion and hetting the baby cry till it stops Sn this is no lite-ordeath matter, However, real struggle is laking place here.

Sone 300 psychologists tave gath end to this conierence that happens in then five days show there are the players in this mund game than the are ply ers in the mund gar the thal be havinur cas be modifed aith "appropri to reinforement". and the iamily torapists, who hold that betause most of us are dependent an bur lanules, then the lunity - not pist the indusidual malut be ireaied.

There are. for example, the psythr stishols, Futudins anong them, and a Frwis raptidy ganing populanty - the foric coitsellus who probe the Fakeup of the whole perean, including hos or her that Trivision in the ranks was endent at the conference - heightened ay the organisers' tendency to divide the

into sestions on the teore of deology as much as illness.

Many psjchologists widened the solite by attending only those secuions that concurred anth their garticular line One bolistic counseltor, asked naively it he hed eniayed the betavioural proly it he had first day betavioural paperk on the wouldn't ouged uprosriously: "You would yrag me in thete, mate." Afler - It illy therapy seminar, torace of betamouralists who bad strayed into the cposition camp temed most unhappy. "Fo "ing lanily therapists" bad one, "1 just gel so pissed of that there's no outcome dats presented with all the religinsity."

Most of the 300 osychologists here will mever offer theis advice to the comm nitnity at Large. More than three-quar. lers of them work in chools, prisons or psychiatric institutions or ate academuct in universities. But during the five days they will be presented with at koast 130 papers. Subjects include child stosse, unemplnyment, industry training plue sniffing and even video sames. Hut buck is ming babies...

The behaviourabists have their answer. You can solve the aying buby problem. You can solve the crying baby mobiem. Canterbury University's kevin Moesbergen reponed results from a New Zealand trial of "extunction plus reinforcenten". he says that in one trial the sleeping problems of all 22 children wete solved when they were left to ery and rewarded with stars on charts for those nights that they did sleep through. The success rale for a funter 22 children given reiniorce. ment alune was bla per cent.

But if farrily therapy advocates were a! that seszion, none asked Mnesbergen if be tad monitored the chituren to see it

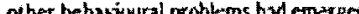

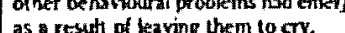
as a resuh of laving them to cry. And if the behaviouralists atiended the Karkland session there as ondy that lowe interiector, Other theories abost cyins 231

latken - auch as the merits or pittalita o the "give in" appresch where distrester chidren are allowed into the parenta ted, of the conlention that crying babies air stuch with their problems for genetic icacons - were not debated.

Sirange, since various contributors at cenderence sessions acknowledged that it was of crucial importance that we find out how best to treat ming ctuldren. because disturbed children often becorne

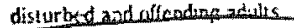




\section{Many babies have sleep problems}

About 40 per cent of babies have sleep prob. lems at some stage, says a Christchurch researcher, Miss Carolyn Lawton.

That often means months of long broken nights and short tempers for parents.

Some become desperate gays Miss Lawton, who runs the University of Canterbury psychology department's sleep programme.

It is natural for babies to wake, especially up to the age of four months.

IIt: becomes a problem when the presence of parents becomes necessary for the child to get back to sleep," she says.

It also becomes a prob. lem when parents become so tired they cannot function and provide the best cate'lor their children.

Miss Lawton sidesteps the present controversy surrounding children's sleeping habits.

That's not what the programme is concerned with she says. "We don't wanl to say what is right or wrong.

"Rather it is helping parents who want their child to sleep through the night on their own."

Miss Lawton says children can learn to sleep to a particular pattern.

She has dealt with about 15 children aged from six months to two years since

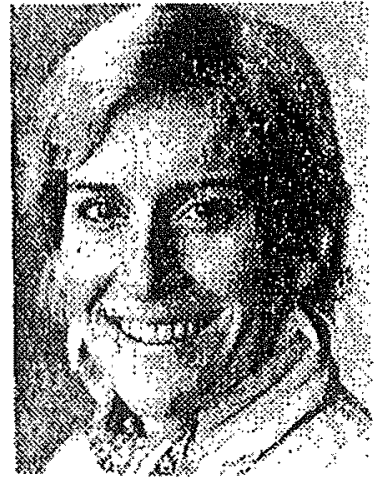

Carolyn Lawton... natural for babies to wake.

she became involved in the programme at the end of last year.

"It has worked in every case and parents. report they are very happy with results," she says.

The programme run by her predecessor, Ms Karen France, had also been successful in every case where parents had not deviated from instructions.

As well as providing a clinical service for parents, the sleep programme is Miss Lawton's masters thesis project.

Parents have to keep a diary of their child's sleeping habits for six to eight weeks after an individual plan has been devised for them.

The sleep pattern tends to stabilise after a month, Miss Lawton says.
She keeps a close'eye on participants by getting regular progress reports over the telephone.

Miss Lawton is reluctant to give too many details because she isays parents should not:! try to do the programme on their own.

This gives + parents the techniques and support so they can withdraw and no longer be an integral part of the child'sisleep cycle; she says.

It also heips parents develop some sort of routine in day-time and night-time sleep.

"The child learns what is expected."

Miss Lawton says children do not learn how to sleep on their own if they regularly sleep with their parents. So when they are no longer allowed in the parental bed they are likely to wake during the night.

Parents who have completed the programme often report that their relationship with their child has improved once the child is able to sleep through the night, Miss Lawton says.

"The grizzly child becomes happler and easier to manage."

The programme will be taking another 20 to 30 children with sleep problems, and their parents in "a couple of tmonths," she says. 


\section{RESEARCH CONSENT FORM}

\section{Dear Parents,}

Thank you for taking part in our research project. Infant sleep disturbance is very common and often of concern to parents, but there is very little research about ways of managing it. The sleep research currently being undertaken in the Psychology Department aims to develop new ways and improve existing methods of managing infant sleep disturbance. The ultimate aim is to inform people such as doctors, plunket nurses and psychologists about our findings. These people can then pass on the information to parents. The part of the study you have been asked to join aims to evaluate a behaviour management programme. We will be trying to find out whether a gradual reduction of the amount of time parents spend with their child when he/she wakes is effective in eliminating infant sleep problems and establishing a regular sleep pattern.

You will be given as much help in managing your child's sleep problem as possible. Throughout the study we will maintain close contact with you by telephone or visit. You will be involved for approximately three months with some follow-up afterwards.

In order to help us do good research you are asked to read the following statements describing your part in the study and sign in the space below.

(a) I/we have read and understood the description of the research project above.

(b) I/we agree to continue filling in the record sheets throughout the study.

(c) I/we agree to carry out management instructions carefully.

Parent/s signatures:

Thank you again for taking part. Please do not hesitate to make contact if you have any questions or problems.

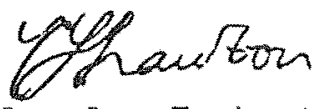

Carolyn F. Lawton

Principal Researcher

482-009, ext. 737 or 8678

(Res) $485-715$.

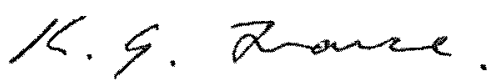

Karyn G. France

Associate Researcher

(Res) $496-906$

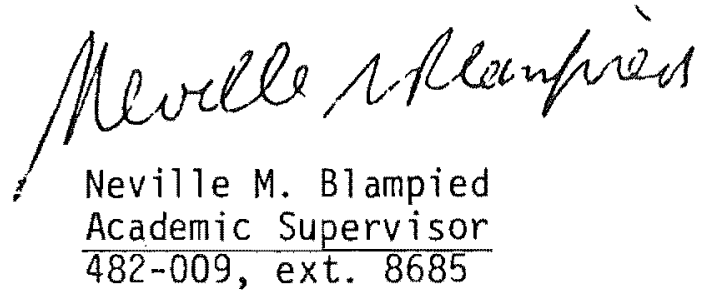


Dear Doctor

Parent(s) of (D.O.B.)

have agreed to our notifying you that they are at present taking part in a research programme offering behaviour mamangement advice, to help with sleep disturbance in infants and preschoolers.

Should you require any more information, please feel free to ring us.

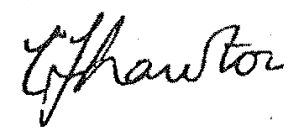

Carolyn F. Lawton, B.Sc.,

Principal Researcher

University $482-009$, ext. 8678 or 737.

Residence 485-715.

$$
\text { 1.5. Prance }
$$

Karyn G. France, M.A. Dip.Clin.Psych. Associate Researcher

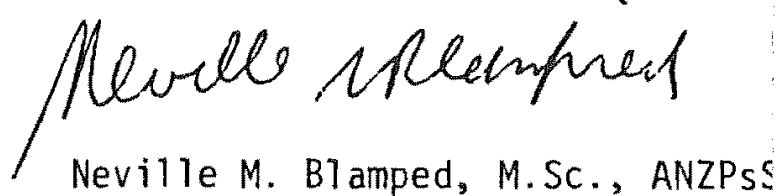
Academic Supervisor University 482-009, ext.8685.

(Signed)

Parent(s) consent/do not consent to notify Dr 
APPENDIX F

DAILY SLEEP DIARY

Data Sheets : Information

1. Record one day down each column. Record nightwakings as they occur if possible. Finish recording each morning for the previous day and night. Please be as accurate as possible.

2. Day Sleep. Record the time the child is placed down; the time he/she wakes for each of 1 or 2 sleeps. Also record where the child sleeps, whether away from home or in the car etc.

3. Night Sleep

(a) Record if at home or out. State actual bed-time and the ideal bed-time for that night. Explain if ideal time is later than goal time, or actual bed-time later than ideal. For example, bed-time is likely to be late if you went out as a family or had visitors.

(b) Record the time the child takes from being placed in bed till he/she is silent and describe the quality of noise in that time i.e. chatting, singing, crying.

(c) Record number of times awake during the night, the duration and what you did for each waking. Since there is 1 imited space on the record sheet, indicate what you did when the child woke with letters under "Key" - e.g. N.C. = nappy change, or $B=$ bottle.

4. Record the time the child wakes in the morning. 


\section{Daily sleep Diary: Weekly Recording sheet}

Child's Name:

Week:

Condition:

Goal Bed-time

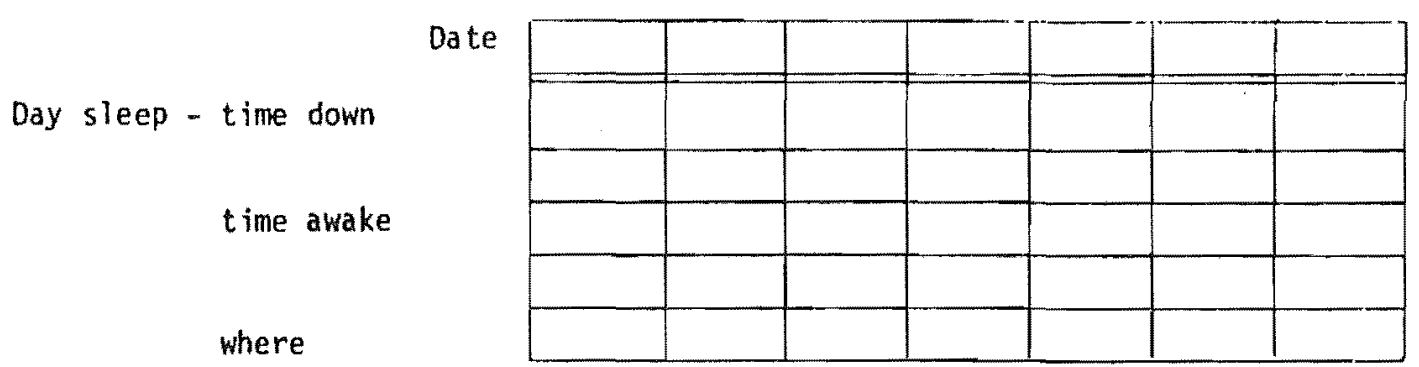

Night sleep - where

Actual bed-time

Ideal bed-time

Explain if necessary

Time from in bed to silence Describe noise

No. of times awake

Approx, duration

What did you do

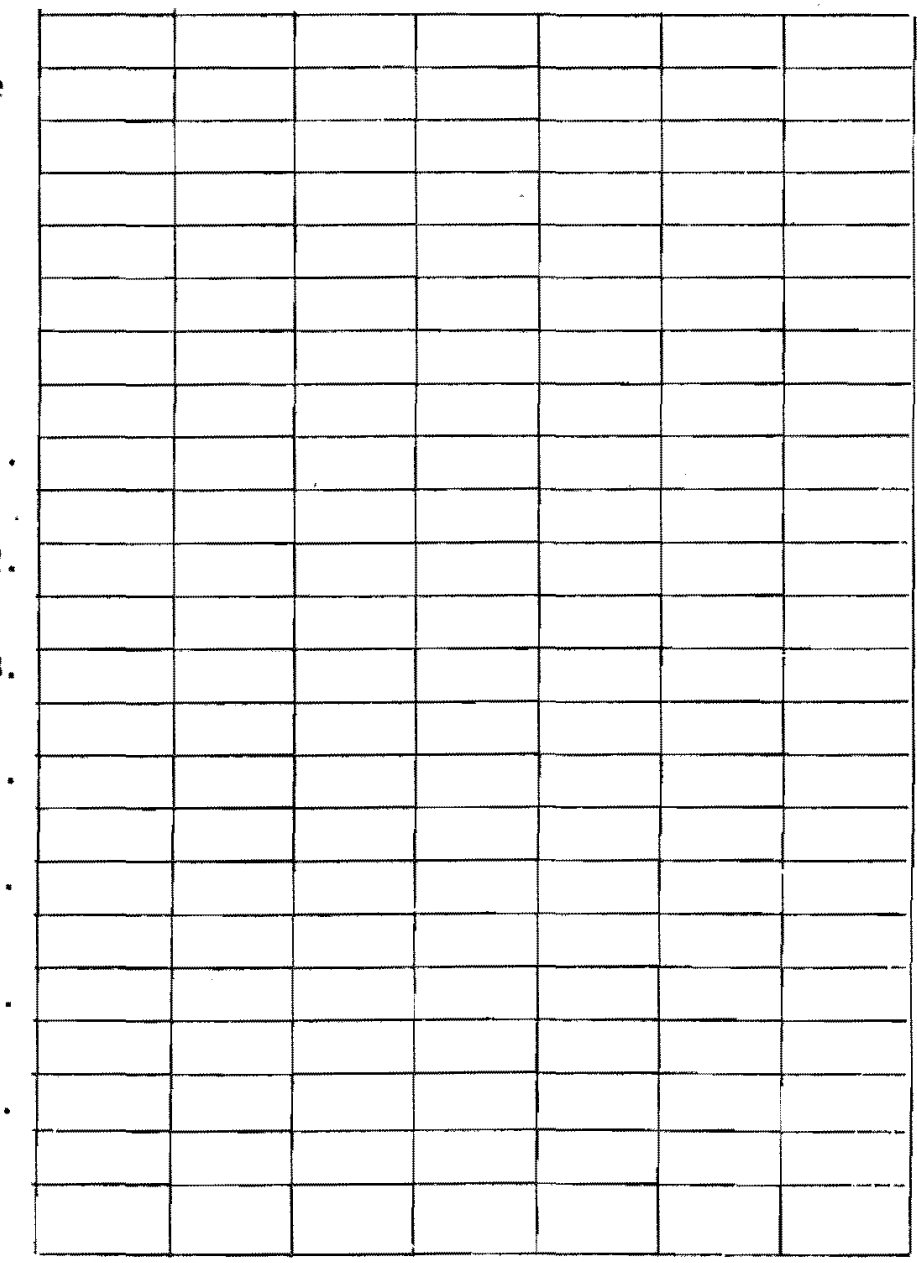

Time Awake In Morning 


\section{WEEKLY SLEEP BEHAVIOUR SCALE}

There are six items below, each of which is scored from 0 to 4. Calculate the score on each item for each week of data, collected on the Daily Sleep Diary. Sum the six scores for each week to give the composite sleep behaviour score.

(1) A Mean time in bed to silence per week (sleep onset latency).

\begin{tabular}{rccccc} 
Score & 0 & 1 & 2 & 3 & 4 \\
\cline { 2 - 6 } Minutes & $0-5$ & $6-15$ & $16-30$ & $31-45$ & $46+$
\end{tabular}

B Mean difference between actual and ideal bedtimes per week (bedtime delay)

\begin{tabular}{rccccc} 
Score & 0 & 1 & 2 & 3 & 4 \\
\cline { 2 - 5 } & $0-30$ & $31-60$ & $61-90$ & $91-120$ & $120+$
\end{tabular}

Score only $1 \mathrm{~A}$ or $1 \mathrm{~B}$ - whichever has the highest value.

(2) Number of nights in which waking occurred per week.

No. of nights \begin{tabular}{rrrrrr} 
Score & 0 & 1 & 2 & 3 & 4 \\
\cline { 2 - 6 } & 0 & $1+2$ & $3+4$ & $5+6$ & 7
\end{tabular}

(3) Mean number of times waking per night per week

Wakings per night \begin{tabular}{llcccc} 
Score & 0 & 1 & 2 & 3 & 4 \\
\cline { 3 - 7 } & 0 & $1+2$ & $3+4$ & $5+6$ & 7
\end{tabular}

(4) Mean time awake per waking per night per week

\begin{tabular}{rccccc} 
Score & 0 & 1 & 2 & 3 & 4 \\
\cline { 2 - 6 } Minutes & $0-2$ & $3-20$ & $21-40$ & $41-60$ & $61+$
\end{tabular}

(5) Mean total time slept per day per week

\begin{tabular}{lccccc} 
Score & 0 & 1 & 2 & 3 & 4 \\
\cline { 2 - 6 } & $12+$ & $11-12$ & $10-11$ & $9-10$ & 8 or less
\end{tabular}

(6) Time slept in parents' bed per week

\begin{tabular}{cccc} 
Score & 0 & \multicolumn{1}{c}{1} & \multicolumn{1}{c}{2} \\
\cline { 2 - 3 } Nil & $\begin{array}{l}\text { During waking } \\
\text { only. Put } \\
\text { back to own } \\
\text { bed from }\end{array}$ & $\begin{array}{l}\text { Child stayed } \\
\text { in parents bed } \\
\text { parents' bed }\end{array}$ & waking \\
&
\end{tabular}

\begin{tabular}{ll}
$\frac{3}{\text { From first night }}$ & \multicolumn{1}{c}{ Parent lies down with } \\
waking for remainder & child till s/he \\
of night & settles. In parents' \\
& bed from first night \\
& waking
\end{tabular}




\section{APPENDIX H}

\section{"DEVIATION FROM IDEAL" SCALE}

Scoring instructions. Total the scores obtained for each behaviour each day, to derive the composite daily "Deviation from ideal" score.

\begin{tabular}{lll}
\hline INFANT SLEEP BEHAVIOUR & "Ideal" $=0$ "Not-ideal" $=1$ \\
\hline $\begin{array}{l}\text { Sleep onset latency } \\
\text { (time from placement in } \\
\text { bed to silence) }\end{array}$ & $0-5$ minutes & $6+$ minutes \\
$\begin{array}{l}\text { Bedtime delay } \\
\text { (actual bedtime - ideal } \\
\text { bedtime) }\end{array}$ & $\leq 30$ minutes & $\geq 31$ minutes \\
$\begin{array}{l}\text { Sleep/wake state when } \\
\text { placed in bed at } \\
\text { bedtime }\end{array}$ & Awake & Asleep \\
$\begin{array}{l}\text { Number of wakings } \\
\text { Duration of wakings }\end{array}$ & 0 & $\geq 1$ \\
Location of sleep & In own bed & In parents' bed \\
\hline
\end{tabular}

Note: It is impossible to be scored "not-ideal" for both sleep onset latency and sleep/wake state, since the two categories are mutually exclusive. 
APPENDIX I

STRUCTURED INTERVIEW

SLEEP PROGRAMME

structured Interview Format

Eamily Surnare:

Adaress:
Date of Initial Interview:

Telephone:

Fanily doctor consulted Yes/No

Data of referral:

Referzal from:

Household Composition

Adults

Name

Age

Race

Occupation

Children

Significant others - re child minding

Child having sleep problem

date of bitth

Actual Bedtime

" Settling tine

" Getting up time

\section{Ileal Bedtime}

* settling time

" Getting up time

Average night wakings over whole of sleep time

Daytime sleep? Yes/No.

Actual tines

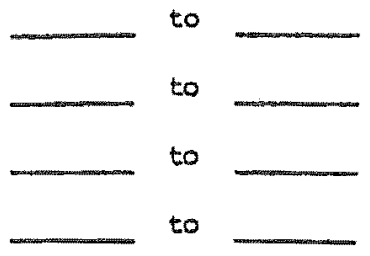


2.

Describe Nature of sleeping Probl

Age at onset

Continuous/Intermittent

Clear Brecipitating Event

Yas/No

Describe

Describe Child's development thus fax:

Pregnancy

Birth

Feeding

Activity

crying

Sleeping pre 3 months

Medical history

Birth order $1,2,3$ or subsequent

sleeps Alone / not alone

Describe

Eamily Life Events over Child's Life

other problems

Describe child: present/absent

Family: present/absent 
3.

What is done now to handle the child's problem?

What has been done in the past?

Advice received from:

or plunket

Mother/in law

Friends

other

Describe

Is Medication used now

Xes/No

Describe

Has Medication been used in the past

yes/No

Describe 
APPENDIX J

PHOTOGRAPH OF RELIABILITY APPARATUS

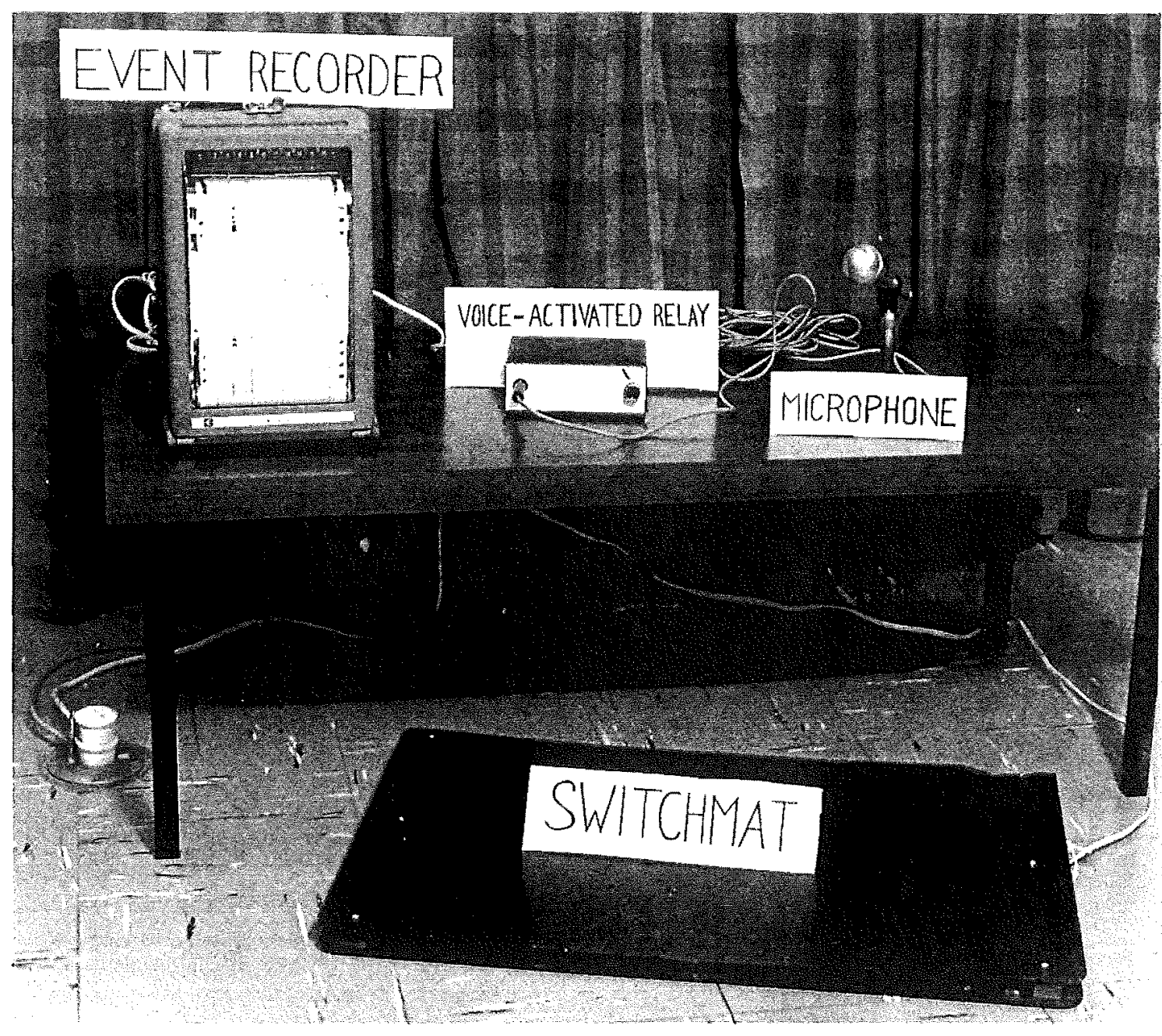




\section{CRITERIA FOR TRANSCRIBING THE EVENT}

RECORD TO NUMERICAL VALUES

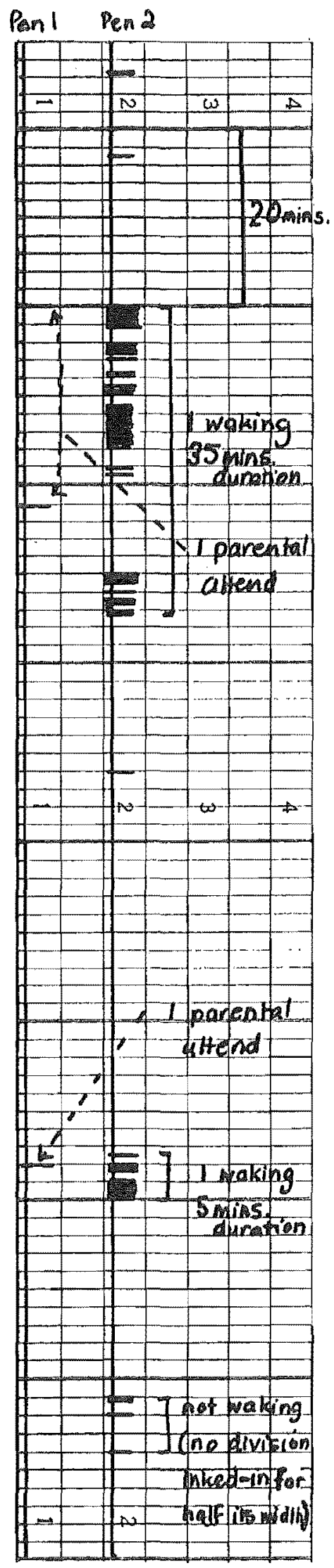

(1) Calculate the time by measuring the distance on the event record from the time the parents started the recorder. Each division on the chart paper (Esterline Angus Type 1710x) represents two minutes, since the paper travelled at $7.6 \mathrm{~cm}$ per hour.

(2) Score a waking if there is a mark on the channel connected to the voice-activated relay (Pen 2), so long as that mark is inked-in for at least half a division.

(3) Do not score another waking until there are at least seven-and-a-half divisions that are blank between wakings. In other words, there must be fifteen minutes of silence before further crying constitutes a 'new' waking rather than the same one.

(4) Measure the duration of waking by counting the divisions inked-in or those marked by numerous pen excursions.

(5) Score a parental attend each time there is a mark on the output from the channel connected to the switchmat (Pen 1), unless there are two parental attends that occur during the same waking. Score these as a single attend. This situation may arise when parents pick up their child and then replace it during one waking. 
APPENDIX L

PROTOCOL

\section{THE SLEEP PROGRAMME}

The Sleep Programme provides you with a systematic method of establishing and maintaining a regular sleep pattern in your child. It is designed to help you help your child learn to go to sleep alone.

The programme helps you teach your child, by suggesting ways of developing a regular night-time routine and for gradualiy reducing the amount of time you spend with your child when he/she wakes.

For you to get the most benefit from the programme it is important that you follow the instructions closely and consistently. Just because you are on the programme it does not mean that your child will not cry or wake at night. We have found that it is of ten when you feel as though the prgramme is not working, that your child is learning the most so even when you feel frustrated it is important to carry on with the programme exactly as detailed. If you do become concerned or have any problems please do not hesitate to contact me anytime.

Work : 482-009, extension.737. Residence : 485-715.

Over page are detailed instructions that will help you understand how the programme works and explain exactly what to do.

I shall keep in regular contact with you by telephone throughout the programme. I wish you the best over the next few months.

Yours sincerely,

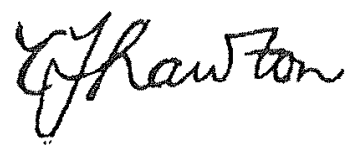

Carolyn Lawton 


\section{THE SLEEP PROGRAMME. INSTRUCTIONS}

\section{STEP 1 Before Bed}

We have found that a regular night-time routine is important. Your child can learn when it is bed-time once he/she knows the set night-time pattern. It helps to feed, bathe and play with your child at the same time every night.

For example: 5.30p.m. Dinner

$$
\begin{aligned}
& 5.50 p . m . \text { Bath } \\
& 6.00-6.30 p . m . \text { Stories and quiet play } \\
& 6.30 \quad \text { Goodnight }+ \text { bedtime }
\end{aligned}
$$

Write your own routine below:

It is a good idea to attend to all your child's needs such as attention, cuddling, food and so on in the living area. Only go into the bedroom at bedtime.

\section{STEP 2 Putting your child to bed}

(a) You have selected p.m. as your child's bedtime. It is important to be as regular as possible, so that your child can learn when he/she is expected to go to sleep.

(b) As already mentioned, it is important to keep activities other than sleeping out of the bedroom. They should be done in the living area. If any activities such as drinking, feeding, playing currently occur in the bedroom you will need to move them to the living area when you start the programme.

(c) It is important that you put your child into bed awake. $\mathrm{He} / \mathrm{she}$ needs to learn to fall asleep without your presence, on his/her own. If you breastfeed your child it is important to get $\mathrm{him} / \mathrm{her}$ stirring before putting him/her down.

STEP 3 Teaching your child to setle and sleep all night

Children do wake at night. When they wake you are not with them. It is important that they learn to go back to sleep on their own. The programme is intended to help you teach your child to settle or go back to sleep without demanding your presence. Your child has come to expect your attention before he/she falls asleep. He/she has learned that if he/she cries you will respond and settle him/her back to sleep. 
In order to teach your child to go to sleep alone, it is important for you to gradually and consistently reduce the amount of time you spend with your child.

Since your started recording your child's sleep pattern you have spent an average of minutes or less, settling your child after each waking. During this time you usually try the following methods of soothing your child:

If you have been taking your child into your own bed it will be necessary to stop doing so as soon as you start the programme. Settle your child in his/her own room instead.

Over the next 28 days you will gradually cut down the amount of time you spend settling your child. You decrease your average time of every 4 days. minutes, by minutes

Day $1-4$
Day $5-9$
Day $10-14$
Day $15=19$
Day $20-24$
Day $24-28$
minutes minutes minutes minutes minutes minutes

You will find that in order to stick to the time limit for a particular day, you may have toleave your child before he/she is fully asleep. It is important that you do this and do not return to the room until he/she has been asleep for at least 10 minutes. As attention time gets shorter there is a greater chance that you will have to leave before he/she is asleep. Eventually you will reach the stage when you no longer go into your child's room when he/she wakes. It is important that you stick to this as in the long run it is the only way your child will learn to sleep alone.

STEP 4 In the morning

A regular getting up time is important. We have found that it is helpful to decide on a time before which you do not wish your child to wake up or get out of bed. Write down the earliest time you consider acceptable for your child to wake - If your child wakes before this time, treat it as a night-waking. Once your child wakes (as long as it is after your chosen time) get him/her up straight away so that he/she learns that it is morning, when it is $0 . k$. to wake. This helps your child to recognise the difference between night time and day time rules. 
4.

\section{SLEEP PROGRAMME}

After your agreed night time ritual is completed, place

in bed at . If does not settle immediately or wakes during the night, attend to him/her for the amount of time specified below. Remember, do not exceed the time set out for each day. If does not go to sleep during the time specified, leave the room. Do not attend again until he/she has been asleep for at least ten minutes.
Day 1-4: minutes
Day 5-9: minutes
Day 10-14 : minutes
Day 15 - 19 : minutes
Day 20-24 : minutes
Day $24-28$ : minutes 


\section{APPENDIX M}

\section{MAINTENANCE INSTRUCTIONS}

\section{Dear}

Thank you for taking part in the sleep study. By this stage, you will have completed more than eight weeks' recording since starting the programe.

At this point parents often ask how to maintain the gains their child has made or wonder how to respond when their child wakes in the future.

I suggest that, from now on, you check............. when wakes and attend to... needs if necessary. If there is no reason for waking or no action is required, immediately leave the room. Should you notice an increase in waking again, particularly after a disruption such as an illness, an outing, or a holiday, it may be necessary to return to the sleep Programe for a few nights.

I have enclosed another set of questionnaires, identical to those you completed earlier. Also included is a short questionnaire asking for your corments, criticisms and feelings about the programe. It is very useful for me to know what you thought of the programme and especially what aspects you consider need improvement. In about two months' time, I am hoping to send you one week's Sleep Diary to fill out. It is important for me to establish whether the gains your child made during the programe are maintained. So I would greatly appreciate your help with this. If I can, I will ring you at this time.

Also enclosed is a large, stamped/addressed envelope. Could you please use it to send all questionnaires and data sheets back to me. Here is a checklist of the material required:-

(1) set of four questionnaires completed during the programme

(2) all sleep record sheets kept during programme and beforehand

(3) final four questionnaires (enclosed)

(4) programme evaluation questionnaire.

Please do not hesitate to contact me if necessary.

Best wishes for the future,

Yours sincerely, 


\section{APPENDIX N}

\section{SLEEP PROGRAIME EVALUATION RUESTIONNAIRE}

Please help us improve the sleep programme by answering some questions about the services you have received at the University of Canterbury. Please answer all of the questions. We are interested in your honest opinions, whether positive or negative. We also welcome your comments and suggestions. Thank you very much, we greatly appreciate your help.

CIRCLE YOUR ANSWER

1. How would you rate the quality of help you received?

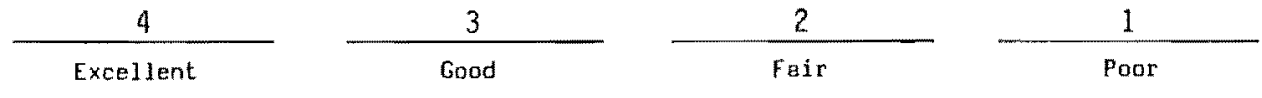

2. Did you get the kind of help (or service) you wanted?

$\frac{1}{\text { No, derinitely not }} \frac{2}{\text { No, not really }} \quad \frac{3}{\text { Yes, generally }} \quad \frac{4}{\text { Yes, definitely }}$

3. To what extent has the Sleep Programe met your needs?

\section{4 \\ Almost all of my}

needs have been met

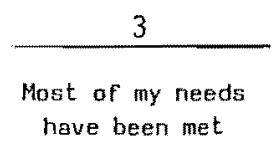

$$
2
$$

Dnly a few of my needs have been met

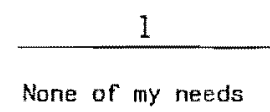

have been met

4. If a friend were in need of similar help, would you recommend the programme to him/her?

$\frac{1}{\text { No, definitely not }} \frac{2}{\text { No, I don't think so }} \frac{3}{\text { Yes, I think so }} \frac{4}{\text { Yes, definitely }}$

5. How satisfied are you with the amount of help you received?

$\frac{1}{\text { Quite dissatisfied }} \frac{2}{\begin{array}{c}\text { Indifferent or } \\ \text { mildiy dissatisfied }\end{array}} \quad \frac{3}{\text { Mostly satisfied }} \quad \frac{4}{\text { Very satisfied }}$


6. Have the services you received helped you to deal more effectively with other difficult child behaviour?

$\begin{array}{cccc}4 & 3 & 2 & 1 \\ \begin{array}{c}\text { Yes, they helped } \\ \text { me a great deal }\end{array} & \begin{array}{c}\text { Yes, they helped } \\ \text { somewhat }\end{array} & \begin{array}{c}\text { No, they really } \\ \text { didn't help }\end{array} & \begin{array}{c}\text { No, they aeerned to } \\ \text { make things worke }\end{array}\end{array}$

7. In an overall, general sense how satisfied are you with the service you received?

$\frac{4}{\text { Very satisfied }} \frac{3}{\text { Mostly satisfied }} \frac{2}{\begin{array}{c}\text { Indirferent or } \\ \text { mildly satisfied }\end{array}} \frac{1}{\text { Quite satisfied }}$

8. If your child had sleeping difficulties again, would you come back to the programme?

$\frac{1}{\text { No, definitely not }} \frac{2}{\text { No, I don't think so }} \frac{3}{\text { Yes, I think so }} \frac{4}{\text { Yes, definitely }}$

9. How stressful did you find the programme?

$\frac{1}{\text { Very stressful }} \frac{2}{\text { Moderately stressful }} \frac{3}{\text { Somewhat stressful }} \frac{4}{\text { Non-stressful }}$

COULO YOU PLEASE COMMENT ON THE FOLLOWING ASPECTS OF THE PROGRAMIIE:-

1) The instruction sheet explaining the programme procedure. (e.g. was it logical, ambiguous, hard or easy to follow, confusing, etc.)

2) The method of teaching your child to sleep alone by gradually reducing the amount of attention given.

(e.g. was it too slow, too difficult to follow, seemed rational, etc.) 
3) The telephone support given by the therapist.

(e.g. was it too frequent, not of ten enough, helpful or not, etc.)

4) Keeping daily records of sleep pattern. (e.g. was it tedious, usefut, etc.)

5) Any other criticisms or comments.

Note: The above questionnaire is an adaptation of the Client Satisfaction Questionnaire, CSQ( Larsen, Attkisson, Hargreaves and Nguyen, 1979). The first eight items come from that source. The ninth item and the five open-ended questions were appended for the purposes of this study. 
Data for Subjects 2 and 8 were unavailable for inclusion in the analysis of the intervention procedures used in this study. Although both subjects completed intervention, their daily sleep behaviour records for all of the treatment phase were lost due to unforeseen circumstances.

subject 2's parents separated just before the end of intervention. When the time came to return the data, Subject 2 's mother could not find it. She did, however, complete the FISS and STAI at maintenance and returned these. Besides the records from the investigator's progress telephone calls these questionnaires are the only data available for subject 2 .

Subject 8 's parents moved house following the completion of intervention and although the parents claimed to have return-mailed their Daily sleep Diary record sheets, these failed to arrive.

Follow-up data were not available for subjects 2,8 and 9. The parents of these subjects failed to complete and return the required week's worth of recording on the Daily sleep Diary, despite telephone calls reminding them to do so.

During the course of the programme a number of parents failed to record data at one time or another. For example, subject 5 's parents did not record their child's sleep behaviour for the week following their instruction in graduated extinction, because their child became ill. They resumed recording on the day that they considered him well enough to begin to implement graduated extinction. Likewise, subject 7 's parents did not record data for four days when they were away at a conference, leaving their daughter behind. Subject $11^{\prime}$ 's parents failed to keep records for 10 days whilst on holiday.

Data collected for the purpose of assessing the clinical significance of behaviour changes and acceptability of the treatment techniques were also incomplete. A number 
of parents, mostly fathers, failed to complete the STAI on each of the three occasions. It was unclear whether these parents misunderstood the research requirements, or whether they failed to complete these questionnaires for other reasons. One parent, subject 6's father, declined to fill out the SPEQ. 


\section{RAW DATA}

$\begin{array}{ll}\text { KEY: D.S } & \text { Length of Day sleep in decimal hours } \\ \text { N.S } & \text { Length of Night Sleep in decimal hours } \\ \text { TOTAL } & \text { Total time asleep in 24-hour period } \\ \text { W/N } & \text { Number of wakings } \\ \text { DW } & \text { Duration of wakings (minutes) } \\ \text { SOL } & \text { Sleep onset latency (minutes) } \\ \text { BD } & \text { Bedtime delay (minutes) }\end{array}$

SUBJECT 1 : RAW DATA

DAY D.S N.S TOTAL W/N DW SOL BD

$\begin{array}{llllllll}1 & 3.0 & 10.7 & 13.7 & 1 & 20 & 7 & 17\end{array}$

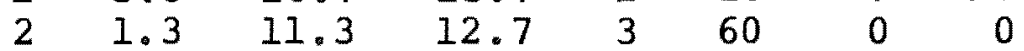

$\begin{array}{llllllll}3 & 1.9 & 10.8 & 12.7 & 2 & 50 & 60 & 0\end{array}$

$\begin{array}{llllllll}4 & 2.5 & 11.4 & 13.9 & 3 & 70 & 0 & 0\end{array}$

$\begin{array}{llllllll}5 & 1.5 & 9.8 & 11.3 & 1 & 90 & 0 & 30\end{array}$

$\begin{array}{llllllll}6 & 2.8 & 11.4 & 14.2 & 2 & 61 & 30 & 0\end{array}$

$\begin{array}{llllllll}7 & 1.3 & 10.0 & 11.2 & 1 & 90 & 1 & 0\end{array}$

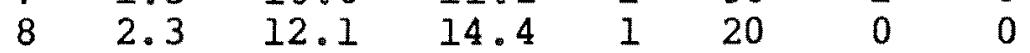

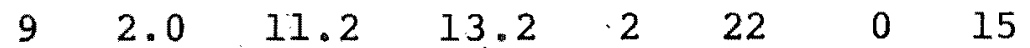

$\begin{array}{llllllll}10 & 1.9 & 12.0 & 13.9 & 2 & 30 & 0 & 0\end{array}$

$\begin{array}{llllllll}11 & 2.0 & 11.1 & 13.1 & 1 & 30 & 0 & 0\end{array}$

$\begin{array}{llllllll}12 & 1.8 & 11.7 & 13.4 & 3 & 31 & 0 & 0\end{array}$

$\begin{array}{llllllll}13 & 2.2 & 10.7 & 12.9 & 0 & 0 & 0 & 0\end{array}$

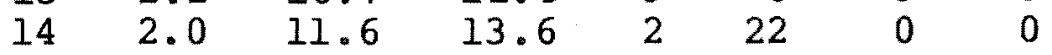

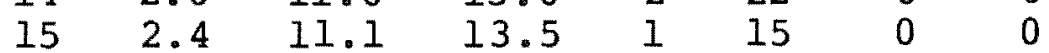

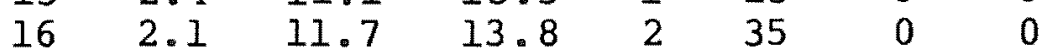

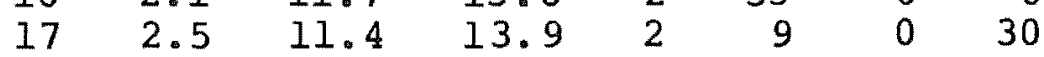

$\begin{array}{llllllll}18 & 2.6 & 11.8 & 14.4 & 3 & 40 & 0 & 0\end{array}$

$\begin{array}{llllllll}19 & 2.3 & 11.1 & 13.4 & 1 & 9 & 0 & 0\end{array}$

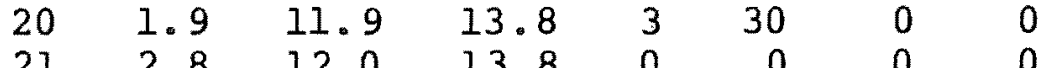

$\begin{array}{rrrrrrrr}21 & 2.8 & 12.0 & 13.8 & 0 & 0 & 0 & 0 \\ 22 & 2.7 & 11.7 & 14.4 & 4 & 23 & 0 & 0\end{array}$

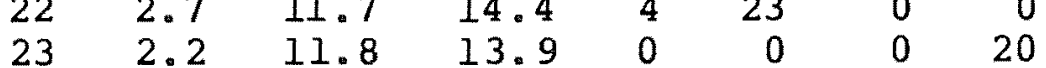

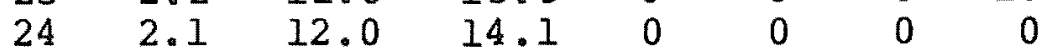

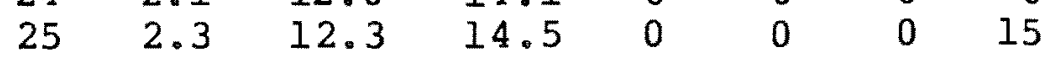

$\begin{array}{llllllll}26 & 0.8 & 10.8 & 11.6 & 4 & 36 & 0 & 5\end{array}$

$\begin{array}{llllllll}27 & 4.0 & 11.4 & 15.4 & 3 & 17 & 10 & 25\end{array}$

$\begin{array}{llllllll}28 & 2.5 & 11.5 & 14.0 & 2 & 18 & 15 & 15\end{array}$

$\begin{array}{llllllll}29 & 2.8 & 11.6 & 14.3 & 2 & 10 & 5 & 10\end{array}$

$\begin{array}{llllllll}30 & 3.0 & 12.0 & 15.0 & 1 & 4 & 2 & 0\end{array}$

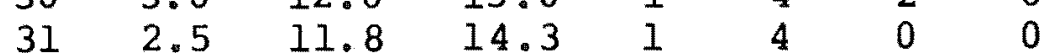

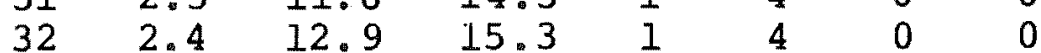

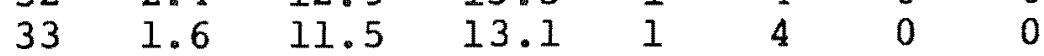

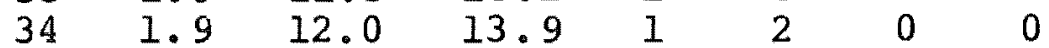

$\begin{array}{llllllll}35 & 1.7 & 12.0 & 13.7 & 1 & 1 & 0 & 0\end{array}$

$\begin{array}{llllllll}36 & 2.5 & 11.9 & 14.4 & 2 & 4 & 0 & 0\end{array}$

$\begin{array}{llllllll}37 & 3.3 & 11.5 & 14.7 & 2 & 6 & 0 & 15\end{array}$

$\begin{array}{llllllll}38 & 3.3 & 11.3 & 14.6 & 0 & 0 & 0 & 30\end{array}$

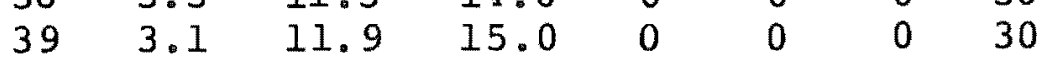

$\begin{array}{rrrrrrr}40 & 1.8 & 12.6 & 14.3 & 0 & 0 & 0\end{array}$

$\begin{array}{llllllll}41 & 3.4 & 13.5 & 16.9 & 0 & 0 & 0 & 0\end{array}$

$\begin{array}{llllllll}42 & 1.3 & 11.4 & 12.7 & 1 & 60 & 0 & 0\end{array}$

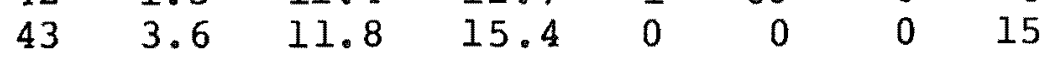


SUBJECT 1 ctd.

$\begin{array}{rrrrrrrr}44 & 2.0 & 12.7 & 14.7 & 0 & 0 & 5 & 0 \\ 45 & 2.0 & 11.0 & 13.0 & 0 & 0 & 20 & 10 \\ 46 & 3.9 & 10.3 & 14.3 & 1 & 30 & 45 & 45 \\ 47 & 1.9 & 12.2 & 14.1 & 0 & 0 & 0 & 0 \\ 48 & 3.5 & 12.3 & 15.8 & 0 & 0 & 0 & 0 \\ 49 & 3.3 & 10.2 & 13.5 & 0 & 0 & 0 & 0 \\ 50 & 1.3 & 12.2 & 13.5 & 0 & 0 & 0 & 0 \\ 51 & 3.3 & 12.1 & 15.3 & 0 & 0 & 2 & 0 \\ 52 & 1.9 & 10.8 & 12.7 & 0 & 0 & 0 & 0 \\ 53 & 2.0 & 11.1 & 13.1 & 0 & 0 & 10 & 10 \\ 54 & 2.6 & 11.1 & 13.7 & 0 & 0 & 0 & 0 \\ 55 & 1.6 & 12.0 & 13.6 & 0 & 0 & 0 & 0 \\ 56 & 3.4 & 10.8 & 14.2 & 0 & 0 & 0 & 0 \\ 57 & 3.3 & 11.8 & 15.2 & 0 & 0 & 15 & 0 \\ 58 & 2.3 & 12.1 & 14.4 & 0 & 0 & 0 & 0\end{array}$


SUBJECT $3:$ RAW DATA

DAY D.S N.S TOTAL W/N DW SOL BD

$\begin{array}{llllllll}1 & 2.0 & 11.3 & 13.3 & 3 & 105 & 0 & 1\end{array}$

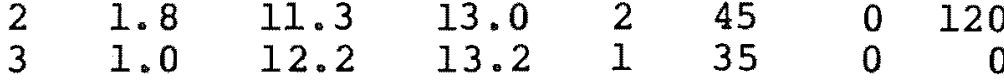

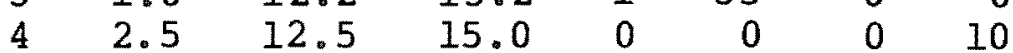

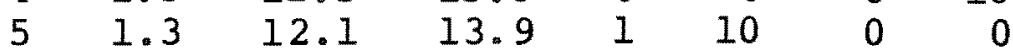

$\begin{array}{llllllll}6 & 1.9 & 10.8 & 12.8 & 3 & 35 & 0 & 0\end{array}$

$\begin{array}{llllllll}7 & 3.8 & 11.3 & 15.1 & 1 & 10 & 0 & 45\end{array}$

$\begin{array}{llllllll}8 & 2.8 & 11.5 & 14.3 & 0 & 0 & 0 & 0\end{array}$

$\begin{array}{lllllllr}9 & 2.8 & 12.3 & 15.0 & 0 & 0 & 0 & 0\end{array}$

$\begin{array}{rrrrrrrr}10 & 4.3 & 9.8 & 14.1 & 0 & 0 & 0 & 130\end{array}$

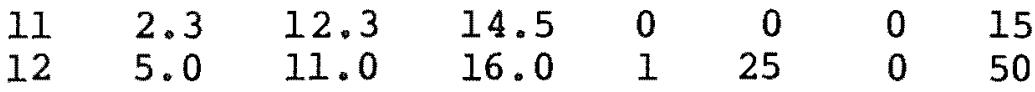

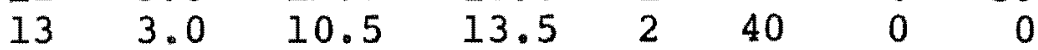

$\begin{array}{llllllll}14 & 3.7 & 11.1 & 14.8 & 2 & 50 & 0 & 15\end{array}$

$\begin{array}{llllllll}15 & 4.6 & 11.2 & 15.8 & 2 & 80 & 0 & 0\end{array}$

$\begin{array}{llllllll}16 & 3.5 & 10.8 & 14.3 & 4 & 130 & 0 & 30\end{array}$

$\begin{array}{llllllll}17 & 3.0 & 10.3 & 13.3 & 2 & 60 & 0 & 45\end{array}$

$\begin{array}{llllllll}18 & 4.3 & 12.5 & 16.8 & 1 & 60 & 0 & 0\end{array}$

$\begin{array}{llllllll}19 & 2.8 & 10.2 & 12.9 & 3 & 95 & 0 & 30\end{array}$

$\begin{array}{llllllll}20 & 3.0 & 10.8 & 13.8 & 3 & 110 & 0 & 0\end{array}$

$\begin{array}{llllllll}21 & 3.4 & 8.5 & 11.9 & 2 & 150 & 0 & 15\end{array}$

$\begin{array}{llllllll}22 & 2.8 & 11.3 & 14.1 & 3 & 70 & 0 & 30\end{array}$

$\begin{array}{llllllll}23 & 2.0 & 10.8 & 12.8 & 3 & 90 & 0 & 90\end{array}$

$\begin{array}{llllllll}24 & 2.8 & 11.3 & 14.1 & 3 & 70 & 0 & 30\end{array}$

$\begin{array}{llllllll}25 & 2.0 & 10.8 & 12.8 & 3 & 90 & 0 & 15\end{array}$

$\begin{array}{llllllll}26 & 2.9 & 10.3 & 13.2 & 2 & 15 & 0 & 75\end{array}$

$\begin{array}{llllllll}27 & 2.5 & 11.6 & 14.1 & 3 & 35 & 0 & 0\end{array}$

$\begin{array}{llllllll}28 & 1.8 & 12.0 & 13.8 & 3 & 35 & 0 & 15\end{array}$

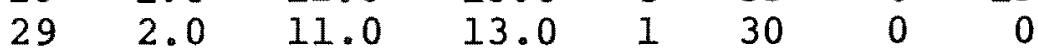

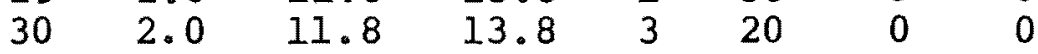

$\begin{array}{llllllll}31 & 2.0 & 12.2 & 14.2 & 2 & 10 & 0 & 0\end{array}$

$\begin{array}{llllllll}32 & 2.0 & 11.5 & 13.5 & 0 & 0 & 0 & 0\end{array}$

$\begin{array}{rrrrrrrr}33 & 5.0 & 11.5 & 16.5 & 3 & 22 & 0 & 0 \\ 34 & 1.8 & 11.1 & 13.0 & 2 & 22 & 0 & 10\end{array}$

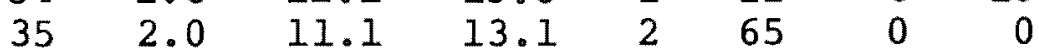

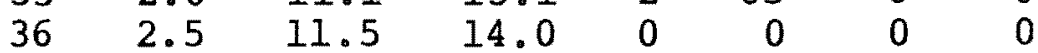

$\begin{array}{llllllll}37 & 3.5 & 11.8 & 15.3 & 0 & 0 & 0 & 15\end{array}$

$\begin{array}{llllllll}38 & 2.5 & 11.3 & 13.8 & 0 & 0 & 0 & 20\end{array}$

$\begin{array}{llllllll}39 & 4.0 & 11.8 & 15.8 & 0 & 0 & 0 & 0\end{array}$

$\begin{array}{llllllll}40 & 2.5 & 11.1 & 13.6 & 0 & 0 & 0 & 0\end{array}$

$\begin{array}{llllllll}41 & 4.5 & 10.8 & 15.3 & 1 & 30 & 0 & 10\end{array}$

$\begin{array}{llllllll}42 & 4.5 & 12.0 & 16.5 & 0 & 0 & 0 & 0 \\ 43 & 4.3 & 12.1 & 16.4 & 0 & 0 & 0 & 0\end{array}$

$\begin{array}{llllllll}44 & 2.5 & 11.5 & 14.0 & 0 & 0 & 0 & 30\end{array}$

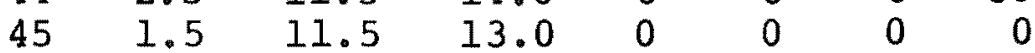

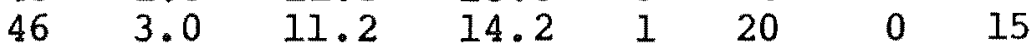

$\begin{array}{llllllll}47 & 2.5 & 11.3 & 13.8 & 0 & 0 & 0 & 0\end{array}$

$\begin{array}{llllllll}48 & 3.0 & 9.6 & 12.6 & 1 & 90 & 0 & 5\end{array}$

$\begin{array}{llllllll}49 & 3.0 & 11.2 & 14.2 & 0 & 0 & 0 & 0\end{array}$

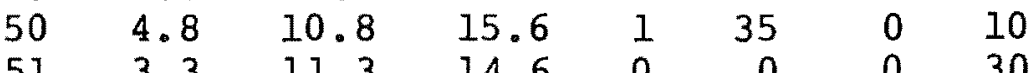

$\begin{array}{rrrrrrrr}51 & 3.3 & 11.3 & 14.6 & 0 & 0 & 0 & 30 \\ 52 & 1.7 & 11.2 & 12.8 & 0 & 0 & 0 & 0\end{array}$

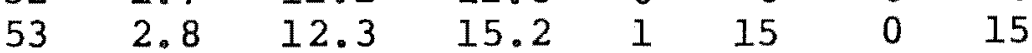

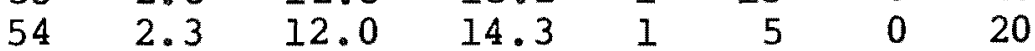

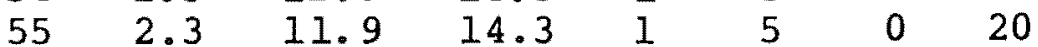

$\begin{array}{llllllll}56 & 3.0 & 11.5 & 14.5 & 1 & 10 & 0 & 30\end{array}$

$\begin{array}{rrrrrrrr}57 & 1.0 & 9.3 & 10.3 & 2 & 135 & 0 & 0 \\ 58 & 3.3 & 11.5 & 14.8 & 0 & 0 & 0 & 30\end{array}$ 
SUBJECT 3 ctd.

$\begin{array}{rrrrrrrr}59 & 3.0 & 12.1 & 15.1 & 1 & 5 & 0 & 30 \\ 60 & 3.0 & 12.4 & 15.4 & 2 & 20 & 0 & 5 \\ 61 & 2.7 & 12.4 & 15.1 & 2 & 9 & 0 & 20 \\ 62 & 2.3 & 12.2 & 14.5 & 0 & 0 & 0 & 0 \\ 63 & 2.0 & 11.8 & 13.8 & 0 & 0 & 0 & 15 \\ 64 & 2.3 & 11.6 & 13.6 & 0 & 0 & 0 & 15 \\ 65 & 3.3 & 11.3 & 14.6 & 0 & 0 & 0 & 60 \\ 66 & 1.3 & 12.6 & 13.6 & 2 & 10 & 0 & 0 \\ 67 & 1.3 & 10.9 & 12.2 & 0 & 0 & 0 & 45 \\ 68 & 3.0 & 11.9 & 15.7 & 1 & 5 & 0 & 15 \\ 69 & 3.0 & 11.8 & 14.8 & 0 & 0 & 0 & 30 \\ 70 & 2.2 & 11.7 & 13.8 & 0 & 0 & 0 & 30 \\ 71 & 3.0 & 12.6 & 15.6 & 1 & 2 & 0 & 15 \\ 72 & 2.8 & 10.9 & 13.8 & 0 & 0 & 0 & 0 \\ 73 & 3.0 & 12.9 & 15.9 & 1 & 5 & 0 & 0 \\ 74 & 3.3 & 11.1 & 14.4 & 0 & 0 & 0 & 75 \\ 75 & 2.7 & 10.3 & 12.9 & 0 & 0 & 90 & 0 \\ 76 & 2.5 & 11.3 & 13.8 & 2 & 7 & 15 & 30 \\ 77 & 2.3 & 15.8 & 13.2 & 0 & 0 & 0 & 60 \\ 78 & 3.0 & 11.7 & 14.7 & 0 & 0 & 15 & 15 \\ 79 & 3.5 & 12.1 & 15.6 & 4 & 12 & 0 & 30 \\ 80 & 2.7 & 9.9 & 12.6 & 1 & 90 & 60 & 15 \\ 81 & 3.3 & 10.7 & 13.9 & 0 & 0 & 0 & 60 \\ 82 & 2.3 & 12.2 & 14.4 & 0 & 0 & 0 & 20\end{array}$


SUBJECT 4: RAW DATA

DAY D.S N.S TOTAL W/N DW SOL BD

$\begin{array}{llllllll}1 & 1.8 & 9.1 & 10.8 & 3 & 130 & 0 & 15\end{array}$

$\begin{array}{llllllll}2 & 1.3 & 8.3 & 9.6 & 3 & 120 & 0 & 90\end{array}$

$\begin{array}{llllllll}3 & 1.3 & 9.2 & 10.5 & 1 & 20 & 0 & 70\end{array}$

$\begin{array}{llllllll}4 & 1.9 & 9.8 & 11.8 & 1 & 85 & 0 & 15\end{array}$

$\begin{array}{llllllll}5 & 3.0 & 8.6 & 11.6 & 1 & 55 & 0 & 75\end{array}$

$\begin{array}{rrrrrrrr}6 & .9 & 8.9 & 9.8 & 1 & 80 & 0 & 15 \\ 7 & 2.1 & 8.7 & 10.8 & 3 & 75 & 50 & 75\end{array}$

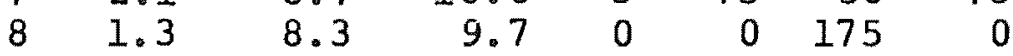

$\begin{array}{llllllll}9 & 2.4 & 9.9 & 12.3 & 1 & 35 & 15 & 90\end{array}$

$\begin{array}{llllllll}10 & 2.3 & 8.3 & 10.6 & 1 & 100 & 30 & 75\end{array}$

$\begin{array}{llllllll}11 & 4.1 & 6.9 & 11.0 & 0 & 0 & 95 & 90\end{array}$

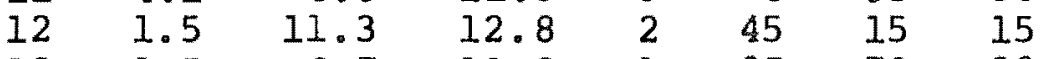

$\begin{array}{llllllll}13 & 1.5 & 9.7 & 11.2 & 1 & 25 & 70 & 30\end{array}$

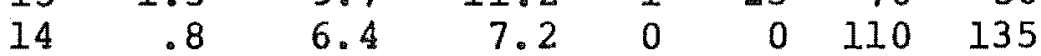

$\begin{array}{rrrrrrrr}15 & 1.0 & 9.8 & 10.8 & 1 & 40 & 60 & 60\end{array}$

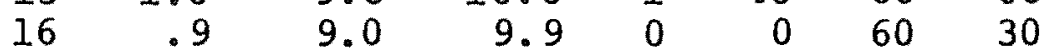

$\begin{array}{llllllll}17 & 2.8 & 8.0 & 10.8 & 3 & 60 & 0 & 90\end{array}$

$\begin{array}{llllllll}18 & 2.0 & 8.8 & 10.8 & 1 & 15 & 0 & 90\end{array}$

$\begin{array}{llllllll}19 & 2.3 & 10.6 & 12.8 & 1 & 20 & 10 & 115\end{array}$

$\begin{array}{llllllll}20 & .3 & 8.4 & 8.7 & 1 & 95 & 50 & 40\end{array}$

$\begin{array}{llllllll}21 & 1.9 & 8.9 & 10.8 & 1 & 45 & 45 & 65\end{array}$

$\begin{array}{llllllll}22 & 8.0 & 9.7 & 10.5 & 3 & 55 & 68 & 0\end{array}$

$\begin{array}{rrrrrrrr}23 & 1.3 & 7.7 & 8.9 & 2 & 75 & 80 & 75\end{array}$

$\begin{array}{llllllll}24 & 2.8 & 8.9 & 11.7 & 1 & 110 & 0 & 45\end{array}$

$\begin{array}{llllllll}25 & 1.0 & 10.4 & 11.4 & 2 & 80 & 0 & 0\end{array}$

$\begin{array}{llllllll}26 & .8 & 9.6 & 10.3 & 2 & 25 & 0 & 105\end{array}$

$\begin{array}{llllllll}27 & .6 & 10.0 & 10.6 & 2 & 30 & 0 & 60\end{array}$

$\begin{array}{llllllll}28 & 2.5 & 9.0 & 11.5 & 1 & 35 & 65 & 0\end{array}$

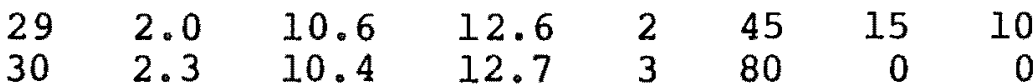

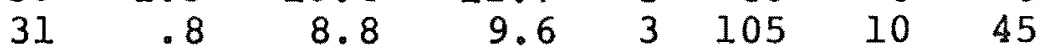

$\begin{array}{llllllll}32 & 2.1 & 9.4 & 11.5 & 2 & 45 & 0 & 30\end{array}$

$\begin{array}{llllllll}33 & .4 & 9.5 & 9.9 & 1 & 10 & 0 & 45\end{array}$

$\begin{array}{llllllll}34 & 1.9 & 9.8 & 11.6 & 1 & 15 & 0 & 45\end{array}$

$\begin{array}{llllllll}35 & 2.0 & 9.7 & 11.7 & 2 & 100 & 0 & 10\end{array}$

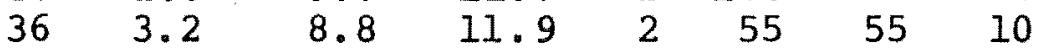

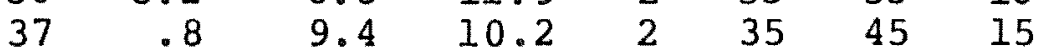

$\begin{array}{rrrrrrrr}38 & .8 & 10.5 & 11.3 & 1 & 15 & 10 & 0\end{array}$

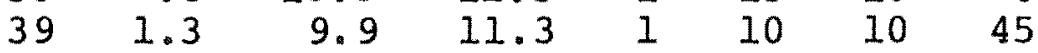

$\begin{array}{llllllll}40 & 2.8 & 8.8 & 11.6 & 1 & 15 & 10 & 45\end{array}$

$\begin{array}{llllllll}41 & 1.2 & 10.4 & 11.6 & 1 & 25 & 0 & 10\end{array}$

$\begin{array}{llllllll}42 & 2.3 & 9.0 & 11.3 & 2 & 100 & 0 & 10\end{array}$

$\begin{array}{llllllll}43 & 2.0 & 11.5 & 13.5 & 1 & 15 & 0 & 0\end{array}$

$\begin{array}{llllllll}44 & 2.2 & 10.3 & 12.4 & 1 & 45 & 25 & 20\end{array}$

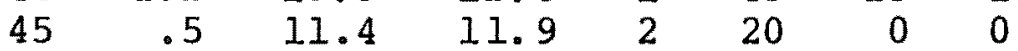

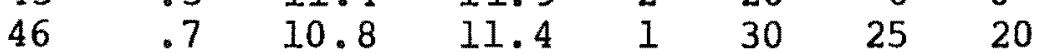

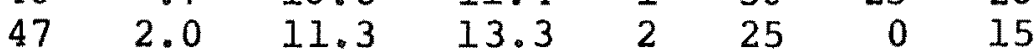

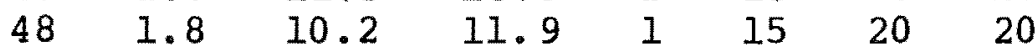

$\begin{array}{llllllll}49 & 2.0 & 11.5 & 13.5 & 1 & 15 & 0 & 0\end{array}$

$\begin{array}{llllllll}50 & 2.3 & 9.7 & 11.9 & 1 & 20 & 0 & 90\end{array}$

$\begin{array}{llllllll}51 & .8 & 9.5 & 10.3 & 1 & 30 & 0 & 0\end{array}$

$\begin{array}{llllllll}52 & 1.3 & 11.1 & 12.3 & 1 & 10 & 0 & 0\end{array}$

$\begin{array}{llllllll}53 & .5 & 12.3 & 12.8 & 1 & 15 & 0 & 0\end{array}$

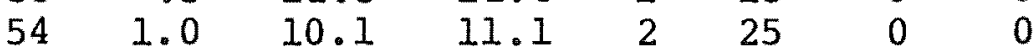

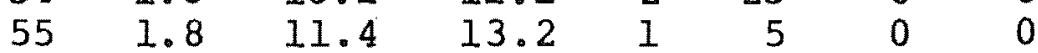

$\begin{array}{llllllll}59 & 1.5 & 10.0 & 11.5 & 0 & 0 & 0 & 15\end{array}$

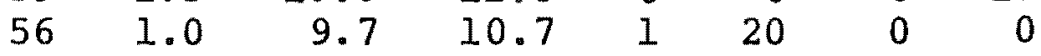

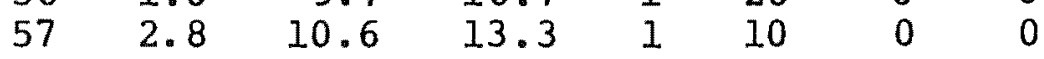

$\begin{array}{llllllll}58 & 1.3 & 9.8 & 11.0 & 1 & 20 & 0 & 0\end{array}$ 
SUBJECT 4 ctd.

$\begin{array}{rrrrrrrr}59 & 1.5 & 10.0 & 11.5 & 0 & 0 & 0 & 15 \\ 60 & 2.0 & 10.5 & 12.5 & 1 & 0 & 0 & 60 \\ 61 & 2.9 & 10.9 & 13.8 & 2 & 20 & 0 & 45 \\ 62 & 2.5 & 9.8 & 12.3 & 1 & 15 & 45 & 30 \\ 63 & 1.5 & 10.2 & 11.7 & 1 & 5 & 0 & 30 \\ 64 & 2.5 & 9.5 & 12.0 & 1 & 15 & 0 & 60 \\ 65 & 1.6 & 11.3 & 12.9 & 2 & 40 & 0 & 0 \\ 66 & 1.0 & 10.8 & 11.8 & 2 & 15 & 0 & 0 \\ 67 & 2.5 & 10.1 & 12.6 & 1 & 15 & 0 & 0 \\ 68 & 2.0 & 8.6 & 10.6 & 1 & 105 & 0 & 0 \\ 69 & 2.5 & 9.8 & 12.3 & 1 & 10 & 0 & 30 \\ 70 & 2.0 & 10.2 & 12.2 & 1 & 2 & 0 & 15 \\ 71 & 2.0 & 10.5 & 12.5 & 1 & 10 & 0 & 10 \\ 72 & 1.3 & 11.1 & 12.4 & 3 & 50 & 0 & 15 \\ 73 & .8 & 9.9 & 10.7 & 1 & 15 & 0 & 15 \\ 74 & 1.3 & 10.6 & 11.9 & 1 & 2 & 0 & 0 \\ 75 & 1.8 & 10.9 & 12.7 & 0 & 0 & 0 & 0 \\ 76 & 1.8 & 8.5 & 10.2 & 1 & 2 & 45 & 60 \\ 77 & .5 & 11.9 & 12.4 & 2 & 20 & 0 & 0 \\ 78 & 2.0 & 10.3 & 12.3 & 2 & 13 & 0 & 0 \\ 79 & 1.4 & 10.4 & 11.8 & 1 & 10 & 0 & 10 \\ 80 & 1.5 & 10.1 & 11.6 & 4 & 55 & 0 & 0 \\ 81 & 2.4 & 9.7 & 12.1 & 1 & 15 & 40 & 30 \\ 82 & 2.4 & 8.3 & 10.7 & 1 & 20 & 75 & 45 \\ 83 & 3.0 & 10.3 & 13.3 & 1 & 55 & 0 & 0 \\ 84 & 2.0 & 9.8 & 11.9 & 2 & 55 & 35 & 0 \\ 85 & 2.3 & 9.8 & 12.2 & 1 & 85 & 0 & 30 \\ 86 & 2.5 & 9.8 & 12.3 & 0 & 0 & 0 & 30 \\ 87 & .8 & 10.7 & 11.4 & 2 & 20 & 0 & 0 \\ 88 & .3 & 10.2 & 10.5 & 1 & 30 & 0 & 0 \\ 89 & 1.1 & 10.4 & 11.5 & 1 & 2 & 0 & 30 \\ 90 & 1.2 & 9.0 & 10.2 & 2 & 60 & 0 & 10 \\ 91 & 2.3 & 9.8 & 12.0 & 2 & 75 & 0 & 0 \\ 92 & 1.3 & 8.9 & 10.2 & 1 & 10 & 90 & 0 \\ 93 & .8 & 9.6 & 10.3 & 1 & 15 & 0 & 45 \\ 94 & 1.5 & 10.4 & 11.9 & 1 & 20 & 0 & 30 \\ 95 & 2.0 & 10.8 & 12.8 & 0 & 0 & 0 & 0 \\ 96 & 1.4 & 10.3 & 11.8 & 0 & 0 & 0 & 30 \\ 97 & 2.5 & 9.3 & 11.8 & 0 & 0 & 0 & 60 \\ 98 & 1.5 & 9.1 & 10.6 & 1 & 10 & 30 & 45 \\ 99 & .6 & 12.3 & 12.8 & 2 & 15 & 0 & 0 \\ 100 & .8 & 11.9 & 12.8 & 0 & 0 & 0 & 5 \\ 101 & 1.0 & 9.6 & 10.6 & 2 & 25 & 0 & 30 \\ 102 & 1.8 & 11.2 & 12.9 & 0 & 0 & 0 & 0 \\ 103 & 1.3 & 10.8 & 12.0 & 1 & 60 & 0 & 30 \\ 104 & 1.5 & 11.5 & 13.0 & 2 & 30 & 0 & 60 \\ 105 & 1.0 & 11.0 & 12.0 & 1 & 30 & 0 & 0 \\ 108 & 1.2 & 10.1 & 11.3 & 1 & 85 & 0 & 15 \\ & 1.0 & 10.2 & 11.3 & 1 & 75 & 45 & 15 \\ & & & & 1 & 30 & 0 & 20\end{array}$


SUBJECT 5 : RAW DATA

DAY D.S N.S TOTAL W/N DW SOL BD

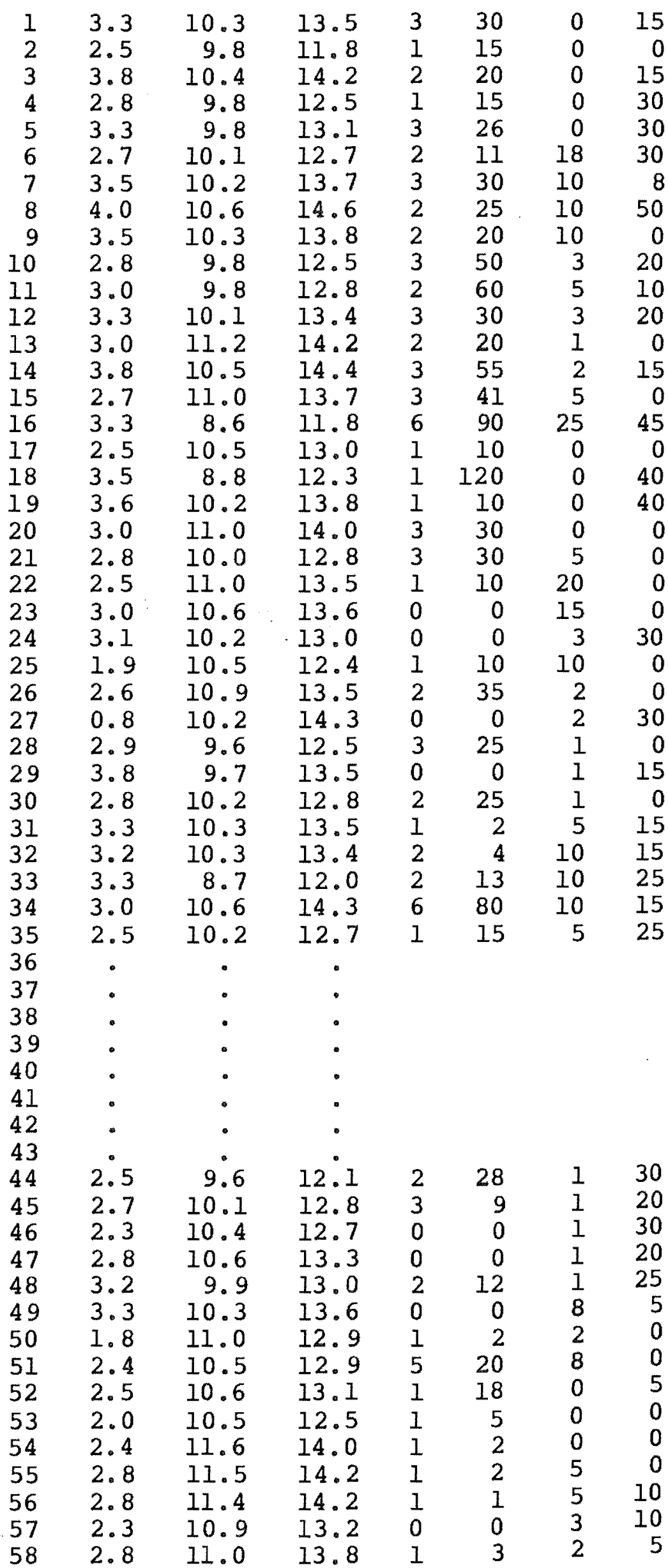


SUBJECT 5 ctd.

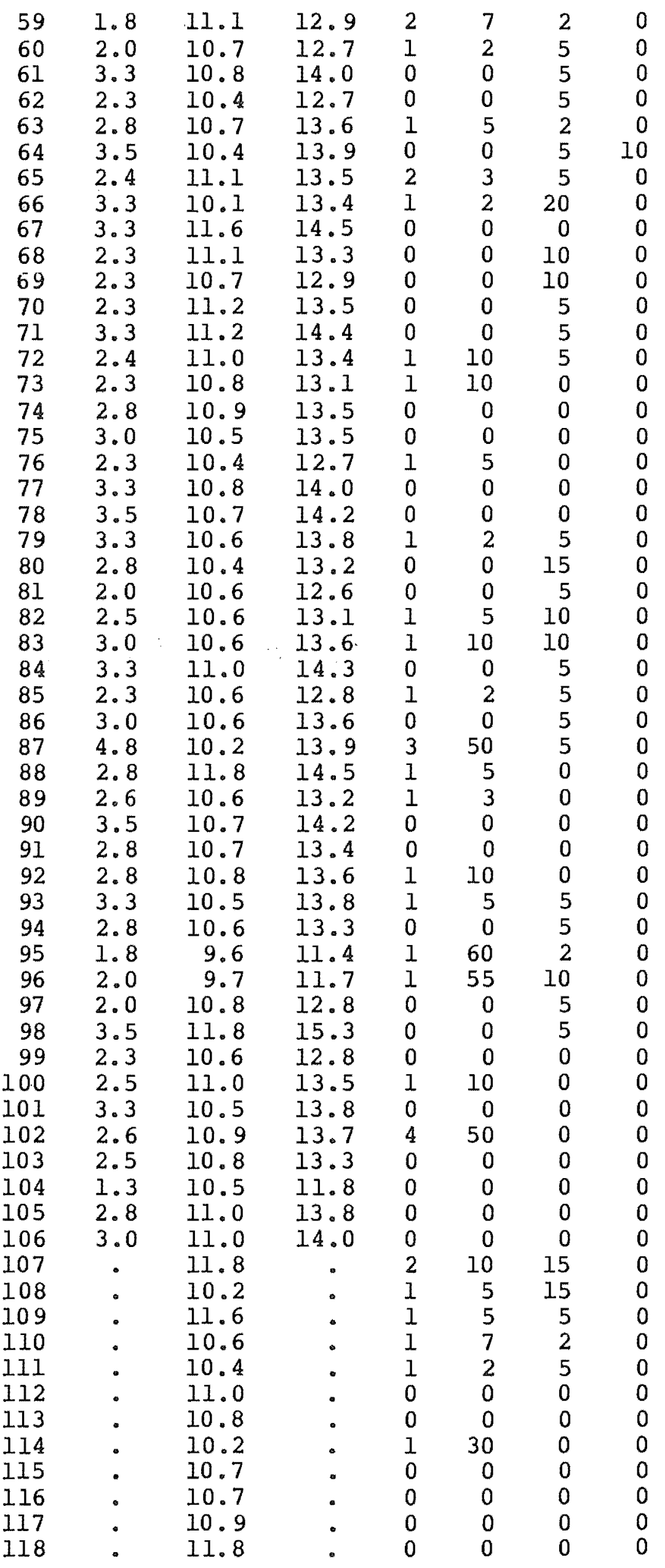


SUBJECT 5 ctd.

$\begin{array}{rccccccc}119 & : & 10.5 & : & 0 & 0 & 0 & 0 \\ 120 & : & 10.7 & : & 0 & 0 & 0 & 0 \\ 121 & : & : & : & 0 & 0 & 0 & 0 \\ 122 & : & : & : & 0 & 0 & 0 & 0 \\ 123 & : & : & : & 0 & 0 & 0 & 0 \\ 124 & : & : & : & 1 & 10 & 0 & 0 \\ 125 & : & : & : & 0 & 0 & 0 & 0 \\ 126 & : & : & : & 0 & 0 & 0 & 0 \\ 127 & : & : & : & 0 & 0 & 0 & 0\end{array}$


SUBJECT $6:$ RAW DATA

DAY D.S N.S TOTAL W/N DW SOL BD

$\begin{array}{llllllll}1 & 2.0 & 11.4 & 13.4 & 3 & 35 & 30 & 30\end{array}$

$\begin{array}{rrrrrrr}2 & 2.5 & 10.6 & 13.1 & 5 & 116 & 0\end{array}$

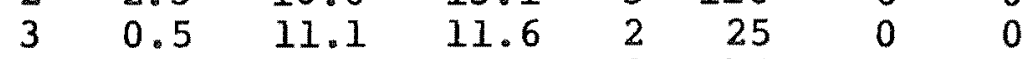

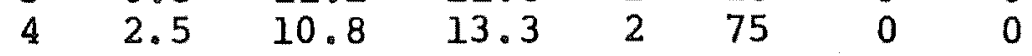

$\begin{array}{llllllll}5 & 2.3 & 11.8 & 14.0 & 2 & 60 & 0 & 0\end{array}$

$\begin{array}{llllllll}6 & 3.0 & 10.7 & 13.7 & 2 & 80 & 5 & 45\end{array}$

$\begin{array}{llllllll}7 & 2.3 & 10.4 & 12.7 & 1 & 25 & 10 & 90\end{array}$

$\begin{array}{llllllll}8 & 1.8 & 10.0 & 11.8 & 0 & 0 & 0 & 90\end{array}$

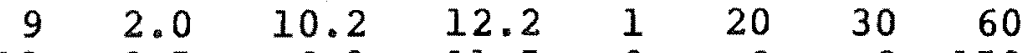

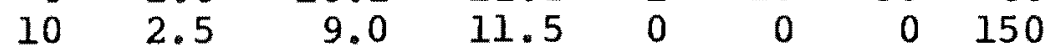

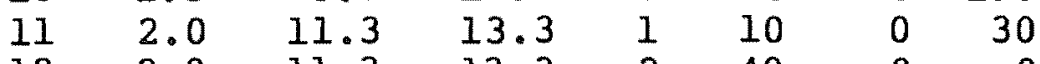

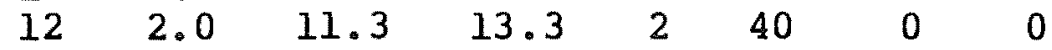

$\begin{array}{llllllll}13 & 2.3 & 10.6 & 12.8 & 2 & 40 & 0 & 75\end{array}$

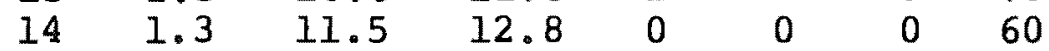

$\begin{array}{llllllll}15 & 2.5 & 10.3 & 12.8 & 1 & 10 & 0 & 60\end{array}$

$\begin{array}{llllllll}16 & 2.3 & 12.3 & 14.5 & 2 & 60 & 0 & 0\end{array}$

$\begin{array}{rrrrrrrr}17 & 2.0 & 13.0 & 15.0 & 1 & 30 & 0 & 0 \\ 18 & 3.0 & 10.5 & 13.5 & 0 & 0 & 6 & 90\end{array}$

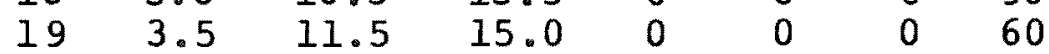

$\begin{array}{llllllll}20 & 2.5 & 13.0 & 15.5 & 0 & 0 & 0 & 0\end{array}$

$\begin{array}{llllllll}21 & 2.3 & 12.8 & 15.0 & 1 & 15 & 0 & 0\end{array}$

$\begin{array}{llllll}22 & 1.5 & 10.6 & 11.9 & 2 & 110\end{array}$

$\begin{array}{llllll}23 & 1.5 & : 11.1 & 12.6 & 3 & 130\end{array}$

$24 \quad 2.0 \quad 9.5 \quad 11.5$

$\begin{array}{llll}25 & 2.5 & 9.8 & 12.3\end{array}$

$\begin{array}{rrrrrr}26 & 2.3 & 12.0 & 14.3 & 1 & 90 \\ 27 & 2.0 & 11.8 & 13.8 & 1 & 10\end{array}$

$\begin{array}{llllll}28 & 0.5 & 10.5 & 11.0 & 1 & 120\end{array}$

$\begin{array}{llllll}29 & 2.0 & 10.3 & 12.3 & 0 & 0\end{array}$

$\begin{array}{llllll}30 & 2.0 & 11.0 & 13.0 & 0 & 0\end{array}$

$\begin{array}{llll}31 & 2.0 & 12.5 & 14.5\end{array}$

$\begin{array}{llll}32 & 2.0 & 10.3 & 12.3\end{array}$

$\begin{array}{llll}33 & 3.3 & 12.8 & 16.1\end{array}$

$\begin{array}{rrrr}34 & 2.0 & 9.8 & 11.8 \\ 35 & 1.8 & 12.2 & 13.8\end{array}$

$\begin{array}{llll}36 & 2.3 & 10.2 & 12.4\end{array}$

$\begin{array}{llll}37 & 2.3 & 11.0 & 13.3\end{array}$

$\begin{array}{llll}38 & 3.0 & 11.3 & 14.3\end{array}$

$\begin{array}{llll}39 & 2.0 & 10.3 & 12.3\end{array}$

$\begin{array}{llll}40 & 2.5 & 13.0 & 15.5\end{array}$

$\begin{array}{llll}41 & 2.8 & 11.8 & 14.6 \\ 42 & 2.8 & 11.0 & 13.8\end{array}$

$\begin{array}{llll}43 & 2.0 & 11.0 & 13.8 \\ 4 & 10.7 & 12.7\end{array}$

$\begin{array}{llll}44 & 1.5 & 13.9 & 15.4\end{array}$

$45 \quad 2.0 \quad 9.0 \quad 11.0$

$\begin{array}{llll}46 & 2.5 & 12.7 & 15.2\end{array}$

$\begin{array}{llllllll}47 & 2.5 & 11.8 & 14.3 & 1 & 100 & 0 & 0\end{array}$

$\begin{array}{llllllll}48 & 2.0 & 11.5 & 13.5 & 1 & 60 & 0 & 0\end{array}$

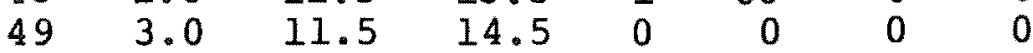

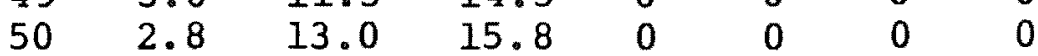

$\begin{array}{llllllll}51 & 2.3 & 13.0 & 15.3 & 0 & 0 & 0 & 0\end{array}$

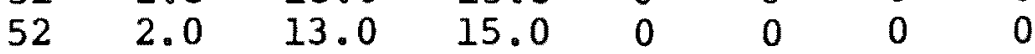

$\begin{array}{llllllll}53 & 3.0 & 11.0 & 14.0 & 1 & 30 & 0 & 60\end{array}$

$\begin{array}{llllllll}54 & 2.5 & 12.4 & 14.9 & 1 & 5 & 0 & 0\end{array}$

$\begin{array}{llllllll}55 & 1.8 & 10.2 & 11.9 & 2 & 20 & 0 & 0\end{array}$

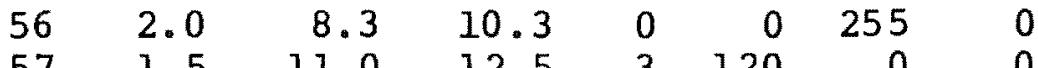

$\begin{array}{rrrrrrrr}57 & 1.5 & 11.0 & 12.5 & 3 & 120 & 0 & 0 \\ 58 & 1.0 & 9.8 & 10.8 & 2 & 70 & 60 & 0\end{array}$ 


\begin{tabular}{|c|c|c|c|c|c|}
\hline 2.5 & 11.0 & 13.5 & 2 & 15 & 45 \\
\hline 2.3 & 12.8 & 15.1 & 2 & 10 & 0 \\
\hline 2.0 & 10.5 & 12.5 & 1 & 120 & 0 \\
\hline 1.5 & 13.0 & 14.5 & 0 & 0 & 0 \\
\hline 2.0 & 12.2 & 14.2 & 2 & 20 & 0 \\
\hline 2.0 & 11.3 & 13.3 & 4 & 105 & 0 \\
\hline 2.0 & 12.4 & 14.4 & 1 & 5 & 0 \\
\hline 2.0 & 12.5 & 14.5 & 0 & 0 & 0 \\
\hline 2.0 & 11.3 & 13.3 & 1 & 30 & 45 \\
\hline 2.0 & 11.5 & 13.5 & 0 & 0 & 0 \\
\hline 1.5 & 12.9 & 14.4 & 1 & 5 & 0 \\
\hline 2.3 & 12.5 & 14.8 & 0 & 0 & 0 \\
\hline 2.0 & 11.4 & 13.4 & 1 & 5 & 30 \\
\hline 2.0 & 13.2 & 15.2 & 1 & 5 & 0 \\
\hline 2.5 & 13.4 & 15.9 & 3 & 20 & 0 \\
\hline 2.8 & 10.4 & 13.2 & 3 & 20 & 0 \\
\hline 2.5 & 11.9 & 14.4 & 2 & 20 & 0 \\
\hline 2.0 & 11.1 & 13.1 & 3 & 85 & 0 \\
\hline 2.8 & 13.4 & 16.2 & 1 & 5 & 0 \\
\hline 2.0 & 12.4 & 14.4 & 2 & 20 & 0 \\
\hline 2.0 & 13.1 & 15.1 & 1 & 10 & 0 \\
\hline 2.0 & 12.3 & 14.3 & 1 & 10 & 0 \\
\hline 2.0 & 12.3 & 14.3 & 4 & 45 & 0 \\
\hline 2.0 & 11.6 & 13.6 & 2 & 70 & 0 \\
\hline 2.0 & 11.0 & 13.0 & 0 & 0 & 0 \\
\hline 2.0 & 7.6 & 9.6 & 1 & 265 & 30 \\
\hline 2.0 & 13.0 & 15.0 & 0 & 0 & 0 \\
\hline 3.3 & 12.8 & 16.0 & 0 & 0 & 0 \\
\hline 2.0 & 12.8 & 14.8 & 0 & 0 & 0 \\
\hline 2.0 & 10.5 & 12.5 & 1 & 90 & 0 \\
\hline 2.7 & 12.0 & 14.7 & 0 & 0 & 0 \\
\hline 2.5 & 9.5 & 12.0 & 1 & 180 & 0 \\
\hline 2.5 & 11.0 & 13.5 & 1 & 90 & 0 \\
\hline 2.0 & 12.5 & 14.5 & 0 & 0 & 0 \\
\hline 2.8 & 12.5 & 15.3 & 0 & 0 & 0 \\
\hline 1.7 & 11.0 & 12.7 & 0 & 0 & 0 \\
\hline 2.0 & 12.1 & 14.1 & 2 & 25 & 0 \\
\hline 2.0 & 8.8 & 10.8 & 2 & 105 & 120 \\
\hline 2.3 & 10.8 & 13.0 & 3 & 30 & 0 \\
\hline 2.0 & 14.0 & 16.0 & 0 & 0 & 0 \\
\hline 2.0 & 8.5 & 10.5 & 0 & 0 & 60 \\
\hline 1.0 & 11.3 & .3 & 1 & 30 & 45 \\
\hline 2.0 & 9.5 & 1.5 & 1 & 150 & 0 \\
\hline 3.8 & 11.5 & 15.3 & 0 & 0 & 0 \\
\hline 2.5 & 10.0 & & 1 & 180 & 0 \\
\hline 2.0 & 12.3 & .3 & 1 & 10 & 0 \\
\hline 2.0 & 11.9 & .9 & 3 & 20 & 0 \\
\hline 2.3 & 13.0 & 15 & 0 & 0 & 0 \\
\hline 2.0 & 12.8 & .8 & 2 & 15 & 0 \\
\hline 2.0 & 13.0 & .0 & 0 & 0 & 0 \\
\hline 3.0 & 12.5 & 15 & 0 & 0 & 0 \\
\hline 2.5 & 12.8 & 15 & 0 & 0 & 0 \\
\hline 2.0 & 12.6 & & 2 & 10 & 0 \\
\hline 2. & 11.5 & & 1 & 5 & 45 \\
\hline 2.0 & 12.5 & & 0 & 0 & 0 \\
\hline 2.0 & 12.9 & & 1 & 5 & 0 \\
\hline 2.5 & 12.3 & & 0 & 0 & 45 \\
\hline 2.0 & 11.8 & & 0 & 0 & 0 \\
\hline 2.5 & 12.5 & 15.0 & 1 & 30 & 0 \\
\hline 2.0 & 13.5 & & 0 & 0 & 0 \\
\hline 2.5 & 12.5 & & 1 & 30 & 0 \\
\hline
\end{tabular}


DAY D.S N.S TOTAL W/N DW SOL BD

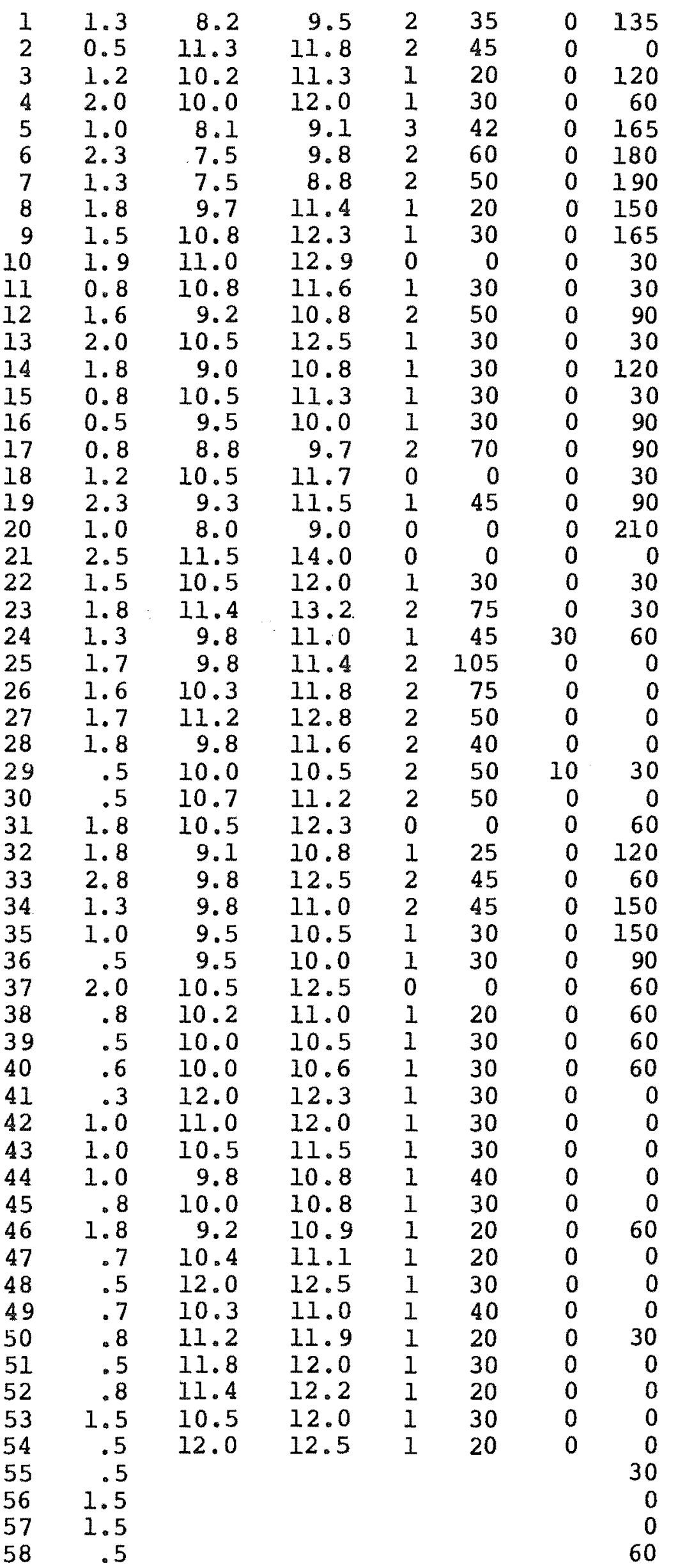


SUBJECT 7 ctd.

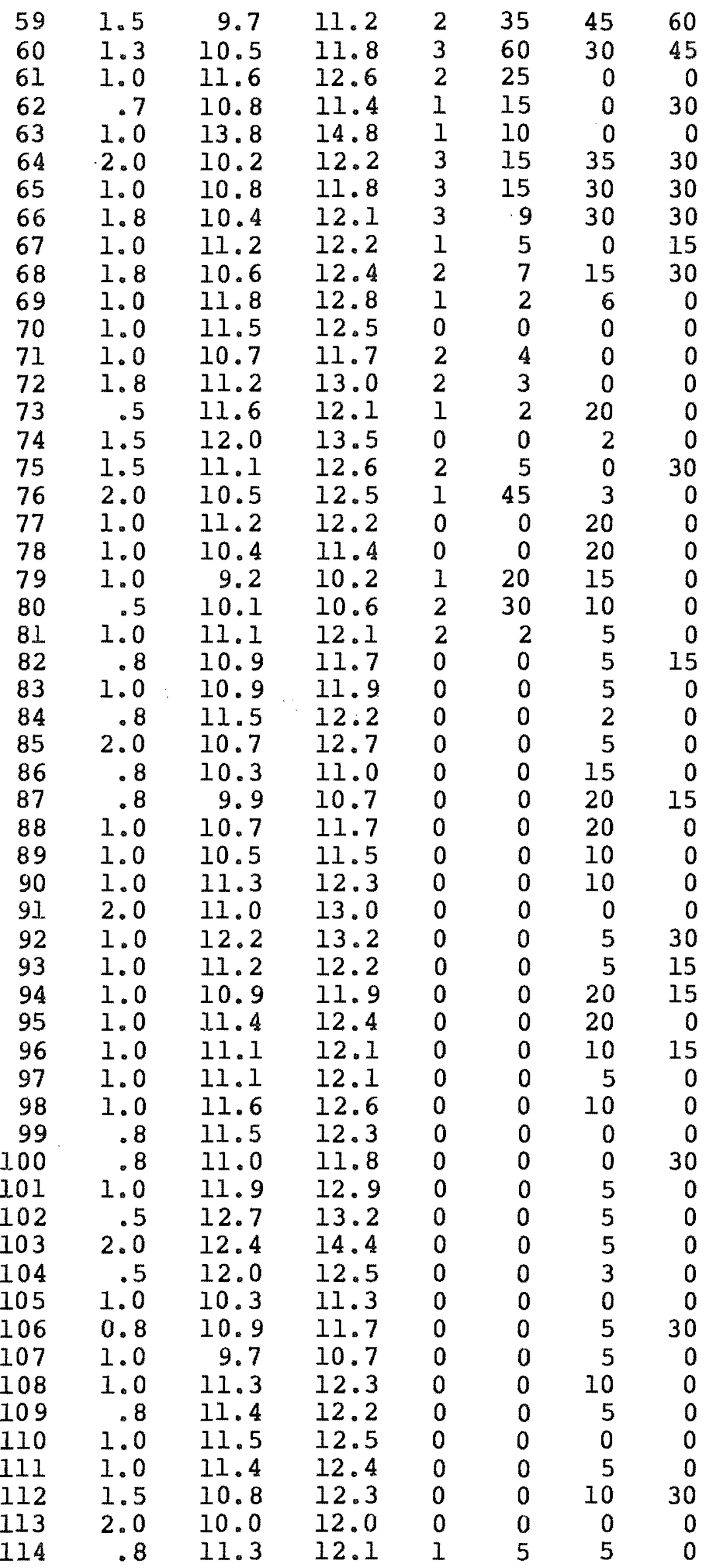


DAY D.S N.S TOTAL W/N DW SOL BD

\begin{tabular}{|c|c|c|c|c|c|c|}
\hline 1.8 & 12.8 & 14.5 & 0 & 0 & 0 & 120 \\
\hline 2.3 & 12.5 & 14.8 & 0 & 0 & 0 & 60 \\
\hline 1.8 & 11.8 & 13.7 & 1 & 10 & 0 & 60 \\
\hline 1.3 & 12.0 & 13.1 & 0 & 0 & 0 & 90 \\
\hline 1.7 & 12.0 & 13.7 & 0 & 0 & 0 & 60 \\
\hline 1.5 & 12.7 & 14.0 & 1 & 20 & 0 & 30 \\
\hline 2.0 & 11.9 & 13.9 & 1 & 5 & 0 & 60 \\
\hline 1.1 & 12.4 & 13.5 & 1 & 5 & 0 & 60 \\
\hline 1.2 & 12.3 & 13.5 & 1 & 8 & 0 & 60 \\
\hline .5 & 12.3 & 12.8 & 1 & 3 & 0 & 75 \\
\hline 1.5 & 11.5 & 13.0 & 0 & 0 & 0 & 110 \\
\hline 1.0 & 12.2 & 13.2 & 1 & 5 & 0 & 90 \\
\hline .3 & 11.4 & 11.7 & 1 & 5 & 0 & 105 \\
\hline .8 & 9.9 & 10.8 & 0 & 0 & 0 & 110 \\
\hline 1.1 & 9.9 & 11.0 & 1 & 5 & 0 & 60 \\
\hline .8 & 10.9 & 11.8 & 1 & 15 & 0 & 70 \\
\hline .7 & 11.6 & 12.3 & 0 & 0 & 0 & 107 \\
\hline .3 & 10.5 & 10.8 & 2 & 10 & 0 & 80 \\
\hline 1.0 & 10.7 & 11.7 & 0 & 0 & 0 & 150 \\
\hline 2.0 & 12.5 & 14.5 & 0 & 0 & 0 & 90 \\
\hline .9 & 12.0 & 12.9 & 0 & 0 & 0 & 60 \\
\hline 1.8 & 10.2 & 11.9 & 5 & 50 & 65 & 0 \\
\hline 4.0 & 12.1 & 16.1 & 2 & 10 & 5 & 0 \\
\hline 2.2 & 11.9 & 14.0 & 2 & 10 & 0 & c \\
\hline .0 & 11.9 & 11.9 & 2 & 65 & 10 & 0 \\
\hline 1.8 & 12.1 & 13.9 & 2 & 7 & 0 & 0 \\
\hline 2.3 & 11.9 & 14.2 & 3 & 6 & 0 & 0 \\
\hline 2.5 & 11.8 & 14.3 & 0 & 0 & 0 & 0 \\
\hline 1.0 & 12.1 & 13.1 & 1 & 1 & 0 & 0 \\
\hline 2.0 & 11.7 & 13.7 & 1 & 2 & 0 & 0 \\
\hline 1.3 & 11.0 & 12.4 & 0 & 0 & 0 & 0 \\
\hline 32 & 11.8 & 12.5 & 5 & 10 & 0 & 0 \\
\hline 1.5 & 11.5 & 13.0 & 3 & 6 & 0 & 0 \\
\hline 2.5 & 11.3 & 13.8 & 0 & 0 & 0 & 0 \\
\hline 2.5 & 11.8 & 14.3 & 0 & 0 & 0 & 0 \\
\hline 3.5 & 10.4 & 13.9 & 2 & 4 & 40 & 0 \\
\hline 2.5 & 11.3 & 13.8 & 1 & 2 & 0 & 0 \\
\hline 1.3 & 12.0 & 13.3 & 0 & 0 & 0 & 0 \\
\hline 1.8 & 12.2 & 13.9 & 2 & 4 & 0 & 0 \\
\hline 2.0 & 11.3 & 13.3 & 0 & 0 & 0 & 0 \\
\hline 1.0 & 11.3 & 12.3 & 0 & 0 & 0 & 0 \\
\hline 3.3 & 11.5 & 14.8 & 0 & 0 & 0 & 0 \\
\hline .6 & 12.3 & 12.9 & 1 & 2 & 0 & 0 \\
\hline 1.3 & 12.3 & 13.5 & 0 & 0 & 0 & 0 \\
\hline 1.0 & 11.5 & 12.5 & 0 & 0 & 0 & 0 \\
\hline 1.7 & 11.5 & 13.2 & 0 & 0 & 0 & 0 \\
\hline 2.5 & 11.5 & 14.0 & 0 & 0 & 0 & 0 \\
\hline 3.0 & 11.5 & 14.5 & 0 & 0 & 0 & 0 \\
\hline 1.8 & 11.5 & 13.3 & 0 & 0 & 0 & 0 \\
\hline 1.3 & 11.5 & 12.8 & 0 & 0 & 0 & 0 \\
\hline 1.8 & 11.3 & 13.0 & 0 & 0 & 0 & 0 \\
\hline .8 & 11.6 & 12.3 & 1 & 1 & 10 & 0 \\
\hline 1.8 & 11.2 & 13.0 & 1 & 2 & 0 & 0 \\
\hline 1.5 & 1.1 .0 & 12.5 & 2 & 4 & 0 & 0 \\
\hline 1.8 & 10.4 & 12.2 & 2 & 4 & 0 & 0 \\
\hline 1.5 & 11.2 & 12.7 & 0 & 0 & 15 & 0 \\
\hline 1.3 & 10.2 & 11.5 & 0 & 0 & 40 & 0 \\
\hline 1.0 & 11.2 & 12.2 & 1 & 2 & 0 & \\
\hline
\end{tabular}


SUBJECT 9 ctd.

$\begin{array}{rrrrrrrr}59 & 1.3 & 11.2 & 12.4 & 1 & 2 & 20 & 0 \\ 60 & 2.0 & 11.2 & 13.2 & 0 & 0 & 20 & 0 \\ 61 & 1.2 & 10.9 & 12.1 & 2 & 4 & 0 & 0 \\ 62 & 2.0 & 11.4 & 13.4 & 4 & 8 & 0 & 0 \\ 63 & 1.0 & 11.0 & 12.0 & 2 & 2 & 0 & 0 \\ 64 & 1.2 & 11.1 & 12.3 & 2 & 4 & 0 & 0 \\ 65 & 1.4 & 10.5 & 11.9 & 0 & 0 & 0 & 0 \\ 66 & 1.7 & 11.7 & 13.4 & 2 & 4 & 0 & 0 \\ 67 & .8 & 11.2 & 11.9 & 2 & 4 & 0 & 0 \\ 68 & .7 & 11.3 & 12.3 & 0 & 0 & 60 & 0 \\ 69 & 1.0 & 9.2 & 10.2 & 0 & 0 & 120 & 20 \\ 70 & .6 & 10.8 & 11.4 & 2 & 4 & 0 & 0 \\ 71 & 2.2 & 10.6 & 12.8 & 0 & 0 & 0 & 0 \\ 72 & 2.0 & 10.8 & 12.8 & 1 & 45 & 0 & 0 \\ 73 & 1.3 & 10.7 & 11.9 & 1 & 10 & 0 & 0 \\ 74 & 1.3 & 11.3 & 12.5 & 0 & 0 & 0 & 0 \\ 75 & 1.6 & 10.5 & 12.1 & 0 & 0 & 0 & 0 \\ 76 & 1.7 & 10.3 & 11.9 & 0 & 0 & 0 & 0 \\ 77 & 1.0 & 11.3 & 12.3 & 0 & 0 & 0 & 0 \\ 78 & 2.1 & 11.8 & 13.8 & 0 & 0 & 0 & 0 \\ 79 & 1.3 & 11.3 & 12.5 & 0 & 0 & 0 & 0 \\ 80 & 1.3 & 11.6 & 12.9 & 0 & 0 & 0 & 0 \\ 81 & 1.5 & 9.6 & 11.2 & 0 & 0 & 0 & 0 \\ 82 & 1.3 & 10.8 & 12.0 & 0 & 0 & 0 & 0 \\ 83 & 2.3 & 10.3 & 12.5 & 0 & 0 & 0 & 0 \\ 84 & 1.3 & 10.5 & 11.8 & 0 & 0 & 0 & 0\end{array}$


SUBJECT 10: RAW DATA

DAY D.S N.S TOTAL N/W DW SOL BD

$\begin{array}{llllllll}1 & 1.5 & 10.5 & 12.0 & 1 & 150 & 0 & 0\end{array}$

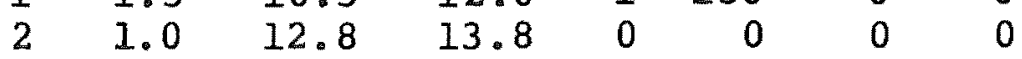

$\begin{array}{llllllll}3 & .8 & 10.5 & 11.3 & 0 & 0 & 0 & 90\end{array}$

$\begin{array}{llllllll}4 & 3.0 & 10.5 & 13.5 & 0 & 0 & 0 & 120\end{array}$

$\begin{array}{llllllll}5 & 2.5 & 11.3 & 13.8 & 0 & 0 & 0 & 165\end{array}$

$\begin{array}{llllllll}6 & 1.8 & 11.3 & 13.0 & 1 & 60 & 0 & 75\end{array}$

$\begin{array}{llllllll}7 & 1.5 & 12.3 & 13.8 & 1 & 30 & 0 & 45\end{array}$

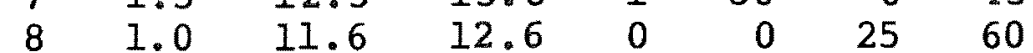

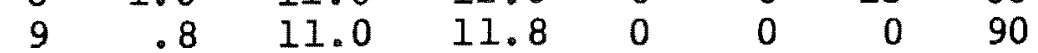

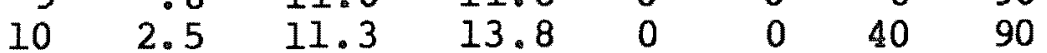

$\begin{array}{llllllll}11 & 1.0 & 11.4 & 12.4 & 1 & 40 & 10 & 75\end{array}$

$\begin{array}{llllllll}12 & .8 & 12.0 & 12.8 & 1 & 60 & 0 & 30\end{array}$

$\begin{array}{llllllll}13 & 3.0 & 9.9 & 12.9 & 0 & 0 & 35 & 120\end{array}$

$\begin{array}{llllllll}14 & 1.3 & 11.0 & 12.3 & 0 & 0 & 0 & 120\end{array}$

$\begin{array}{llllllll}15 & 2.0 & 12.3 & 14.3 & 0 & 0 & 0 & 105\end{array}$

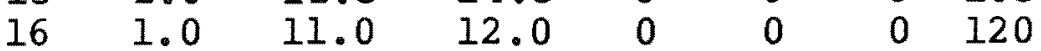

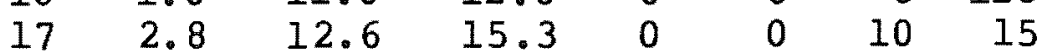

$\begin{array}{llllllll}18 & 1.5 & 12.3 & 13.8 & 0 & 0 & 25 & 75\end{array}$

$\begin{array}{llllllll}19 & 1.5 & 10.3 & 11.8 & 0 & 0 & 10 & 120\end{array}$

$\begin{array}{llllllll}20 & 3.0 & 11.7 & 14.7 & 0 & 0 & 20 & 60\end{array}$

$\begin{array}{llllllll}21 & 3.0 & 11.7 & 14.7 & 0 & 0 & 20 & 30\end{array}$

$\begin{array}{llllllll}22 & 2.0 & 10.8 & 12.8 & 0 & 0 & 0 & 135\end{array}$

$\begin{array}{llllllll}23 & 2.3 & 10.7 & 12.9 & 0 & 0 & 20 & 90\end{array}$

$\begin{array}{llllllll}24 & 2.3 & 11.0 & 13.3 & 0 & 0 & 15 & 75\end{array}$

$\begin{array}{rrrrrrrr}25 & 2.3 & 10.0 & 12.3 & 0 & 0 & 0 & 150\end{array}$

$\begin{array}{llllllll}26 & 3.0 & 11.1 & 14.1 & 0 & 0 & 10 & 105\end{array}$

$\begin{array}{llllllll}27 & 2.5 & 9.9 & 12.4 & 0 & 0 & 35 & 90\end{array}$

$\begin{array}{llllllll}28 & 2.0 & 11.0 & 13.0 & 0 & 0 & 0 & 90\end{array}$

$\begin{array}{llllllll}29 & 1.5 & 10.7 & 12.2 & 0 & 0 & 20 & 120\end{array}$

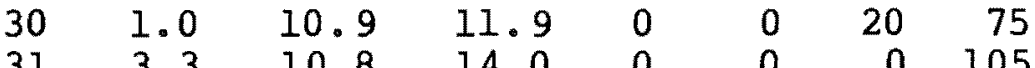

$\begin{array}{rrrrrrrr}31 & 3.3 & 10.8 & 14.0 & 0 & 0 & 0 & 105 \\ 32 & 1.8 & 11.3 & 13.1 & 0 & 0 & 40 & 60\end{array}$

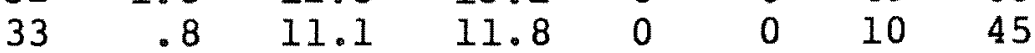

$\begin{array}{llllllll}34 & 1.3 & 11.5 & 12.8 & 0 & 0 & 0 & 30\end{array}$

$\begin{array}{llllllll}35 & 2.5 & 11.0 & 13.5 & 0 & 0 & 0 & 30\end{array}$

$\begin{array}{llllllll}36 & 1.5 & 11.0 & 12.5 & 0 & 0 & 0 & 60\end{array}$

$\begin{array}{llllllll}37 & .8 & 11.8 & 12.5 & 0 & 0 & 0 & 45\end{array}$

$\begin{array}{llllllll}38 & 1.3 & 11.0 & 12.3 & 0 & 0 & 0 & 90\end{array}$

$\begin{array}{llllllll}39 & .5 & 11.5 & 12.0 & 0 & 0 & 0 & 30\end{array}$

$\begin{array}{llllllll}40 & 3.0 & 11.5 & 14.5 & 0 & 0 & 0 & 60\end{array}$

$\begin{array}{llllllll}41 & .8 & 12.0 & 12.8 & 0 & 0 & 0 & 30\end{array}$

$\begin{array}{llllllll}42 & 2.5 & 10.8 & 13.3 & 0 & 0 & 40 & 30\end{array}$

$\begin{array}{llllllll}43 & 0.5 & 12.3 & 12.8 & 0 & 0 & 15 & 30\end{array}$

$\begin{array}{llllllll}44 & 1.8 & 11.5 & 13.3 & 0 & 0 & 0 & 30\end{array}$

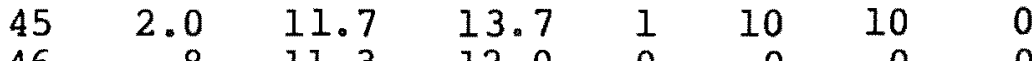

$\begin{array}{rrrrrrrr}46 & .8 & 11.3 & 12.0 & 0 & 0 & 0 & 0 \\ 47 & 2.5 & 10.8 & 13.3 & 0 & 0 & 0 & 75\end{array}$

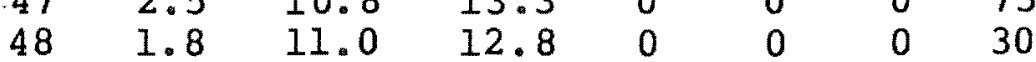

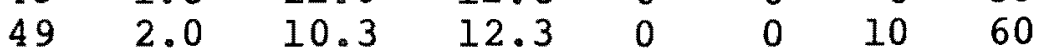

$\begin{array}{llllllll}50 & 1.3 & 11.0 & 12.3 & 0 & 0 & 30 & 30\end{array}$

$\begin{array}{llllllll}51 & 3.0 & 10.3 & 13.3 & 0 & 0 & 30 & 45\end{array}$

$\begin{array}{llllllll}52 & 2.3 & 11.3 & 13.5 & 0 & 0 & 15 & 30\end{array}$

$\begin{array}{llllllll}53 & .5 & 11.5 & 12.0 & 0 & 0 & 0 & 30\end{array}$

$\begin{array}{rrrrrrrr}54 & 1.8 & 9.8 & 11.5 & 1 & 5 & 40 & 60\end{array}$

$\begin{array}{llllllll}55 & 2.0 & 10.5 & 12.5 & 0 & 0 & 0 & 120\end{array}$

$\begin{array}{llllllll}56 & 1.5 & 11.3 & 12.8 & 0 & 0 & 0 & 45\end{array}$

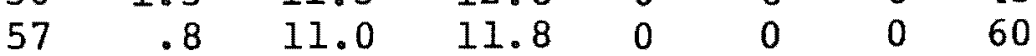

$\begin{array}{llllllll}58 & 1.5 & 11.0 & 12.5 & 0 & 0 & 0 & 30\end{array}$ 
SUBJECT 10 ctd.

$\begin{array}{rrrrrrrr}59 & 1.5 & 11.3 & 12.8 & 0 & 0 & 0 & 45 \\ 60 & 2.8 & 11.2 & 13.9 & 0 & 0 & 5 & 45 \\ 61 & 2.0 & 11.5 & 13.5 & 0 & 0 & 0 & 30 \\ 62 & .5 & 11.5 & 12.0 & 0 & 0 & 0 & 30 \\ 63 & .8 & 12.3 & 13.0 & 0 & 0 & 0 & 15 \\ 64 & 1.8 & 10.9 & 12.7 & 0 & 0 & 5 & 30 \\ 65 & 1.0 & 11.0 & 12.0 & 0 & 0 & 0 & 30 \\ 66 & 1.5 & 10.8 & 12.3 & 0 & 0 & 0 & 45 \\ 67 & 3.8 & 10.7 & 14.4 & 1 & 15 & 5 & 0 \\ 68 & 2.8 & 10.4 & 13.2 & 0 & 0 & 0 & 90 \\ 69 & 3.0 & 11.5 & 14.5 & 0 & 0 & 5 & 30 \\ 70 & 2.5 & 10.9 & 13.4 & 0 & 0 & 5 & 30 \\ 71 & .5 & 11.2 & 11.7 & 0 & 0 & 5 & 60 \\ 72 & 2.0 & 11.7 & 13.7 & 0 & 0 & 5 & 30\end{array}$


DAY D.S N.S TOTAL N/W DW SOL BD

\begin{tabular}{|c|c|c|c|c|c|}
\hline 0.6 & 9.2 & 9.8 & 5 & 124 & 15 \\
\hline 1.1 & 11.3 & 12.4 & 6 & 73 & 10 \\
\hline 2.3 & 10.6 & 12.9 & 4 & 11 & 15 \\
\hline .0 & 11.9 & 11.9 & 3 & 27 & 10 \\
\hline 0.8 & 10.6 & 11.4 & 3 & 52 & 10 \\
\hline 1.2 & 10.5 & 11.7 & 8 & 74 & 15 \\
\hline 1.8 & 9.6 & 11.4 & 1 & 90 & 0 \\
\hline 0.8 & 10.9 & 11.6 & 2 & 22 & 10 \\
\hline 1.1 & 11.6 & 12.7 & 2 & 4 & 2 \\
\hline 1.2 & 11.2 & 12.2 & 3 & 33 & 5 \\
\hline 1.3 & 10.4 & 11.6 & 3 & 102 & 20 \\
\hline 1.3 & 11.1 & 12.3 & 2 & 31 & 15 \\
\hline .0 & 11.1 & 11.1 & 2 & 35 & 10 \\
\hline 1.0 & 10.7 & 11.7 & 1 & 10 & 25 \\
\hline 0.8 & 11.5 & 12.3 & 3 & 37 & 15 \\
\hline 1.5 & 10.8 & 12.3 & 3 & 17 & 25 \\
\hline .0 & 10.5 & 10.5 & 1 & 5 & 25 \\
\hline 1.7 & 10.9 & 12.6 & 6 & 57 & 15 \\
\hline 2.5 & 11.2 & 13.7 & 3 & 9 & 15 \\
\hline 1.9 & 10.8 & 12.7 & 3 & 35 & 20 \\
\hline 1.3 & 9.4 & 10.7 & 1 & 90 & 20 \\
\hline 1.8 & 10.7 & 12.4 & 2 & 32 & 45 \\
\hline 1.5 & 11.7 & 13.2 & 4 & 22 & 10 \\
\hline 1.5 & 12.0 & 13.5 & 3 & 12 & 10 \\
\hline 1.0 & 10.7 & 11.7 & 2 & 32 & 30 \\
\hline
\end{tabular}

\begin{tabular}{|c|c|c|c|c|c|c|}
\hline 1.0 & 10.7 & 11.7 & 2 & 32 & 30 & 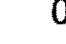 \\
\hline 26 & • & • & & & & \\
\hline 27 & - & . & & & & \\
\hline 28 & - & . & & & & \\
\hline 29 & - & - & & & & \\
\hline . & - & - & & & & \\
\hline - & - & - & & & & \\
\hline - & - & - & & & & \\
\hline - & - & " & & & & \\
\hline - & - & - & & & & \\
\hline • & $\circ$ & $\circ$ & & & & \\
\hline 1.5 & 11.3 & 12.8 & 2 & 15 & 0 & 30 \\
\hline 1.3 & 11.7 & 13.0 & 0 & 0 & 0 & 5 \\
\hline 1.2 & 11.0 & 12.2 & 2 & 40 & 0 & 0 \\
\hline 1.4 & 11.1 & 12.5 & 3 & 48 & 0 & 5 \\
\hline 1.5 & 12.2 & 13.7 & 1 & 5 & 0 & 15 \\
\hline 1.3 & 11.9 & 13.2 & 1 & 5 & 0 & 5 \\
\hline 1.3 & 11.0 & 12.3 & 0 & 0 & 15 & 0 \\
\hline 1.3 & 11.2 & 12.5 & 1 & 10 & 10 & 0 \\
\hline 1.3 & 10.8 & 12.1 & 1 & 20 & 10 & 0 \\
\hline .8 & 11.2 & 11.9 & 2 & 20 & 5 & 0 \\
\hline 1.3 & 11.3 & 12.5 & 0 & 0 & 15 & 0 \\
\hline 1.5 & 11.4 & 12.9 & 3 & 6 & 25 & 0 \\
\hline 1.0 & 11.5 & 12.5 & 0 & 0 & 0 & 0 \\
\hline 1.2 & 11.6 & 12.8 & 0 & 0 & 0 & 0 \\
\hline 1.3 & 11.2 & 12.4 & 3 & 6 & 25 & 0 \\
\hline .0 & 11.7 & 11.7 & 1 & 5 & 15 & 0 \\
\hline 1.3 & 11.8 & 13.0 & 0 & 0 & 0 & 0 \\
\hline .8 & 11.3 & 12.1 & 0 & 0 & 0 & 0 \\
\hline .8 & 11.6 & 12.4 & 1 & 2 & 0 & 5 \\
\hline 1.8 & 11.6 & 13.3 & 1 & 5 & 0 & 0 \\
\hline 1.0 & 11.7 & 12.7 & 1 & 10 & 0 & 10 \\
\hline 1.2 & 8.7 & 9.8 & 2 & 45 & 125 & 0 \\
\hline .8 & 10.0 & 10.7 & 3 & 42 & 45 & 0 \\
\hline
\end{tabular}


SUBJECT $11 \mathrm{ctd}$.

$\begin{array}{rrrrrrrr}59 & 1.3 & 10.9 & 12.2 & 0 & 0 & 30 & 0 \\ 60 & 1.3 & 11.1 & 12.3 & 1 & 10 & 10 & 5 \\ 61 & 1.2 & 10.8 & 12.0 & 0 & 0 & 20 & 10 \\ 62 & .8 & 11.6 & 12.5 & 2 & 7 & 5 & 0 \\ 63 & .8 & 11.4 & 12.3 & 0 & 0 & 0 & 5 \\ 64 & 1.0 & 10.9 & 11.9 & 0 & 0 & 5 & 30 \\ 65 & 0.3 & 11.8 & 12.0 & 0 & 0 & 5 & 0 \\ 66 & .8 & 10.6 & 11.4 & 1 & 10 & 60 & 0 \\ 67 & 1.1 & 10.0 & 11.1 & 2 & 10 & 70 & 0 \\ 68 & 1.8 & 11.0 & 12.8 & 1 & 5 & 15 & 0 \\ 69 & .8 & 11.2 & 11.9 & 0 & 0 & 15 & 0 \\ 70 & 1.6 & 11.5 & 13.1 & 1 & 5 & 5 & 0 \\ 71 & 1.0 & 10.5 & 11.5 & 0 & 0 & 25 & 5 \\ 72 & .0 & 11.2 & 11.7 & 1 & 10 & 0 & 0 \\ 73 & 1.6 & 10.7 & 12.3 & 1 & 5 & 5 & 0 \\ 74 & .5 & 11.5 & 12.0 & 0 & 0 & 5 & 0 \\ 75 & 1.1 & 11.4 & 12.5 & 1 & 5 & 5 & 0 \\ 76 & 1.3 & 9.4 & 10.8 & 2 & 120 & 20 & 0 \\ 77 & 1.1 & 10.9 & 12.0 & 2 & 30 & 0 & 0 \\ 78 & 1.3 & 11.8 & 13.0 & 0 & 0 & 0 & 0 \\ 79 & .8 & 11.0 & 11.8 & 1 & 2 & 25 & 0 \\ 80 & 1.0 & 11.0 & 12.0 & 2 & 4 & 5 & 0 \\ 81 & 1.3 & 10.4 & 11.7 & 0 & 0 & 30 & 0 \\ 82 & 1.1 & 10.9 & 11.9 & 1 & 4 & 5 & 15 \\ 83 & 1.3 & 11.3 & 12.6 & 2 & 7 & 10 & 0 \\ 84 & .7 & 11.3 & 11.9 & 1 & 5 & 5 & 0 \\ 85 & 0.8 & 11.1 & 11.8 & 2 & 35 & 20 & 0 \\ 86 & 1.8 & 10.8 & 12.7 & 1 & 5 & 15 & 0 \\ 87 & .8 & 11.5 & 12.3 & 0 & 0 & 0 & 0 \\ 88 & 1.2 & 11.3 & 12.5 & 1 & 10 & 0 & 5 \\ 89 & .0 & 10.8 & 10.8 & 0 & 0 & 0 & 15 \\ 90 & .8 & 11.3 & 12.1 & 0 & 0 & 5 & 0 \\ 91 & 1.3 & 11.4 & 12.7 & 2 & 12 & 5 & 5\end{array}$


SUBJECT 12 : RAW DATA

DAY D.S N.S TOTAL N/W DW SOL BD

$\begin{array}{llllllll}1 & 3.3 & 10.8 & 14.0 & 2 & 45 & 0 & 60\end{array}$

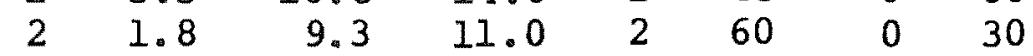

$\begin{array}{llllllll}3 & 3.8 & 8.2 & 11.9 & 1 & 20 & 0 & 165\end{array}$

$\begin{array}{llllllll}4 & 2.8 & 11.1 & 13.9 & 2 & 45 & 0 & 60\end{array}$

$\begin{array}{llllllll}5 & 2.3 & 9.5 & 11.8 & 1 & 30 & 0 & 0\end{array}$

$\begin{array}{llllllll}6 & 4.3 & 10.3 & 14.5 & 2 & 105 & 0 & 0\end{array}$

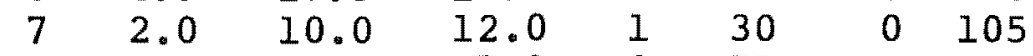

$\begin{array}{llllllll}8 & 1.8 & 9.3 & 11.0 & 3 & 75 & 0 & 120\end{array}$

$\begin{array}{lllllllr}9 & 3.5 & 9.5 & 13.0 & 3 & 135 & 0 & 60\end{array}$

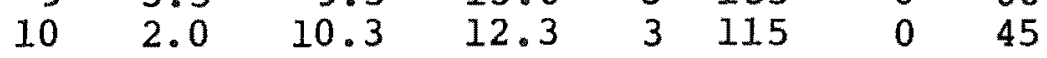

$\begin{array}{llllllll}11 & 2.3 & 11.0 & 13.3 & 2 & 60 & 0 & 75\end{array}$

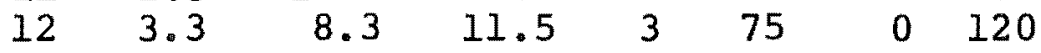

$\begin{array}{lllllllr}13 & 3.4 & 9.9 & 13.3 & 2 & 50 & 0 & 75\end{array}$

$\begin{array}{llllllll}14 & 1.8 & 10.8 & 12.5 & 2 & 105 & 0 & 60\end{array}$

$\begin{array}{llllllll}15 & 1.5 & 9.3 & 10.8 & 2 & 45 & 0 & 210\end{array}$

$\begin{array}{lllllllr}16 & 2.0 & 10.4 & 12.4 & 2 & 80 & 0 & 45\end{array}$

$\begin{array}{llllllll}17 & 2.5 & 8.3 & 10.8 & 1 & 30 & 0 & 150\end{array}$

$\begin{array}{lllllllr}18 & 3.3 & 10.4 & 13.7 & 2 & 50 & 0 & 60\end{array}$

$\begin{array}{llllllll}19 & 2.8 & 7.8 & 10.5 & 2 & 45 & 0 & 180\end{array}$

$\begin{array}{llllllll}20 & 3.3 & 11.7 & 14.9 & 2 & 35 & 0 & 75\end{array}$

$\begin{array}{llllllll}21 & 1.5 & 10.2 & 11.7 & 2 & 35 & 0 & 150\end{array}$

$\begin{array}{rrrrrrrr}22 & 2.5 & 9.9 & 12.4 & 3 & 50 & 0 & 30 \\ 23 & 3.8 & 9.2 & 12.9 & 2 & 35 & 0 & 0\end{array}$

$\begin{array}{llllllll}24 & 3.8 & 7.9 & 11.7 & 2 & 35 & 0 & 165\end{array}$

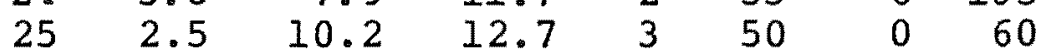

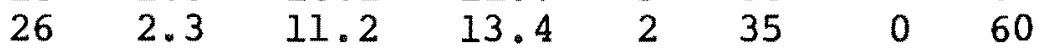

$\begin{array}{llllllll}27 & 3.0 & 10.6 & 13.6 & 3 & 55 & 0 & 60\end{array}$

$\begin{array}{llllllll}28 & 1.3 & 10.7 & 11.9 & 2 & 35 & 0 & 0\end{array}$

$\begin{array}{llllllll}29 & 4.3 & 8.9 & 13.2 & 2 & 35 & 0 & 150\end{array}$

$\begin{array}{llllllll}30 & 3.2 & 8.7 & 11.8 & 1 & 20 & 0 & 120\end{array}$

$\begin{array}{llllllll}31 & 2.8 & 8.8 & 11.5 & 1 & 15 & 0 & 120\end{array}$

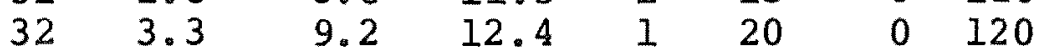

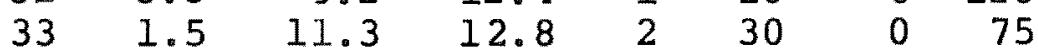

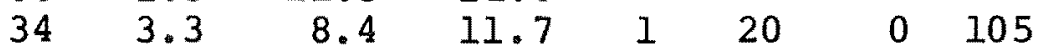

$\begin{array}{llllllll}35 & 3.5 & 9.0 & 12.5 & 1 & 60 & 0 & 75\end{array}$

$\begin{array}{llllllll}36 & 4.0 & 9.7 & 13.7 & 1 & 20 & 0 & 105\end{array}$

$\begin{array}{llllllll}37 & 4.3 & 10.7 & 14.9 & 2 & 35 & 0 & 135\end{array}$

$\begin{array}{llllllll}38 & 2.3 & 9.4 & 11.7 & 2 & 35 & 0 & 120\end{array}$

$\begin{array}{llllllll}39 & 2.0 & 12.2 & 14.2 & 2 & 35 & 0 & 15\end{array}$

$\begin{array}{llllllll}40 & 0.9 & 9.5 & 12.4 & 1 & 75 & 30 & 0\end{array}$

$\begin{array}{llllllll}42 & 2.3 & 11.6 & 14.3 & 1 & 10 & 0 & 15\end{array}$

$\begin{array}{llllllll}43 & 2.0 & 11.7 & 13.7 & 1 & 15 & 0 & 15\end{array}$

$\begin{array}{llllllll}44 & 2.0 & 11.5 & 13.5 & 1 & 15 & 0 & 0\end{array}$

$\begin{array}{llllllll}45 & 3.3 & 12.2 & 15.5 & 1 & 15 & 0 & 15\end{array}$

$\begin{array}{llllllll}46 & 3.0 & 11.3 & 14.3 & 0 & 0 & 0 & 15\end{array}$

$\begin{array}{rrrrrrr}47 & 2.7 & 11.8 & 14.4 & 0 & 0 & 0\end{array}$

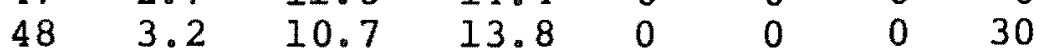

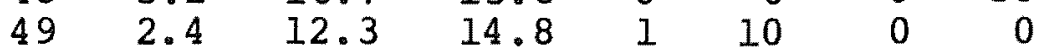

$\begin{array}{llllllll}50 & 2.5 & 11.5 & 14.0 & 0 & 0 & 0 & 0\end{array}$

$\begin{array}{llllllll}51 & 2.1 & 11.7 & 13.8 & 1 & 5 & 0 & 0\end{array}$

$\begin{array}{llllllll}52 & 2.8 & 11.2 & 13.9 & 3 & 15 & 0 & 0\end{array}$

$\begin{array}{llllllll}53 & 1.5 & 10.8 & 12.3 & 2 & 30 & 0 & 0\end{array}$

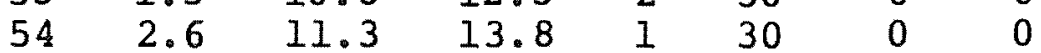

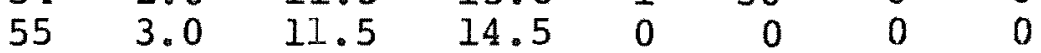

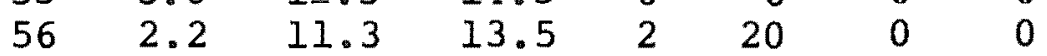

$\begin{array}{llllllll}57 & 1.0 & 11.8 & 12.8 & 0 & 0 & 0 & 0\end{array}$

$\begin{array}{llllllll}58 & 1.5 & 11.2 & 12.5 & 0 & 0 & 0 & 0\end{array}$ 
SUBJECT 12 ctd.

$\begin{array}{rrrrrrrr}59 & 2.4 & 11.4 & 13.7 & 0 & 0 & 0 & 0 \\ 60 & 2.8 & 10.5 & 13.3 & 0 & 0 & 0 & 30 \\ 61 & 1.5 & 12.3 & 13.8 & 0 & 0 & 0 & 0 \\ 62 & 2.1 & 10.0 & 12.1 & 0 & 0 & 0 & 0 \\ 63 & 2.0 & 11.2 & 13.2 & 1 & 5 & 0 & 0 \\ 64 & 1.8 & 11.8 & 13.5 & 0 & 0 & 0 & 0 \\ 65 & 2.5 & 11.3 & 13.8 & 0 & 0 & 0 & 0 \\ 66 & 1.5 & 10.8 & 12.3 & 4 & 25 & 0 & 0 \\ 67 & 2.5 & 11.3 & 13.8 & 0 & 0 & 0 & 0 \\ 68 & 1.5 & 11.8 & 13.3 & 0 & 0 & 0 & 0 \\ 69 & 2.0 & 10.8 & 12.8 & 0 & 0 & 0 & 10 \\ 70 & 3.3 & 10.1 & 13.3 & 1 & 10 & 0 & 15 \\ 71 & 2.8 & 10.5 & 13.3 & 0 & 0 & 0 & 30 \\ 72 & 1.5 & 12.3 & 13.8 & 0 & 0 & 0 & 0 \\ 73 & 2.5 & 10.9 & 13.4 & 0 & 0 & 0 & 20 \\ 74 & 2.0 & 10.8 & 12.8 & 1 & 5 & 0 & 0 \\ 75 & 3.5 & 10.8 & 14.3 & 0 & 0 & 0 & 10 \\ 76 & 1.5 & 11.6 & 13.1 & 0 & 0 & 0 & 0 \\ 77 & 2.4 & 12.2 & 14.6 & 0 & 0 & 0 & 0 \\ 78 & 2.2 & 11.8 & 12.9 & 0 & 0 & 0 & 0 \\ 79 & 1.5 & 11.3 & 12.8 & 0 & 0 & 0 & 0 \\ 80 & 1.9 & 10.9 & 12.8 & 1 & 5 & 0 & 10 \\ 81 & 2.0 & 11.3 & 13.3 & 0 & 0 & 0 & 0 \\ 82 & 2.5 & 10.8 & 13.3 & 0 & 0 & 0 & 0\end{array}$

